\title{
CHANGES IN SPATIAL MEMORY FOLLOWING INTRA-CA3 INJECTIONS OF KAINATE IN RATS
}

\author{
A thesis submitted to \\ the Faculty of Graduate Studies and Research \\ in Partial Fulfillment of the requirements for the degree Masters of Science
}

by

Catherine Smith

Department of Psychology

Carleton University

January, 2010

(C) Catherine Smith 


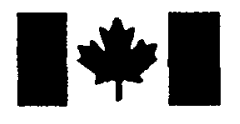

\author{
Library and Archives \\ Canada \\ Published Heritage \\ Branch \\ 395 Wellington Street \\ Ottawa ON K1A ON4 \\ Canada
}

Bibliothèque et

Archives Canada

Direction du

Patrimoine de l'édition

395, rue Wellington

Ottawa ON K1A 0N4

Canada
Your file Votre reférence
ISBN: 978-0-494-64428-7
Our file Notre référence
ISBN: $978-0-494-64428-7$
NOTICE:

The author has granted a nonexclusive license allowing Library and Archives Canada to reproduce, publish, archive, preserve, conserve, communicate to the public by telecommunication or on the Internet, loan, distribute and sell theses worldwide, for commercial or noncommercial purposes, in microform, paper, electronic and/or any other formats.

The author retains copyright ownership and moral rights in this thesis. Neither the thesis nor substantial extracts from it may be printed or otherwise reproduced without the author's permission.
AVIS:

L'auteur a accordé une licence non exclusive permettant à la Bibliothèque et Archives Canada de reproduire, publier, archiver, sauvegarder, conserver, transmettre au public par télécommunication ou par l'Internet, prêter, distribuer et vendre des thèses partout dans le monde, à des fins commerciales ou autres, sur support microforme, papier, électronique et/ou autres formats.

L'auteur conserve la propriété du droit d'auteur et des droits moraux qui protège cette thèse. $\mathrm{Ni}$ la thèse ni des extraits substantiels de celle-ci ne doivent être imprimés ou autrement reproduits sans son autorisation.
In compliance with the Canadian Privacy Act some supporting forms may have been removed from this thesis.

While these forms may be included in the document page count, their removal does not represent any loss of content from the thesis.
Conformément à la loi canadienne sur la protection de la vie privée, quelques formulaires secondaires ont été enlevés de cette thèse.

Bien que ces formulaires aient inclus dans la pagination, il n'y aura aucun contenu manquant. 


\begin{abstract}
Kainate receptors (KARs) are involved in short- and long-term plasticity at mossy fibreCA3 synapses in vitro. Since the majority of research conducted to date has been restricted to in vitro experiments, the objective of the present thesis was to activate KARs with low doses of kainate and determine how this manipulation influenced synaptic plasticity in vivo. It was hypothesized that spatial information processing improvements would be observed at doses showing potentiated responses in vitro. Post-training intra-CA3 injections of $100 \mathrm{nM}$ kainate led to the greatest enhancement in spatial memory performance, demonstrating a potential role for KARs in the consolidation of spatial information. These findings imply that the administration of kainate into the CA3 may lead to enhanced expression of spatial information in vivo and parallel in vitro findings that kainate receptors play a critical role in multiple forms of plasticity at the mossy fiber synapse.
\end{abstract}




\section{Acknowledgements}

I would like to thank Dr. Matthew Holahan for his direction and advice throughout the duration of this project. 


\section{Table of Contents}

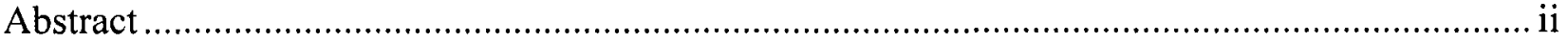

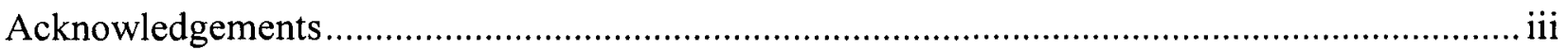

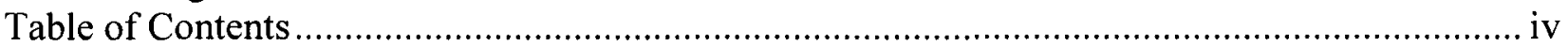

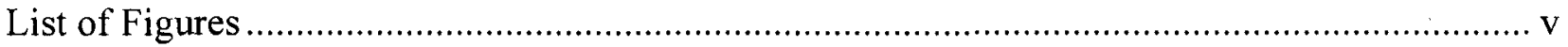

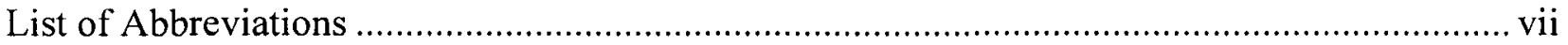

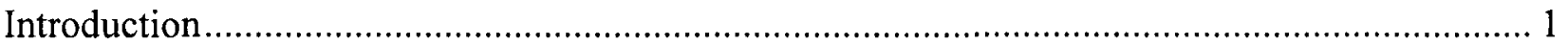

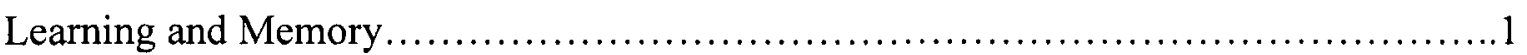

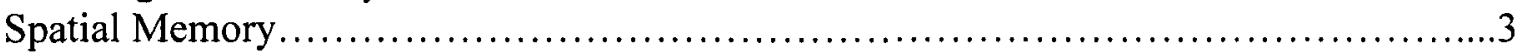

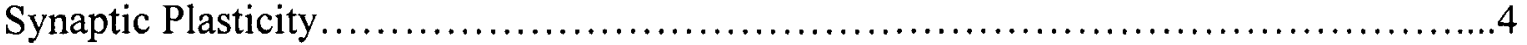

The Role of the Hippocampus in Learning and Memory.............................6

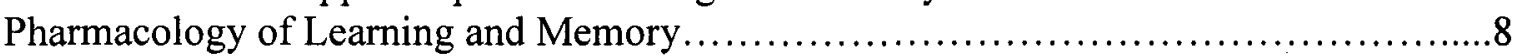

NMDA receptors............................................................

AMPA receptors............................................................... 13

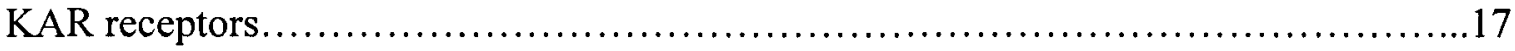

Behavioural Measures of Plasticity .............................................24

Rationale for Present Thesis................................................. 25

Experiment 1: Pre-training Injections............................................26

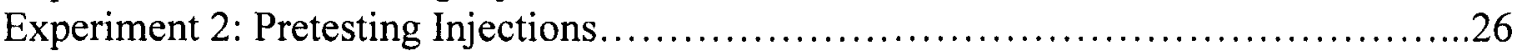

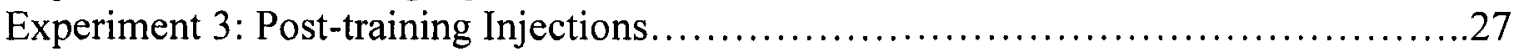

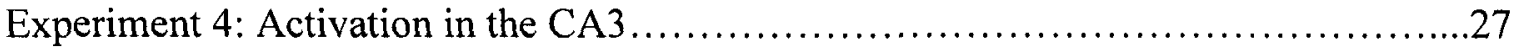

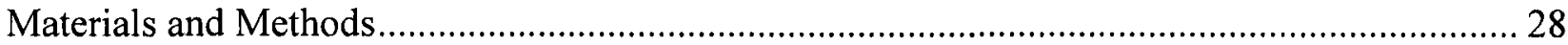

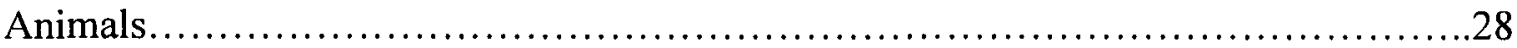

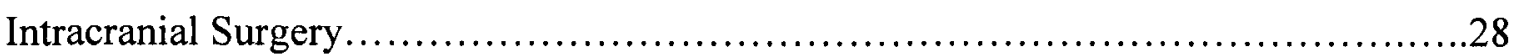

Microinjection Procedure.........................................................29

Morris Water Maze................................................................ 30

Water Maze Training........................................................... 30

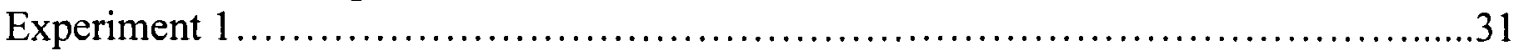

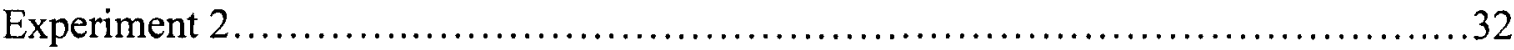

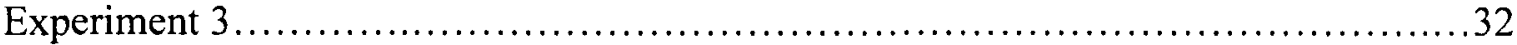

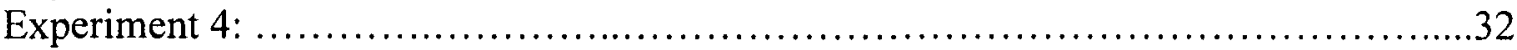

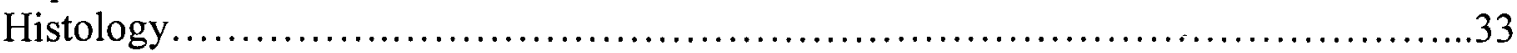

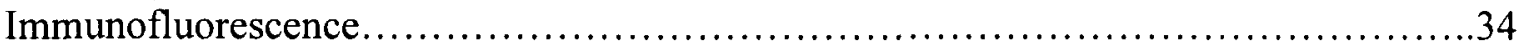

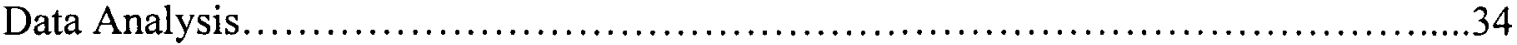

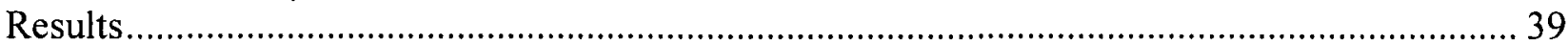

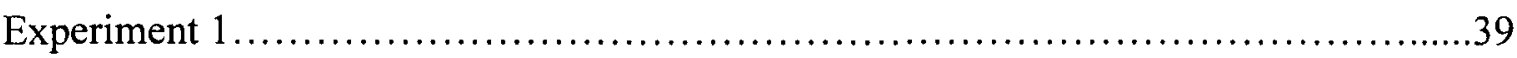

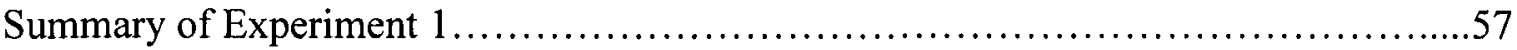

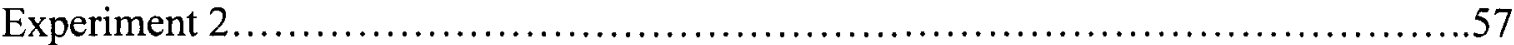

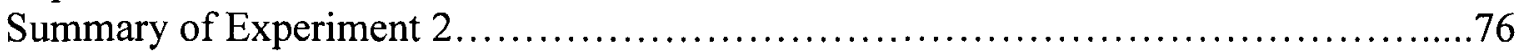

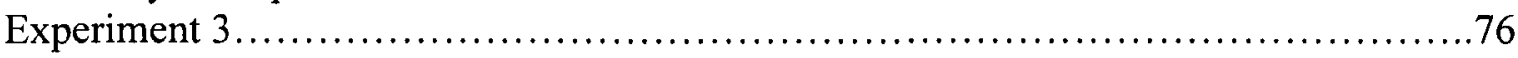

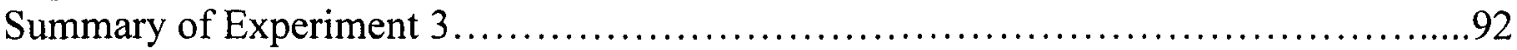

Cell death in the CA3 ..............................................................92

Phosphorylated ERK labelling in the CA3 .....................................97

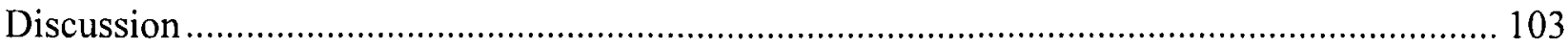

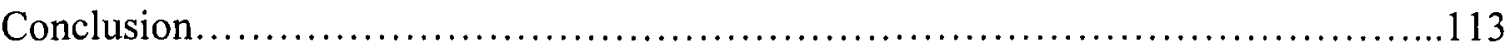

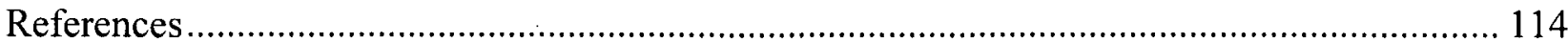




\section{List of Figures}

Figure 1

Experimental procedures for experiments 1-3

Figure 2

Photomicrographs of intra-CA3 cannula placement.

Figure 3

Average latency to locate hidden platform for each training session (exp. 1)

Figure 4

Average latency to locate hidden platform for each training trial - all doses (exp. 1)

Figure 5

Average latency to locate hidden platform for each training trial $-0 \& 100 \mathrm{nM}$ (exp. 1).........46

Figure 6

Twenty-four hour memory recall across training sessions - all doses (exp. 1)....

Figure 7

Twenty-four hour memory recall across training sessions $-0 \& 100 \mathrm{nM}$ (exp. 1).............52

Figure 8

Percent time spent searching within the target annulus during drug-free probe test (exp. 1)......55

Figure 9

Average latency to locate hidden platform for each training trial - all doses (exp. 2)............59

Figure 10

Percent time spent searching within the target annulus during probe test (exp. 2).

Figure 11

Average number of times rats passed through the target annulus during probe test (exp. 2)......65

Figure 12

Retention of platform location at 15 second time intervals during probe test (exp. 2). 68

Figure 13

Percent time in annuli located in the four quadrants of the pool during probe test (exp. 2)........72

Figure 14

Average swimming speed for each group during the probe test (exp. 2)......................74

Figure 15

Average latency to locate hidden platform for each training trial - all doses (exp. 3) 
Figure 16

Percent time spent searching within the target annulus during probe test (exp. 3) ................82

Figure 17

Average number of times rats passed through the target annulus during probe test (exp. 3) .......84

Figure 18

Retention of platform location at 15 second time intervals during probe test (exp. 3)

Figure 19

Percent time in annuli located in the four quadrants of the pool during probe test (exp. 3)........90

Figure 20

Representative photomicrographs of the CA3

Figure 21

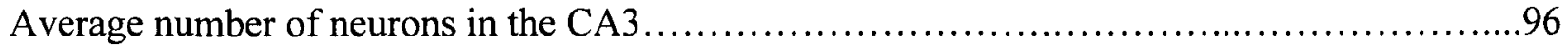

Figure 22

Representative photomicrographs of $\mathrm{pERK}$ labelling in the CA3

Figure 23

Average intensity of pERK staining in the CA3 101 


\section{List of Abbreviations}

AMPAR - $\alpha$-amino-3-hydroxy-5-methyl-4-isoxazoleproprionic acid receptor ATPA - $(R S)$-a-amino-3-hydroxy-5-tertbutyl-4-isoxazolepropionic acid AP5 - (2R)-amino-5-phosphonovaleric acid; (2R)-amino-5-phosphonopentanoate CA - cornu ammonis

$\mathrm{Ca}^{+2}-$ calcium ions

$\mathrm{CaMKII}-\mathrm{Ca}^{+2} /$ calmodulin-dependent protein kinases

CNQX - 6-cyano-7-nitroquinoxaline-2,3-dione

EPSP - excitatory postsynaptic potential

GABA - $\gamma$-aminobutyric acid

GYKI53655 - 1-(4-aminophenyl)-4-methyl-7,8-methylenedioxy-5H-2,3-benzodiazepine

GluR1-GluR4 - AMPAR subunits

GluR5-GluR7 - KAR subunits

Glu - glutamate

$\mathrm{K}^{+}$- potassium ions

KA1-KA2 - KAR subunits

$\mathrm{KAR}$ - kainate receptor

LTD - long-term depression

LTP - long-term potentiation

LY382884 - (3S, 4aR,6S, 8aR)-6-((4-carboxyphenyl)methyl-1,2,3,4,4a,5,6,7,8,8a-

decahydroisoquinoline-3-carboxylic acid)

mGluR - metabotropic glutamate receptor

$\mathrm{Mg}^{+2}-$ magnesium ions

$\mathrm{Na}^{+}$- sodium ions 
$\mathrm{NaCl}$ - saline

NMDAR - N-methyl-D-aspartate receptor

NR1-NR2 - NMDAR subunits

PBS - phosphate buffered saline

PCP - phencyclidine

p-ERK - phosphorylated extracellular signal regulated kinase

PFA - paraformaldehyde

PKC - protein kinase C

$\mathrm{S}-$ serine

$\mathrm{T}$ - threonine

UBP296 - (S)-1-(2-Amino-2-carboxyethyl)-3-(2-carboxybenzyl)pyrim idine-2,4-dione 


\section{Changes in spatial memory following pre-testing and post-training intra-CA3 kainate}

\section{injections in rats}

\section{Learning and Memory}

Learning and memory are unique cognitive abilities essential for many types of behaviours. The ability to learn is possessed by humans and animals alike. It refers to the process by which organisms acquire knowledge and skills through experience (Squire \& Kandel, 1999). Newly acquired information is integrated with previously stored information in the brain (i.e., memories). Learning can be directly observed through changes in an organism's behaviour as a result of these experiences.

Memory, which can be described as the ability to store, recall and recognize previous experiences, is the persistence of learning. That is, the continuation of behavioural changes as a function of experience. It can be divided into short- and long-term processes. Short-term memory refers to memory for immediate events, which may last for minutes whereas long-term memory is a relatively permanent memory store for events that may last for days to years (Matlin, 2006). Short-term memory has a finite capacity. George Miller reported in 1956 in his now famous paper that the capacity of short-term memory was $7 \pm 2$ items. Today, estimates of capacity are much lower today, ranging from 4 to 5 items (Cowan, 2001). Short-term memory can be further sub-divided into sensory and working memory. Sensory memory refers to an organism's memory for sensory information (i.e., information from one or more of the five senses - vision, audition, taste, touch and smell) from the environment. This type of memory typically degrades very quickly without rehearsal - lasting for less than one second (Matlin, 2006). Working memory is a temporary memory store for events actively being processed, (Baddeley, 1986). Working memory is comprised of three components: central executive, phonological loop and 
visuospatial sketchpad. According to Baddeley's model, the central executive is responsible for updating material in storage, shifting attention between various tasks and inhibiting automatic responses whereas the phonological loop component refers to the temporary memory store for verbal material and the visuospatial sketchpad component refers to the temporary memory store for visual and spatial information.

Long-term memory can be sub-divided into procedural, declarative and spatial memory. Procedural memory refers to long-term storage for skills and procedures and is shown by performance (Matlin, 2006). There are three subtypes of procedural memory: skill learning, priming and conditioning. Skill learning occurs when an organism learns to perform a challenging task with practice (i.e., learning to read upside down) whereas priming describes when the exposure to an earlier stimulus influences the processing of a later stimulus (i.e., reusing a word that you have heard recently; Matlin, 2006). Conditioning refers to the formation of associations between two or more stimuli, a stimulus and a response or a response and its consequence (Matlin, 2006).

Declarative memory refers to memory for facts and events that can be shown by conscious recollection of information (Matlin, 2006). Declarative memory can be further subdivided into semantic and episodic memory. Semantic memory describes an organism's generalized memory for facts independent of time and place whereas episodic memory is an organism's memory of personal experiences in terms of temporal and spatial context (Matlin, 2006). Spatial memory is the final type of long-term memory. It can be describes as an organism's memory for information about the environment (see next section for a more detailed description; Squire \& Kandel, 1999). Regardless of the duration of the memory storage or the type of memory stored, the formation and the subsequent recall of a memory follows three 
stages: (1) acquisition and consolidation where the information is processed and encoded, (2) retention which consists of the storage of information and (3) retrieval or recall of the stored information in response to a cue.

\section{Spatial Memory}

Spatial memory is a specific form of memory that stores information about an organism's environment (Squire \& Kandel, 1999). It is the process by which sensory information (mostly vision and proprioception - the sense of the body's position in space) from the environment is acquired and integrated to determine the location of an object or oneself in space. Over the years, researchers have uncovered a number of factors that influence spatial information processing, such as stimulus, temporal and movement factors (see White \& McDonald, 2002 for review). Distal environmental stimuli (i.e., cues located within the environment far from a point of reference) are important for the processing of spatial information. The relationships between these cues are integrated together to form a spatial representation or 'spatial map' of the environment with respect to a particular reference point. The formation of a spatial map is necessary for an organism's ability to navigate effectively through their environment.

Temporal factors have also been implicated in the acquisition of spatial information (White \& McDonald, 2002; White \& Ouellet, 1997). In one experiment, researchers reported that the ability to distinguish between two distinct sets of arms in a radial arm maze apparatus (one set that contained food and the other that contained no food) influenced the resulting integration of spatial information. One group of animals was exposed to the food arms of the maze and then exposed to the no-food arms 24 hours later. Each exposure lasted for 30 minutes. The second group of animals was exposed to the food and no-food arms in alternating five minute sessions 
for 30 minutes. This procedure was repeated 24 hours later. Each group of rats were exposed to the both sets of arms for equal amounts of time. The rats trained in the five minute procedure spent more time searching in the food arms than the no-food arms suggesting that these rats were better able to express their memory for the location of the food arms. These findings highlight the importance of temporal factors in the acquisition and integration of spatial information.

Movement is a third factor that plays an important role in spatial information processing (White \& McDonald, 2002). While movement in the environment is not necessary to acquire information, the integration of cues from at least two separate locations can lead to the formation of a more complete and detailed spatial map of the environment. When allowed to actively explore a maze, rats were more successful in the navigation of that maze later on whereas the restriction of movement led to poorer navigation (White \& McDonald, 2002).

Overall, stimulus, temporal and movement factors represent key features in the acquisition of spatial information. When integrated together, these factors provide valuable information about the environment with respect to a particular reference point. Further, the assimilation of these factors allows the organism to learn relationships between different cues in the environment as well as distinguish between ambiguous cues in order to determine the exact location of an object or oneself in space.

\section{Synaptic Plasticity}

The mammalian brain is an extremely adaptive organ that can undergo changes in organization and function with experience; a property referred to as neural plasticity (Citri \& Malenka, 2008). This unique characteristic is a bidirectional phenomenon responsible for the formation of new neural pathways, the strengthening of existing connections and the weakening 
or elimination of rarely used pathways (Citri \& Malenka, 2008). Synaptic plasticity is a specific form of neural plasticity that is expressed by changes in the strength of synaptic connections (i.e. the efficiency whereby one neuron excites or inhibits another neuron) as a function of neural activity (Citri \& Malenka, 2008; Tsanov \& Manahan-Vaughan, 2008). More specifically, the synaptic connection between two neurons can increase in strength when the pre-synaptic neuron repeatedly causes the post-synaptic neuron to fire. Conversely, the inability to consistently and sufficiently depolarize the post-synaptic neuron can lead to a weakening (and occasionally the elimination) of synaptic connections. It is the combination of synaptic activity and efficacy of signal propagation that determines overall synaptic strength. Given the malleability and flexibility of synaptic connections in response to experience, researchers believe that synaptic plasticity may represent a valid biological mechanism of learning and memory (Kopp, 2007).

The idea that synaptic plasticity is at the very core of learning and memory has considerable support within the literature (Blokland \& Boess, 2008; Martin et al., 2000; Kopp, 2007). Morphological and physiological modifications to neuronal architecture are strong candidates for the biological mechanisms underlying these cognitive processes (Blokland \& Boess, 2008). The activation of a neural circuit can promote the development of new synaptic connections between neurons as well as the rearrangement of existing connections (Globus et al., 1973; Maletic-Savatic et al., 1999). It is the formation of these new connections and circuits that are thought to underlie the storage of information.

Synaptic plasticity can be subdivided into two main categories: short-term and long-term plasticity. Short-term synaptic plasticity refers to modifications to the synapse that influence the likelihood of synaptic neurotransmission whereas long-term plasticity represents more permanent alterations to synaptic strength (i.e. long-term potentiation or LTP). LTP can be 
described as an increase in synaptic strength following high-frequency stimulation of a neural pathway that remains after the stimulus has been removed (Bliss \& Lomo, 1973). LTP shares many properties with what researchers have described as the "ideal memory process" (Martin, Grimwood \& Morris, 2000; Remy \& Spruston, 2007). It can be induced rapidly at synapses through high frequency electrical stimuli (Blokland \& Boess, 2008; Remy \& Spruston, 2007). Once LTP has been induced, the increase in synaptic strength can remain for hours or days after the removal of the stimuli. If electrical stimulation is repeated, the increase in strength may last for several weeks (Blokland \& Boess, 2008; Remy \& Spruston, 2007). This persistent increase in synaptic strength that is believed to be indicative of memory storage. For that reason, it is strongly believe that LTP represents one of the main mechanisms of information processing and storage within the brain.

\section{The Role of the Hippocampus in Spatial Learning and Memory}

The hippocampus has long been implicated as a key brain region for spatial learning and memory (Burgess, 2008; Martin et al., 2000). Impaired performance in spatial learning and memory has been well-documented in animals with hippocampal lesions (Logue et al., 1997; Morris et al., 1982) and in animals infused with pharmacological compounds or genetic modifications that interfere with normal hippocampal functioning (Morris et al., 1986; Tsien et al., 1996). The role of the hippocampus in learning and memory was first uncovered in 1957 through the study of patient H.M (Scoville \& Milner, 1957). Medial temporal lobe structures, including the hippocampus, were surgically removed from H.M. in hopes of eliminating seizures originating from those brain regions. The removal of the hippocampus did prevent the seizures but it also interfered with H.M.'s ability to form new declarative memories (i.e. memories for places, objects, people and events). Interestingly, H.M. was still able to recall memories that had 
been stored several years prior to the surgery - only memories for events from a relatively shorttime span prior to surgery and events that took place post-surgery were affected suggesting the medial temporal lobe, and in particular, the hippocampus, may play an important role in learning and memory processes.

Hippocampal Anatomy. The hippocampal region is located within the medial temporal lobe and can be divided into four main regions: the hippocampus proper, the dentate gyrus, the subculum and the entorhinal cortex (Gluck \& Myers, 1997). The hippocampus proper is further subdivided into three regions: the cornu ammonis (CA) $1,2 \& 3$. Information is relayed within these brain regions in a primarily unidirectional manner through excitatory connections in three distinct pathways: the preforant pathway, the mossy fibre pathway and the Schaffer collateral pathway (Gluck \& Meyers, 1998; Squire \& Kandel, 1999). In the perforant pathway, information is relayed through projections from the entorhinal cortex to the granule cells located in the dentate gyrus. Information is then transmitted through the axons of these granule cells (the mossy fibre pathway), which terminate on pyramidal cells of the CA3. From here, information is relayed through axons from $\mathrm{CA} 3$ pyramidal neurons to the $\mathrm{CA} 1$ region of the hippocampus (the Schaffer collateral pathway).

Synaptic plasticity is most prolific throughout an individual's lifetime in the hippocampus (Kelso \& Brown, 1986; Kopp, 2007). LTP is one of the most commonly studied forms of synaptic plasticity in the hippocampus and has been documented in all three hippocampal pathways: the perforant, the mossy fibre pathway and the Schaffer-Collaterals pathway (Blokland \& Boess, 2008). 


\section{Pharmacology of learning and memory}

Glutamate (Glu) is the primary excitatory neurotransmitter in the brain with receptors located throughout the central nervous system (Castillo, Malenka \& Nicoll, 1997; Collingridge \& Singer, 1990; Watkins \& Evans, 1981). Glu is an important neurotransmitter used in many hippocampal pathways and is the main neurotransmitter used by pyramidal neurons. There are two major classes of Glu receptors: ionotropic and metabotropic (Palmada \& Centelles, 1998). Ionotropic receptors or ligand-gated ion channels are membrane-bound protein complexes composed of four or five subunits that form an ion channel (Dingledine et al., 1999). Chemical ligands, like glutamate, bind to these receptors to regulate the opening and closing of the ion channel. Ionotropic receptors mediate synaptic transmission directly by altering the configuration of the ion channel and thus, producing quick localized changes in postsynaptic membrane potential (Dingledine et al., 1999). There are three subtypes of ionotropic Glu receptors: $N$ methyl-D-aspartate (NMDA), amino-3-hydroxy-5-methylisoxazoleproprionic acid (AMPA) and kainate (McBain \& Mayer, 1994; Watkins \& Evans, 1981). Each receptor is named for the chemical compound that selectively activates it.

Metabotropic receptors are composed of a single protein that when bound by chemical ligands indirectly affect the opening and closing of an ion channel (Hollmann \& Heinemann, 1994; Ohashi, Maruyama, Higashi-Matsumoto, Nomoto, Nishimura \& Takeuchi, 2002). The influx of ions through the ion channels alters membrane potential of the postsynaptic neuron. The latency and duration of the change in membrane potential is in general much longer than the ionotropic receptor postsynaptic response. There are at least eight documented metabotropic Glu receptor (mGluR) subtypes: mGluR1-mGluR8 (Ohashi et al., 2002). These eight subtypes are further subdivided into 3 groups based on (1) structure and (2) implicated second messenger 
systems (Hollmann \& Heinemann, 1994). Group I receptors include mGluR1 and mGluR5 subtypes. These receptors are located postsynaptically and are thought to play a role in the potentiation of NMDA receptor synaptic currents by elevating levels of intracellular $\mathrm{Ca}^{+2}$ and activating the second messenger protein kinase C (PKC; Lea, Custer, Vicini \& Faden, 2002; Skeberdis, Lan, Opitz, Zheng, Bennett \& Zukin, 2001). Group II (subtypes mGluR2 \& mGluR3) and III (subtypes mGluR4 \& mGluR6-8) receptors are found presynaptically (Shigemoto, Kinoshita, Wada, Nomura, Ohishi, Takada et al., 1997). These receptors are important for the attenuation of NMDA receptor-mediated synaptic responses by inhibiting the formation of the second messenger cAMP (Ambrosini, Bresciani, Fracchia, Brunello \& Racagni, 1995). For the purpose of this thesis only the ionotropic receptors will be discussed in detail.

\section{NMDA receptors}

Structure. NMDA receptors (NMDAR) are a family of ionotropic Glu receptors located in high densities within the hippocampus (Bliss \& Collingridge, 1993; Monaghan \& Cotman, 1985; Olverman et al., 1984). They are transmembrane heteromeric protein complexes composed of four subunits: two NR1 and two NR2 subunits. The binding sites for ligands are located on the extracellular side of these subunits; the NR1 subunit binds the amino acid glycine whereas the NR2 subunit binds glutamate. Together glycine and glutamate act as co-agonists; meaning both neurotransmitters must bind to the receptor concurrently to activate the receptor complex (Mori \& Mishina, 1995; Seeburg et al., 1995).

At normal membrane resting potential $(-70 \mathrm{mV})$, the NMDAR is impermeable to ion influx due to a voltage-dependent magnesium ion $\left(\mathrm{Mg}^{+2}\right)$ block within the channel pore (Evans,

Francis \& Watkins, 1977; Seeburg et al., 1995). The removal of the $\mathrm{Mg}^{+2}$ block requires the 
depolarization of postsynaptic membrane (by means other than the NMDAR) in concert with the co-activation of the receptor complex by glycine and glutamate (Foster \& Fagg, 1987; Mayer, Westbrook \& Guthrie, 1984; Nowak, 1984). Temporary membrane depolarization (i.e., excitatory postsynaptic potential or EPSP) can occur from the influx of sodium ions $\left(\mathrm{Na}^{+}\right)$ through AMPA receptors, another ionotropic Glu receptor, or through nicotinic receptors (Mayer et al., 1984; Nowak et al., 1984). Once the $\mathrm{Mg}^{+2}$ block is displaced, the receptor channel opens leading to an influx of $\mathrm{Na}^{+}$and $\mathrm{Ca}^{+2}$ ions causing further postsynaptic depolarization (Foster \& Fagg, 1987; Mayer et al., 1984; Nowak et al., 1984).

Decades of research have uncovered ample evidence that supports the idea that NMDARs are important for learning and memory (Collingridge \& Bliss, 1995; Li \& Tsien, 2009; Morris, 1989). It has been well documented that rats given systemic injections of NMDA show potentiated cognitive functioning (Koek et al. 1990, Hlinak \& Krejci, 2002a). The administration of NMDAR antagonists (i.e. compounds which block NMDAR channels) is an alternate approach used by researchers to determine the role of NMDARs in learning and memory (Anis et al., 1983; Huettner \& Bean, 1988; Lodge \& Johnson, 1990). Given that NMDARs require the binding of glycine and glutamate as well as the depolarization of the postsynaptic membrane to become activated, there are multiple sites at which NMDAR antagonists can act with a wide range of outcomes.

The illicit drugs phencyclidine (PCP) and ketamine, noncompetitive NMDAR antagonists (i.e. drugs which inhibit receptor functioning by binding to allosteric sites), bind to a site located inside the channel pore blocking subsequent ion influx into the neuron (Anis et al., 1983; Lodge \& Johnson, 1990). Similarly, MK-801 or dizocilpine, an extensively used experimental drug, has a high affinity for this binding site (Wong et al., 1986). These drugs act in a use- and voltage- 
dependent manner; that is, the NMDARs channels must be in its open state before they can enter and bind to the ion channel (Huettner \& Bean, 1988; Lodge \& Johnson, 1990). These antagonists block the receptor channel preventing the influx of ions into the neuron and thereby reducing LTP induction in the hippocampus (Abraham \& Mason, 1988; Anis et al., 1983; Lodge \& Johnson, 1990).

Given that the generation of LTP is believed to represent one of the major biological mechanisms of learning and memory, it follows that any biological process which influences the production of LTP would also play an integral role in the processing and storage of information. In fact, marked learning and memory impairments have been observed in animals treated with any of these drugs on a variety of learning and memory paradigms (Butelman, 1989; Kant, Wright, Robinson \& D'Angelo, 1991; Zajaczkowski, Quack \& Danysz, 1996). For instance, MK801-infused animals demonstrated severe memory impairments during the retention session of a spatial version of the elevated plus maze (Hlinak \& Krejci, 2002b; Zajaczkowski, et al., 1995), dose-dependent impairments in the radial arm maze (Butelman, 1989) and increase latency to learn a novel water maze task (Kant et al., 1991).

Unlike the previous NMDAR antagonists discussed, the clinical drug memantine is a low affinity NMDA channel blocker (Robinson \& Keating, 2006). This means memantine adheres to the channel pore less effectively and the NMDAR can still be activated in the presence of high levels of Glu (Chen \& Lipton, 2006). Like PCP and MK-801, memantine is voltage-dependent and the NMDAR channel must be open in order for it to bind and inhibit the influx of $\mathrm{Ca}^{+} 2$ and $\mathrm{Na}^{+}$ions (Robinson \& Keating, 2006). Clinically, memantine is used in the treatment of Alzheimer's disease and evidence from several studies suggests it is effective in improving cognitive function in patients with moderate to severe Alzheimer's (see Areosa, Sherriff \& 
McShane, 2005 for review) further implicating the NMDAR as a key player in learning and memory.

Other types of NMDAR antagonists include the competitive antagonist AP5 which blocks normal NMDAR functioning by binding to the same site that Glu binds on the receptor (Morris, 1989). When administered in vitro, AP5 inhibits LTP induction in hippocampal slices (Herron et al., 1986) whereas in vivo, AP5 administration only blocks the production of LTP in the hippocampus at high concentrations (Collingridge et al., 1983; Hablitz \& Langmoen, 1986). Researchers have also documented numerous spatial learning impairments in AP5 treated animals at doses that block hippocampal LTP (Morris, 1989). Interestingly, only the formation of new spatial memories was blocked; AP5 did not interfere with the retention or recall of previously stored spatial information. The resulting spatial memory impairments in AP5 treated animals were comparable to impairments observed in animals with hippocampal lesions (Morris, Garrud, Rawlins \& O'Keefe, 1982; Morris, Anderson, Lynch \& Baudry, 1986). These results suggest NMDAR are crucial for LTP induction in the hippocampus and certain types of spatial information processing.

The role of NMDARs in spatial memory is further validated through a series of experiments that involved NMDA 1 receptor knockout mice (Tsien, Huerta \& Tonegawa, 1996). Researchers genetically created a strain of mice that did not possess the NMDAR1 gene and, as a result, these mice lacked NMDARs located in CA1 pyramidal neurons. The NMDA knockout mice were equivalent to wild-type mice in all aspects except for spatial memory (Tsien et al., 1996). Wild-type mice demonstrated superior performance in the spatial version of a water maze task when compared to the knockout mice. No differences were found between wild-type and knockout mice on tasks that did not involve spatial memory. In addition, high-frequency 
stimulation in the CA1 region in vitro did not induce LTP in the knock-out mice (Tsien et al,, 1996). Taken together, this strongly suggests that NMDARs in the CAl region of the hippocampus are necessary for the generation of LTP and spatial learning and support the hypothesis that LTP in the hippocampus is essential to the formation of spatial memories.

Given the above evidence, it appears that NMDARs play a major role in spatial learning and memory through their influence on the production of LTP in hippocampal neurons. Given the relationship between NMDA and AMPA receptors, it is clear that NMDARs do not act alone in the mediation of these cognitive processes. In fact, researchers have uncovered considerable evidence that suggests non-NMDA receptors, like AMPA and kainate receptors, also have important roles in synaptic efficacy and spatial information processing (Jonas, 2000; Reisel, Bannerman, Schmitt, Deacon, Flint Borchardt et al., 2002; Smith, Gorski, \& Dell'Acqua, 2005).

\section{AMPA receptors}

Structure. AMPA receptors (AMPAR) are ionotropic Glu receptors responsible for fast signal propagation within the hippocampus and other brain regions (Jonas, 2000; Smith et al., 2005). Like NMDARs, AMPARs are transmembrane heteromeric protein complexes composed of four subunits (GluR1-GluR4); each with their own binding site for glutamate and other AMPAR agonists. The subunit composition of each AMPAR varies depending on the type of neuron, the brain region and the developmental stage (Greger, Ziff \& Penn, 2007; Smith et al., 2005). In the adult hippocampus, the GluR1, GluR2 and GluR3 subunits are the most prevalent (Shi et al., 2001; Wenthold et al., 1996). These subunits combine to form two receptor complexes: GluR1/GluR2 and GluR2/GluR3. The GluR4 subunit is also expressed within hippocampus but only during early development (Wenthold et al., 1996). 
AMPAR activation requires a minimum of two binding sites to be occupied. If more than two binding sites are activated, the AMPAR shows a potentiated response (Rosenmund, SternBach \& Stevens, 1998). Once the receptor is activated, $\mathrm{Na}^{+}$enters the neuron and generates a short-lived EPSP is generated. This is because AMPAR channels are open for only very short periods of time; after which they become desensitized and synaptic transmission is blocked (Armstrong, Jasti, Beich-Frandsen \& Gouaux, 2006). It is this very quick opening and closing of the channel pore than results in the fast conductance of signals mediated by AMPARs.

Subunit composition and phosphorlylation are properties which regulate the functioning of AMPARs. The permeability of AMPARs to $\mathrm{Ca}^{+2}$ is dependent on the presence of GluR2 subunit in the AMPAR complex (Kim, Kim, Choi, Min \& Gwag, 2001). Most AMPARs that possess the GluR2 subunit prevent the entry of $\mathrm{Ca}^{+2}$ into the neuron upon activation. This impermeability to $\mathrm{Ca}^{+2}$ is directly linked to a modification in amino acid composition within the receptor pore on the GluR2 subunit where the uncharged amino acid glutamine is switched for the positively changed amino acid arginine. Almost all AMPARs located within the central nervous system possess this amino acid alteration in the GluR2 subunit and thus, are impermeable to $\mathrm{Ca}^{+2}$ (Kim et al., 2001). Researchers have suggested this protects the postsynaptic neuron from the potential danger of excitotoxicity (i.e., the overactivation of Glu receptors leading to neuronal damage or death) due to $\mathrm{Ca}^{+2}$ influx (Manev, Favaron, Guidotti \& Costa, 1989).

Phosphorylation (i.e., the process by which a phosphate group is added to an organic molecule, like a protein) of AMPARs is another mechanism that can regulate receptor functionality (Boehm, Kang, Johnson, Esteban, Huganir \& Malinow, 2006; Delgado, Coba, Anderson, et al., 2007). All GluR subunits have the potential for phosphorylation and contain 
multiple phosphorylation sites (Song \& Huganir, 2002). GluRl is been the most researched subunit and will be the focus of this discussion. There are four phosphorylation sites along the GluR1 protein located at serine (S) 818, S831, S845 and threonine (T) 840 (Banke, Bowie, Lee, Huganir, Schousboe \& Traynelis, 2000; Boehm et al., 2006; Delgado et al., 2007). Protein kinase $\mathrm{C}$ ( $\mathrm{PKC}$ ) and $\mathrm{Ca}^{2+} /$ calmodulin-dependent protein kinases (CaMKII) are responsible for the addition of phosphate groups to S818 and S831 residues, respectively. The phosphorylation of these residues is implicated in the induction of LTP by potentiating synaptic currents through an increase in single-channel conductance (Boehm et al., 2006; Derkach, Barria \& Soderling, 1999). Conversely, it has been suggested that the phosphorylation of the T840 residue may act as a potential mediator of long-term depression or LTD (i.e., the weakening of neuronal synapses from consistently weak synaptic transmission; Delgado et al., 2007). It appears that the length of dephosphorylation at T840 is important for determining the degree of depression in synaptic strength. Transient reductions in T840 phosphorylation stimulate a short-term depression of synaptic transmission whereas more lasting reductions in phosphorylation induce a persistent decrease synaptic transmission. The activation of NMDARs mediates the decrease in T840 phosphoryation (Delgado et al., 2007). The final phosphorylation site, S845, regulates the opening of AMPARs in the presence of protein kinase A (PKA; Banke et al., 2000). Overall, phosphorylation of AMPAR subunits appears to be an important aspect of regulating synaptic plasticity and synaptic transmission in neurons.

Subunit composition of AMPARs is also crucial to hippocampal LTP (Reisel et al., 2002). GluR1 subunit knockout mice show reduced LTP induction compared to wild-type controls. Interestingly, these GluR1 deficient mice did not exhibit deficits in spatial reference memory on cued learning tasks. However, they do display deficits in spatial working memory 
tasks as demonstrated on non-matching to place maze procedures where animals are rewarded for choosing to enter the arm of either a $\mathrm{T}$ or $\mathrm{Y}$-maze that it did not previously enter immediately before (Reisel et at., 2002). Knockout mice were more likely to enter the same arm they visited on the initial trial. The protection of spatial reference memory and the impairment of spatial working memory tasks in mice that lack the GluR1 subunit suggest that different types of spatial memory can be modulated by different structural and functional properties of AMPARs.

Synaptic Transmission. AMPARs working together with NMDARs mediate synaptic plasticity and neural transmission. As mentioned, postsynaptic depolarization throughout AMPAR activation is required for the opening of NMDAR ion channels and the influx of $\mathrm{Ca}^{+2}$ and $\mathrm{Na}^{+}$into the neuron (Foster \& Fagg, 1987; Mayer et al., 1984; Nowak et al., 1984). Once $\mathrm{Ca}^{+2}$ ions enter the neuron, they act as second messengers triggering the up-regulation of AMPARs on the postsynaptic membrane leading to a sustained increase in the amplitude of excitatory postsynaptic potentials (EPSP; Bear \& Abraham, 1996; Bliss \& Collingridge, 1993; Song \& Huganir, 2002). The influx of $\mathrm{Ca}^{+2}$ also phosphorylates CaMKII which, as previously described, phosphorylates the GluR1 subunit potentiating synaptic transmission (Hayashi et al., 2000). When taken together, the above evidence suggests that the co-localization of AMPARs and NMDARs is essential to the generation of LTP and thus, the processing and storage of information in the brain.

There is an inherent flaw in pharmacological studies investigating the effects of AMPAR agonists and antagonists on receptor functioning and signal conductance (Lerma, Paternain, Rodriguez-Moreno \& Lopez-Garcia, 2001; Lerma, 2006) such that many pharmacological agonists and antagonists lack specificity for AMPARs (Lerma et al., 2001; Lerma, 2006). Often, these compounds bind to and activate KARs as well. This led to the classification of both 
AMPARs and KARs as non-NMDARs. Today, the development of synthetic drugs that can selectively antagonize either AMPARs or KARs has provided great insight into the functions of both receptors in synaptic plasticity and neurotransmission. The infusion of LY300268, a AMPARs antagonist, blocks AMPAR mediated synaptic transmission and prevents the induction of mossy fibre LTP but does not antagonize KARs (Paternain, Morales \& Lerma, 1995; Wilding \& Huettner, 1996). More recently, the synthesis of pharmacological agonists and antagonists specific to particular KAR subunits has further advanced our understanding of role of both AMPARs and KARs in synaptic transmission and plasticity (Lerma, 2006).

\section{Kainate receptors}

Structure. The kainate receptor (KAR) is the lesser known of the three ionotropic Glu receptor subtypes. They are located throughout the central nervous system but in particularly high densities at mossy fibre synapses (Chittajallu, Braithwaite, Clarke \& Henley, 1999; Monaghan \& Cotman, 1982). There are five KAR subunits which combine in groups of four to form the channel pore: GluR5-GluR7, KA-1 and KA-2 (Chittajallu et al., 1999; Lodge \& Dingledine, 2000). The resulting protein complexes can be either homomeric or heteromeric. Only the GluR5, GluR6 and GluR7 subunits form functional homomeric KAR complexes; although the efficacy of the homomeric GluR7 receptor is greatly reduced. Despite having a higher affinity for kainate than GluR5-GluR7, the KA-1 and KA-2 subunits do not form functional homomeric receptor complexes (Chittajallu et al., 1999).

The administration of different KAR agonists and antagonists has differential effects depending on subunit composition (Chittajallu et al., 1999). The homomeric GluR5 receptor, but not homomeric GluR6 or GluR7 receptors, can be activated by the infusion of AMPA (Schiffer, 
Swanson \& Heinemann, 1997; Sommer et al., 1992). Interestingly, when the homomeric GluR6 receptor is made chemically similar to the homomeric GluR5 receptor, researchers reported comparable activation by AMPA (Swanson, Kamboj \& Cull-Candy, 1997). Likewise, when GluR6 subunits are co-expressed with KA-2 subunits, the resulting receptor complex demonstrates a sensitivity to AMPA (Howe, 1996; Sakimura et al., 1992). The administration of kainic acid is more effective in activating homomeric GluR6 receptors than herteromeric GluR6/KA-2 receptors (Howe, 1996). Another KAR agonist, (RS)-a-amino-3-hydroxy-5tertbutyl-4-isoxazolepropionic acid (ATPA), shows selectivity for GluR5 subunits over GluR6 and GluR7 subunits. Researchers have demonstrated that it is more effective activating heteromeric GluR5/KA-2 and GluR5/GluR6 receptors than homomeric GluR5 receptors (Swanson et al., 1998). In addition, the KAR antagonist UBP296 shows a higher affinity for GluR5 subunits when compared to all other receptor subunits (More, Nistico, Dolman, Clarke, Alt, Ogden, et al., 2004). These differences in the sensitivity to various KAR agonists and antagonists have important implications in efficacy of synaptic transmission and synaptic plasticity.

Similar to receptor sensitivity distinctions between KAR subunit compositions, there are variations in receptor combinations within different locations in the brain. Pyramidal neurons and granule cells predominately express the GluR6 subunit whereas the GluR5 subunit is more commonly found within nonpyramidal neurons (Bahn et al., 1994; Wisden \& Seeburg, 1993). More specifically, in CA3 pyramidal neurons, GluR6, KA-1 and KA-2 subunits are most abundant whereas only GluR6 and KA-2 subunits are expressed in high levels in CA1 pyramidal neurons (Bahn et al., 1994; Wisden \& Seeburg, 1993). In GABAergic interneurons located within the hippocampus, heteromeric GluR5/GluR6 receptor complexes are more commonly 
expressed. In fact, at least $80 \%$ of all KARs found in those neurons were GluR5/GluR6 heteromers (Paternain, Herrera, Nieto \& Lerma, 2000). This diversity in the composition of KARs throughout the brain may account for the discrepancies in receptor characteristics and functionality between different brain regions.

Role in synaptic plasticity. Unlike NMDARs and AMPARs which are primarily located postsynaptically, KARs are found on both pre- and postsynaptic elements (Bortolotto, Nistico, More, Jane \& Collingridge, 2005; Lerma, 2003; Jiang et al., 2001). It has been well documented that the synaptic release of glutamate activates presynaptic KARs on mossy fibres and postsynaptic KARs on CA3 pyramidal neurons, where they are located in high densities (Castillo et al., 1997; Frerking, Malenka, \& Nicoll, 1998; Lauri et al., 2001; Vignes \& Collingridge, 1997). The activation of these receptors leads to synaptic responses that are much smaller in amplitude and last for significantly longer periods than those generated by AMPARs (Castillo et al., 1997; Frerking et al., 1998; Vinges \& Collingridge, 1999).

KARs play a critical role in multiple forms of plasticity at the mossy fiber synapse in vitro. Postsynaptic receptors mediate EPSPs in hippocampal neurons (Frerking \& OhligerFrerking, 2002). Researchers have observed that the generation of KAR-mediated EPSPs from small to moderate presynaptic activity can lead to postsynaptic depolarization. The ease in which depolarization occurs from even modest presynaptic input can be attributed to the much slower kinetics of KARs. Presynaptic receptors play an important role in the mediation of excitatory synaptic transmission through the modulation of neurotransmitter release (Bortolotto et al., 2005; Lerma, 2003). The activation of KARs mediates the release of Glu in a bidirectional manner. At low concentrations, kainate stimulates Glu release, potentiating excitatory synaptic transmission 
at mossy fibre synapses (Schmitz et al., 2001) whereas at high concentrations, excitatory synaptic transmission is attenuated at both mossy fibre and Schaffer collateral synapses (Kamiya and Ozawa, 2000; Schmitz et al., 2000, 2001).

The mechanism underlying the presynaptic KAR-mediated synaptic plasticity at mossy fibre synapses involves $\mathrm{Ca}^{+2}$ signalling (Lauri et al., 2003; Scott, Lalic, Kullmann, Capogna \& Rusakov, 2008). The activation of presynaptic KARs triggers the entry of $\mathrm{Ca}^{+2}$ through these receptors that, in turn, stimulate the release of $\mathrm{Ca}^{+2}$ from $\mathrm{Ca}^{+2}$ intracellular stores (Lauri et al., 2003; Scott et al, 2008). The intracellular release of $\mathrm{Ca}^{+2}$ is blocked philanthotoxin, a drug which targets $\mathrm{Ca}^{+2}$ permeable Glu receptors (Lauri et al., 2003). When the entry of $\mathrm{Ca}^{+2}$ is blocked by philanthotoxin, synaptic transmission and LTP at mossy fibres is attenuated, suggesting that the release of $\mathrm{Ca}^{+2}$ from intracellular stores is critically involved in mossy fibre synaptic plasticity (Lauri et al., 2003).

In GluR6 knockout mice, activation of KARs does not mediate synaptic transmission in either direction (Bureau, Bischoff, Heinemann, \& Mulle, 1999; Mulle et al., 1998) whereas in KA-2 knockout mice, only the enhancement of excitatory synaptic transmission is affected (Contractor et al., 2003). Therefore, it appears the GluR6 and KA-2 KAR subunits are important for KAR-mediated synaptic transmission. Presynaptic KARs can also mediate inhibitory synaptic transmission (Clarke et al., 1997). Antagonism of AMPARs by GYKI53655 leads to a reduction in inhibitory PSPS in kainate or ATPA infused animals. Similar results are obtained with the GluR5 KAR antagonist (Clarke et al., 1997) suggesting that presynaptic KARs may contain the GluR5 subunit. 
KARs have been implicated in the induction of LTP at mossy fibre synapses (Bortolotto et al., 2005; Breustedt \& Schmitz, 2004; Schmitz et al., 2003); a form of NMDA-independent LTP. When these receptors are activated, they considerably lower the threshold at which LTP can be induced (Schmitz et al., 2003). Moreover, the application of potassium ions $\left(\mathrm{K}^{+}\right)$further reduces the threshold for which LTP can be induced at the same synapses. Finally, in the presence of CNQX (an AMPAR and KAR antagonist), LTP can be produced; although it requires a substantial increase in tetanic stimulation. Taken together, these findings suggest KARs, while not critical for LTP, are important modulators of mossy fibre LTP by lowering the induction threshold.

The subunit composition of KARs at mossy fibre synapses has not yet been fully elucidated; both GluR5 and GluR6 have been implicated. In GluR6 knockout mice, mossy fibre LTP is significantly reduced (Breustedt \& Schmitz, 2004; Contractor et al., 2001; Schmitz et al., 2003) and could not be reversed with the infusion of kainate (Breustedt \& Schmitz, 2004). Interestingly, low levels of $\mathrm{K}^{+}$applied during tetanus were able to reverse the attenuation of LTP in these mutant mice suggesting GluR6 subunits (1) are critically involved in LTP induction and (2) enhance LTP induction through the depolarization of the presynaptic terminal (Schmitz et al., 2003).

Researchers have reported conflicting results as to the role of the GluR5 subunit in mossy fibre LTP. One group of researchers has reported that the pharmacological antagonism of GluR5 subunit with LY382884 and UBP296 blocked the generation of LTP (Bortolotto et al., 1999; More et al., 2004). In a separate lab, the opposite was found - the administration of LY382884 had no effect on LTP induction (Breustedt \& Schmitz, 2004; Contractor et al., 2001; Schmitz et al., 2001). The genetic deletion of the GluR5 subunit had a similar effect on LTP (Breustedt \& 
Schmitz, 2004; Contractor et al., 2001). It is possible that inconsistencies in methodology could have contributed to the divergence in findings. It is more likely that the GluR5 subunit is not essential for LTP given the low expression of this subunit at mossy fibre synapses (Bahn et al., 1994). However, more research is necessary in order to confirm or disprove these findings.

Kainate. Kainate is a KAR specific agonist that mimics the effects of Glu. KA-1 and KA2 subunits have a higher affinity for kainate than Glu (Chittajallu et al., 1999). The infusion of kainate at mossy fibre synapses has a bidirectional effect on synaptic transmission (Contractor et al., 2000; Lauri et al., 2001; Schmitz et al., 2001). Low levels (20-100 nM) of kainate enhance synaptic neurotransmission as well as AMPAR and NMDAR EPSPs (Contractor et al., 2000; Schmitz et al., 2001) which can be reversed through the application of CNQX. This enhancement of synaptic transmission is thought to involve the increase in the release of Glu (Schmitz et al., 2001) providing further support that KARs play a major role in short-term synaptic plasticity. While it is possible that KARs are also important for the expression of LTP at these synapses, it is likely that the elevated release of Glu may mediate the generation of LTP and KARs may not be directly responsible for its induction.

At high concentrations (greater than $200 \mathrm{nM}$ ), kainate attenuates synaptic transmission through the depression of the presynaptic neuron (Contractor et al., 2000). The GluR5 subunit is one potential mechanism for reduced neurotransmission. The application of ATPA (a GluR5specific agonist) leads to a similar synaptic response. The excitation of GABAergic interneurons causing the release of inhibitory neurotransmitter GABA is thought to be the mechanism underlying ATPA action (Schmitz et al., 2000). At mossy fibre synapses, the antagonism of $\mathrm{GABA}_{\mathrm{B}}$ receptors does not reverse the depression of synaptic transmission but does lead to a 
reduction in the depressant effect when applied to GABA interneurons. Further, the genetic deletion of the GluR6 subunit (but not the GluR5 subunit) prevents the attenuation of synaptic responses (Contractor et al., 2000). Taken together, these findings support the idea that presynaptic KARs found at mossy fibre synapse contain GluR6 which is important for synaptic plasticity. Conversely, it is probable the GluR5 subunit is predominately located on interneurons where the synaptic release of GABA leads to the attenuation of the synaptic response at mossy fibre synapses.

At much higher concentrations $\left(9.4 \times 10^{5}\right.$ to $\left.4.9 \times 10^{7} \mathrm{nM}\right)$, intra-hippocampal injections of kainate cause hippocampal lesions (Gröticke et al., 2008; Ozaki et al., 1985) as well as lead to spontaneous, recurrent seizures (Bouilleret et al., 1999; Gröticke et al., 2008; Raedt, Van Dycke, Van Melkebeke, De Smedt, Claeys, Wyckhuys et al., 2009). Mice with bilateral hippocampal lesions to the $\mathrm{CA} 3$ region show acquisition impairments in the jump-box avoidance task (Ozaki et al., 1985). Unilateral injections of kainate into the dorsal hippocampus lead to marked neural damage in a number of ipsilateral hippocampal regions, $\mathrm{CAl}, \mathrm{CA} 3$ and the dentate hilus, which are accompanied by deficits in the acquisition and the retention of spatial information in the spatial version of the Morris water maze task (Gröticke et al., 2008). Together, these findings support the idea that the $\mathrm{CA} 3$ region of the hippocampus may be important for information processing.

Ample research examining NMDARs and AMPARs in vitro and in vivo has established these receptors as key players in synaptic plasticity as well as learning and memory (Bliss \& Collingridge, 1993; Blokland \& Boess, 2008; Martin et al., 2000). The importance of KARs in the mediation of synaptic plasticity in vitro is also well supported by the literature (Bortolotto et al. 2005). Little research has been conducted in vivo and consequently, little is known about the 
role of KARs in learning and memory, in particular spatial information processing. Therefore, the goal of this thesis was to activate KARs with low doses of kainic acid and determine how this manipulation influenced synaptic plasticity in vivo, through behavioural measures of plasticity.

\section{Behavioural Measures of Plasticity}

Researchers have developed a variety of behavioural procedures that assess synaptic plasticity at the behavioural level including the Morris water maze, the radial arm maze, the Hebb-Williams maze and the Barnes maze, to name a few. For the purposes of this thesis, only the Morris water maze procedure will be discussed.

The Morris water maze was first developed in 1981 by Richard Morris to assess spatial learning in the rat (Morris, 1981, 1984). The maze was initially designed to compare the ability to learn the location of a platform using either proximal or distal cues within the same basic paradigm. Cues are considered proximal when they can be detected by sight, audition or olfaction whereas distal cues represent cues not directly linked to the target object (i.e., the spatial location of the target was inferred from these cues). At that time, no learning task was available that could assess both types of cues. The crucial finding from this study was that rats are capable of learning the spatial location of an objection using only distal cues (Morris, 1981).

Water maze procedure. Rats were placed in a large pool of water in which an escape platform was hidden just below the surface of the water. Using only distal cues (i.e., cues external to the pool), rats were repeatedly tested from different starting positions on their ability to locate the hidden platform. Normally, rats quickly learn where the platform is located and thus, latency and path length (i.e., path travelled to platform becomes more direct once location is learnt) to reach the hidden platform decreases over time. There are many variations to the 
standard Morris water maze paradigm, including matching-to-place learning where the platform is located in a different position every day (Whishaw, 1989) and landmark learning where rats use cues located within the pool instead of distal cues to find the platform (Kolb \& Walkey, 1987).

Latency to locate the platform was and continues to be the traditional measure of spatial learning for this procedure. However, this may not be the most valid measurement of spatial learning given that latency is dependent on swimming speed and ability. Further, during training, animals may not be using distal cues to locate the platform (Clapcote \& Roder, 2004; Gallagher et al., 1993). It is possible that animals develop an effective searching technique highlighting the need for a more objective measure of spatial learning. To account for this, probe trials (which follow the training session) are used. During a probe trial, the platform is removed and the rat is given a fixed amount time to search the pool. Information, such as the number of phantom platform crossings, average proximity to the target and the amount of time spent in the target annulus and target quadrant, are used as measures of spatial learning. In a recent meta-analysis of 1600 mouse probe trials, researchers evaluated these measures to determine which were the most effective at evaluating spatial learning (Maei, Zaslavsky, Teixeira \& Frankland, 2009). Overall, measures of proximity to the target annulus were more effective than all other measures in assessing spatial learning, emphasising the importance of including this measure when analyzing water maze data.

\section{Rationale for Present Thesis}

Considerable evidence supports the idea that NMDARs and AMPARs are critically involved in spatial information processing (Bliss \& Collingridge, 1993; Blokland \& Boess, 2008; 
Martin et al., 2000). Conversely, the role of KARs in spatial learning and memory is much less established (Bortolotto et al. 2005). Preliminary evidence does suggest a potential role for KARs in short- and long-term plasticity in vitro; particularly within the mossy fibre synapses where KARs are found in high-densities (Monaghan \& Cotman, 1982). Moreover, the majority of research conducted to date has been restricted to in vitro experiments, highlighting the need for more experimental research studies using in vivo methods. Given the substantial amount of evidence implicating synaptic plasticity as a valid mechanism of learning and memory and the lack of in vivo experiments conducted, the objective of this research was to examine the effects of intra-CA3 kainate injections on the acquisition and retrieval of spatial information in live subjects.

\section{Experiment 1: Pretraining injections}

The underlying goal was to examine whether intra-CA3 injections of kainic acid influenced the acquisition and/or performance on the spatial version of a water maze task. Male Wister rats received bilateral microinjections of $0,25,50$ or $100 \mathrm{nM}$ kainic acid into the CA3 region of the hippocampus prior to training on the Morris water maze for 4 consecuive days. On the fifth day, rats completed a 60 second probe swim to determine memory retention for the platform location. It was hypothesized that acquisition improvements would be observed at doses showing potentiated responses in vitro.

\section{Experiment 2: Pretesting injections}

A second objective was to investigate the effect of pretesting bilateral intra-CA3 injections of kainic acid on spatial memory retention. Wistar rats were trained for 4 consecutive 
days in the Morris water maze task with no injections. Pretesting microinjection of $0,25,50$ or $100 \mathrm{nM}$ kainic acid was given on day 5 prior to the completion of a 60 second probe test. It was hypothesized that rats injected with kainic acid would show a dose-dependent enhanced retention/retreival of spatial information during the probe test.

\section{Experiment 3: Posttraining injections}

A third objective was to explore whether posttraining injections of kainic acid would alter the consolidation of spatial information. Wistar rats were trained for 4 consecutive days in the Morris water maze. Following each training day, rats received a microinjection of 0 or $100 \mathrm{nM}$ kainic acid. On day 5, rats completed a 60 second probe test. It was hypothesized that rats injected with $100 \mathrm{nM}$ kainic acid would be better able to express their spatial memory for the platform location indicating an enhanced consolidation process.

\section{Experiment 4: Activation in the CA3}

A final objective was to examine whether injections of saline and $100 \mathrm{nM}$ differentially effect CA3 activation. Wistar rats were injected bilaterally or unilaterally with saline or $100 \mathrm{nM}$ kainate. Fifteen minutes after the injection, rats were sacrificed so that the activation in the CA3 as a result of these injections would reflect the activation in the CA3 during Morris water maze training in experiments 1 and 2. CA3 activation was assessed using phosphorylated form of extracellular signal regulated kinase (p-ERK) immunofluorescence. It was hypothesized that 100 nM kainate-injected rats would show more activation in the CA3. 


\section{Materials and Methods}

\section{Animals}

Male Wistar rats $(N=95$; Charles River, St. Constant, Québec, Canada) were housed in groups of two in polycarbonite $48 \times 26 \times 20 \mathrm{~cm}^{3}$ cages within a temperature controlled environment. All animals were on a 12 hour light-dark cycle (lights on at 8:00 a.m.) with ad libitum access to food (Purina rat chow) and tap water. Following intracranial surgery, rats were housed individually. All animal procedures were approved by the Canadian Council on Animal Care (CCAC) and Carleton University Ethics Board.

\section{Intracranial Surgery}

Rats were anaesthetized with Isoflurane ( $3 \%$ in pure $\mathrm{O} 2$ to induce and $2 \%$ in pure $\mathrm{O} 2$ to maintain). Their scalps were shaved and the animals were mounted in a stereotaxic apparatus on top of a heating pad. Their scalp was cleaned and tear gel was applied to their eyes. An incision was made using a $10 \mathrm{~mm}$ scalpel from just behind the eyes to the ears. The skin was scraped off the skull and the incision was held open using haemostats. For each animal, two stainless-steel $10 \mathrm{~mm}$ guide cannula (25 Gauge) were implanted bilaterally $1 \mathrm{~mm}$ above the CA3 region of the hippocampus at the following stereotaxic coordinates relative to bregma and skull surface: Anteroposterior $=-3.0 ;$ Mediolateral $=+3.0(\mathrm{left}) ;$ Dorsoventral $=-2.6$. The guide cannula were secured in place using dental cement and skull screws. Stylets (32 Gauge) were inserted into the guide cannula to ensure they would not become blocked prior to the testing phase. The antibiotic Polysporn was applied all around the wound and underneath the skin. The incision was then closed using a surgical suture and topical lidocaine was applied around the wound. In addition, all animals received a subcutaneous injection of Metacam $(0.1 \mathrm{~mL})$. Following surgery, animals 
were place in a clean home cage on a heating pad for approximately 20 minutes. All surgeries lasted approximately 45-60 minutes and the surgical instruments were autoclaved prior to the first surgery and cleaned after each surgery.

\section{Microinjection Procedure}

The experiments were performed after a recovery period of at least 5 days in awake, freely moving animals during the day. Rats were handled for 5 minutes each for 5 days to minimize stress during testing. Stylets were removed and two stainless-steel injection cannula (32 Gauge) separately connected to $10 \mu$ l Hamilton syringes by polyethylene tubing were carefully lowered through the guide cannula. Both syringes were connected to an injection pump (Braintree Scientific, Inc.) which was programmed to deliver a $0.5 \mu \mathrm{L}$ injection of kainate at a rate of $0.15 \mu \mathrm{L} / \mathrm{min}$. Each rat received a bilateral injection of $0,25,50$ or $100 \mathrm{nM}$ kainate into the CA3 that lasted approximately 200 seconds. The injection cannula was left in place for an additional 3 minutes to ensure adequate diffusion of the solutions to the target area. Each animal was held by the experimenter for the duration of the injection. Following the injection, rats were placed into their home cage for 5-minute recovery period. Each animal was injected at approximately the same time every day.

Kainate. Each dose of kainate was prepared using $0.9 \% \mathrm{NaCl}$ (saline) solution and (432 $\mathrm{nM}$ ) kainic acid. The $100 \mathrm{nM}$ kainate was prepared using equal parts $0.9 \% \mathrm{NaCl}$ solution and (concentration) kainic acid. The $50 \mathrm{nM}$ and $25 \mathrm{nM}$ solutions were prepared using equal parts of $0.9 \% \mathrm{NaCl}$ solution or $100 \mathrm{nM}$ or $50 \mathrm{nM}$ kainic acid, respectively. For the $0 \mathrm{nM}$ kainate solution, rats received a solution of $0.9 \% \mathrm{NaCl}$. 


\section{Morris Water Maze}

All animals were trained in a standard water maze apparatus. The pool was $1.55 \mathrm{~m}$ in diameter and $0.6 \mathrm{~m}$ in height with a black insert. The platform was $14.5 \mathrm{~cm}$ in diameter and was submerged just below the water level located in the in the same position every day. The pool was filled to water depth of approximately $40 \mathrm{~cm}$. The water temperature was kept constant at $21^{\circ} \mathrm{C}$ throughout the trials. Visual cues (i.e. posters and cardboard shapes) were placed on the walls surrounding the pool and the same audio cue was played continuously during each trial. Both sets of cues remained constant throughout the experiments. As well, the experimenter stood in the same location for each trial to ensure consistency. The pool was located in a $2.5 \times 2.5$ test room illuminated by a single floor light. Movements were tracked using either the Smart Tracking System or HVS Water.

\section{Water Maze Training}

Training Days 1-4. All animals received 4 consecutive days of training (4 trials per day) to find the hidden platform. For each trial, animals started at a different location in the pool and had 60 seconds to reach the platform. If the platform was not located after 60 seconds, animals were guided to the platform location by the experimenter. Animals remained on the platform for 30 seconds. After which animals were towel dried and placed in a recovery cage for 30 seconds. Following the final trial, rats were towel dried and placed in home cage on a heating pad for approximately 15 minutes. Latency to reach the platform served as the operational measure of task performance and was recorded for each trial.

Probe Test Day 5. To determine memory retention for platform location, each rat completed a 60 second free swim with no platform in the pool 24 hours after the final day of 
training. The placement of a circle 3 times ( $8 \%$ of pool area) the diameter of the platform centered on the original platform location was used to infer memory retention of the target. The amount of time spent searching in this region was recorded along with the amount of time spent searching the target quadrant and the number of phantom crossings of the target annulus.

\section{Experiment 1: Pretraining Injections}

Experiment 1 assessed the effects of different doses of kainate injected into the CA3 on the acquisition of spatial memory prior to water maze training. Twenty-eight rats were trained for four consecutive days with 4 trials per day on the water maze acquisition task. The starting locations for each trial were pre-selected from a set of 4 locations and were different for each trial in one training day. For every trial, rats were placed in the pool facing the pool wall and given 60 seconds to swim to the hidden platform located in the same position each time. Rats remained on the platform for 30 seconds before they were dried off and placed in a recovery cage for another 30 seconds. Rats that could not locate the platform in 60 seconds were guided to the platform's location by the experimenter where they remained on the platform for another 30 seconds. Following this, rats were removed from the pool, dried off and placed in a recovery cage for 30 seconds. Prior to water maze training, each rat was given a daily bilateral injection of $0,25,50$ or $100 \mathrm{nM}$ kainate. Injections were delivered approximately 5 minutes prior to the first trial. On the fifth day, rats completed a 60 second drug-free probe test with no platform. Each rat was randomly assigned a start location from a set of four locations in the pool. (See Figure 1A). 


\section{Experiment 2: Pretesting Injections}

Experiment 2 was designed to evaluate the effects of pretesting kainate injections into the $\mathrm{CA} 3$ on the recall of spatial memory in a water maze task. Thirty-six rats underwent four days of drug-free acquisition training run as described in experiment 1 . On the fifth day, each rat received a bilateral injection of $0,25,50$ or $100 \mathrm{nM}$ kainate and then tested in a 60 second probe test. The injections were given approximately 5 minutes prior to completing the free swim (See Figure 1B). A no surgery-no injection control group $(n=7)$ was also run following the same procedures outlined above.

\section{Experiment 3: Post-training Injections}

Experiment 3 examined the effects of post-training injections on the acquisition of spatial memory in a water maze task. Sixteen rats were trained to locate a hidden platform in a water maze for four days run as described in experiment 1. Immediately following the fourth trial of each training day, rats received a daily injection of 0 or $100 \mathrm{nM}$ kainate. After each injection, rats were returned to their home cage. On the fifth day, each rat completed a 60 seconds drug-free probe test with no platform. (See Figure 1C).

\section{Experiment 4: Activation in the CA3}

Experiment 4 evaluated the intensity of $\mathrm{CA} 3$ activation following bilateral and unilateral injections of saline and $100 \mathrm{nM}$ kainate. Rats received a single bilateral injection of saline or 100 $\mathrm{nM}$ kainate ( $n=3$ / group) or a single unilateral injection of $100 \mathrm{nM}$ kainate into the right hemisphere (saline injected into the left hemisphere; $n=2$ ). All rats were sacrificed 15 minutes after each injection. 


\section{Histology}

Following transcardial perfusion with $4 \%$ paraformaldehyde (PFA), rat brains were removed and postfixed overnight in 4\% PFA. Brains were then cryoprotected in $30 \%$ sucrose in $0.1 \mathrm{M}$ phosphate buffer solution and stored at $4^{\circ} \mathrm{C}$ until sectioning. To verify cannula placements, brains were cut into $30 \mu \mathrm{m}$ coronal sections using a Leica CM1900 cryostat. Sections were then mounted onto slides and stained with cresyl violet.

Cresyl violet staining. Each slide with mounted sections was submerged in the following series of solutions for 2 minutes each: $100 \%, 95 \%$ and $70 \%$ ethanol. Sections were then rinsed in distilled water to remove the excess ethanol and placed in $1 \%$ cresyl violet solution in distilled water for 3 minutes. Sections were rinsed in distilled water to remove excess stain and immersed in a $.8 \%$ acetic acid solution in distilled water until fibre tracks became unstained (about 3-5 minutes). They were then placed in $70 \%, 95 \%$ and $100 \%$ ethanol for 2 minutes each. Following staining, sections were placed in clearene solution for a minimum of 15 before they were coverslipped with the mounting medium clarion. Slides were examined for using a light microscope. See Figure 2 for representative photomicrographs (4 X) of intra-CA3 cannula placement.

Cell death analysis. The CA3 hippocampal region of rats that received four bilateral injections of saline or $100 \mathrm{nM}$ kainate ( $n=4$ / group) was examined for cell death using an Olympus BX-UCB microscope. Photomicrographs $(40 \mathrm{X})$ of the CA3 for each rat were taken and the number of cell bodies located in this region were counted. See Figure 20 for representative photomicrographs of the $\mathrm{CA} 3$ region of the hippocampus. 


\section{Immunofluorescence for p-ERK}

Brains from rats that received a single bilateral injection of saline or $100 \mathrm{nM}$ kainate or a single unilateral injection of $100 \mathrm{nM}$ kainate (right hemisphere) were sectioned at $40 \mu \mathrm{m}$. Sections were taken from $\mathrm{CA} 3$ region of the hippocampus and stored in a $0.1 \%$ sodium azide solution in $0.1 \mathrm{M}$ phosphate buffered saline (PBS) at $4^{\circ} \mathrm{C}$. All staining procedures were conducted at room temperature. Sections were washed for in $0.1 \mathrm{M}$ PBS-Trition X, pH 7.4, for 15 minutes. This was followed by a blocking step to prevent non-specific binding of the primary antibody. Sections were preincubated with blocking solution (animal-free blocker (AFB) in 0.1 M PBS-Triton X) for 60 minutes. Staining was performed with rabbit polyclonal antibodies that detected the phosphorylated form of extracellular signal regulated kinase (p-ERK). The sections were then incubated in primary antibodies (p-ERK 1:5000) overnight in $0.1 \mathrm{M}$ PBS-Triton X. The next day, sections were washed for 15 minutes with 0.1 PBS-Triton $X$ and then incubated for 2 hours with a biotinylated anti-rabbit secondary antibody (1:500). Sections were rinsed for 15 minutes in $0.01 \mathrm{M}$ PBS and then mounted on glass slides and coverslipped using DAPI hardset mounting medium. Slides were examined under an Olympus BX-UCB microscope. See Figure 22 for representative photomicrographs $(10 \mathrm{X})$ of p-ERK labeling in the CA3.

\section{Data Analysis}

Acquisition data were analyzed using a two-way (kainate dose by daily latencies) mixed design ANOVA. Probe test data was examined with three separate one-way ANOVAs (for phantom crossings and for time spent searching in target quadrant and in the target annulus). In all statistical tests, a $p$-value of 0.05 or less was considered significant. 


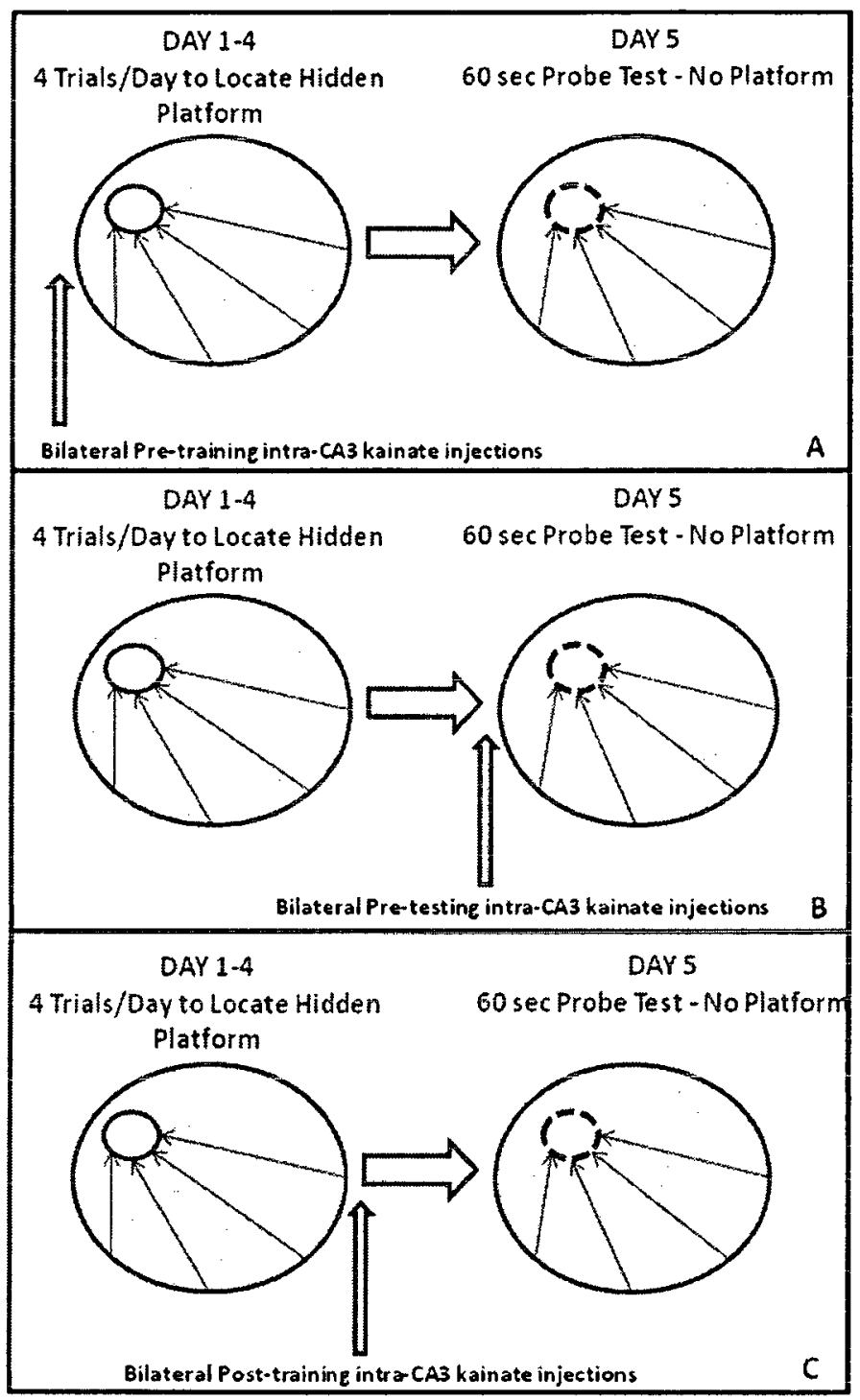


Figure 1. Experimental procedures for experiments 1-3. Four consecutive days of Morris water maze training followed by a 60 second probe test on the fifth day. (A) Experiment 1 - Daily pretraining bilateral intra-CA3 kainate injections of $0,25,50$ or $100 \mathrm{nM}$ on days $1-4$ prior to water maze training. No injection given prior to probe test $(n=7)$. (B) Experiment $2-$ No injections given during training days 1-4. A single pretesting bilateral intra-CA3 kainate injection of $0,25,50$ or $100 \mathrm{nM}$ given prior to probe test $(n=7)$. (C) Experiment 3 - Daily posttraining intra-CA3 kainate injections of 0 or $100 \mathrm{nM}$ given following water maze training. No injections given following probe test $(n=6)$. 


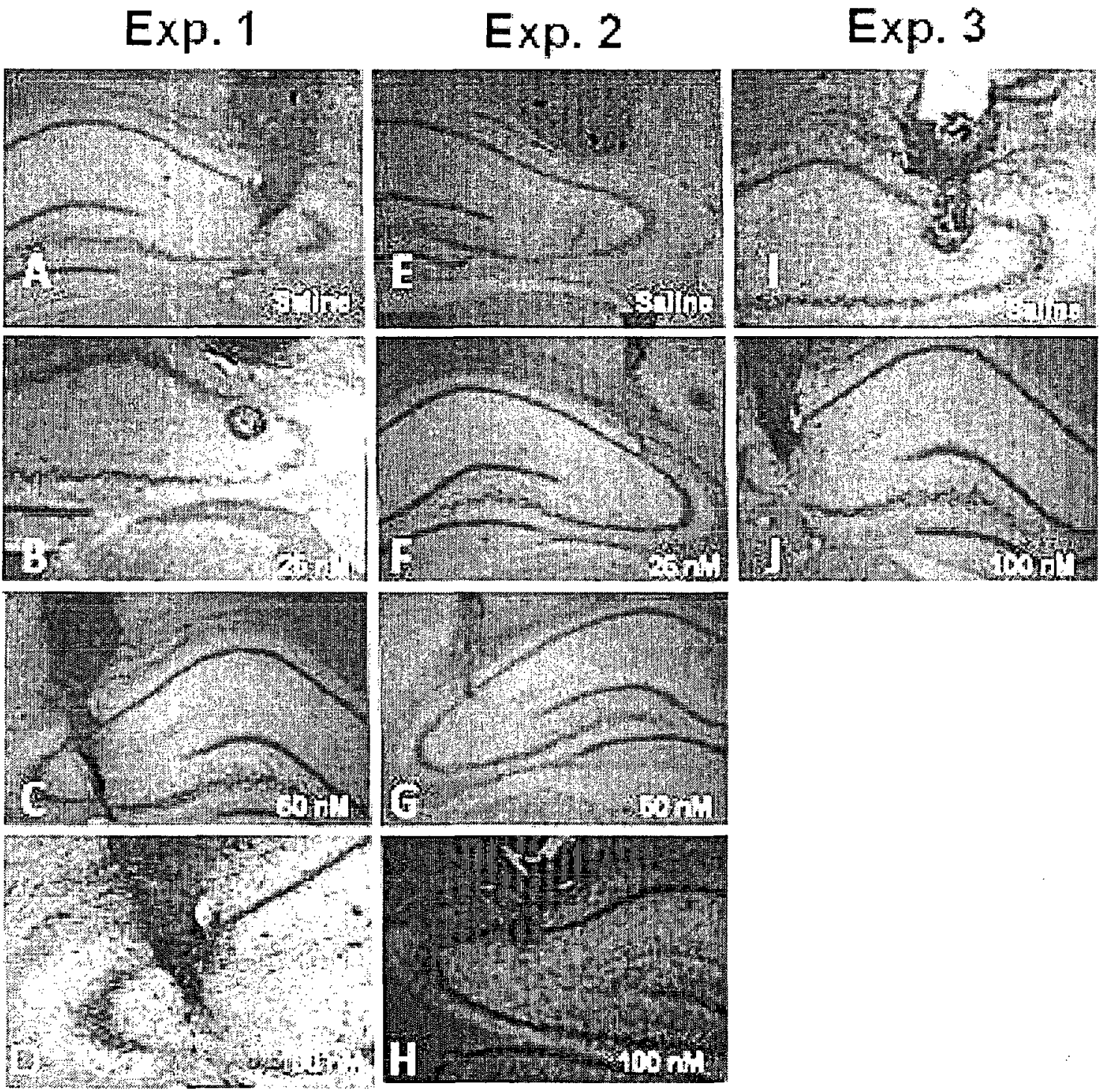


Figure 2 A-J. Photomicrographs showing cannulae placements into the CA3. A-D Representative sections of rats injected with saline (A) or 25 (B), 50 (C) or 100 nM kainate (D) prior to training trials (Experiment 1). E-H Representative sections of rats injected with saline (E) or $25(\mathrm{~F}), 50(\mathrm{G})$ or $100 \mathrm{nM}$ kainate $(\mathrm{H})$ prior to probe test (Experiment 2). I-J Representive sections of rats injected with saline (I) or $100 \mathrm{nM}$ kainate (J) following training trials (Experiment 3). 


\section{Results}

\section{Experiment 1}

A main goal of Experiment 1 was to evaluate whether pre-training intra-CA3 injections of kainate influenced the acquisition ability to locate a hidden platform in the Morris water maze task. Rats received daily bilateral injections of $0,25,50$ or $100 \mathrm{nM}$ kainate prior to each training session on the Morris water maze task for four consecutive days ( $n=7 /$ dose). Latency to locate the hidden platform was used as the operational measure of task performance. It was hypothesized that animals would show dose-dependent improvement in their ability to locate the hidden platform.

A two-way (group $x$ day) ANOVA was conducted to evaluate the effect of kainate injections on the average latency to locate the hidden platform for each training day (Figure 3). No interaction was found between kainate dose and average escape latency per training day; $F(9,72)=.82, \mathrm{p}=.60$. Similarly, there was no main effect of dose; $F(3,24)=.78, \mathrm{p}=.51$. An effect of training session was found; $F(3,72)=60.16, \mathrm{p}<.001$. A downward linear relationship on escape latencies was found across training days; $F(1,24)=179.34, \mathrm{p}<.001$. Follow-up tests were conducted to evaluate pairwise differences among the means. Tukey's HSD post hoc comparisons identified significant differences in the means between each training session, $\mathrm{p}<$ .01 , indicating that the time required to locate the hidden platform decreased as training increased regardless of drug condition (see Figure 3). 


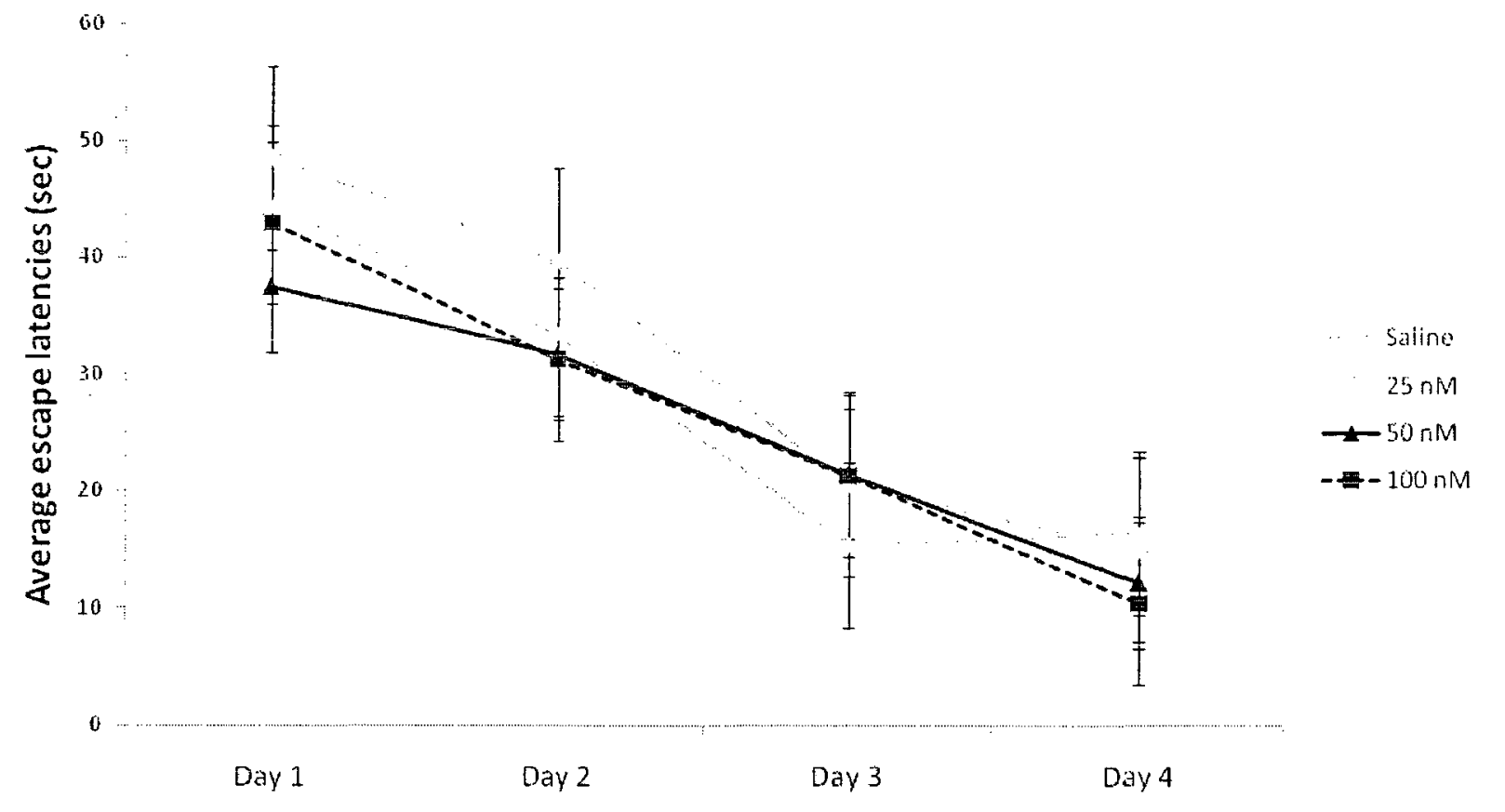


Figure 3. Average latency (seconds) to locate hidden platform for each training session following intra-CA3 kainate injections of $0,25,50$ or $100 \mathrm{nM}(n=7)$. No differences were observed between groups, $\mathrm{p}>.05$. 
Each training day was then analyzed as a trial-by-trial fashion for each day and a twoway (group $\mathrm{x}$ trial) ANOVA was conducted to determine the effect of kainate injections on the escape latencies for the 16 training trials (Figure 4). There was no interaction between group and trial; $F(45,360)=.71, p=.92$ and no main effect of dose; $F(3,24)=.78, p=.51$. There was a main effect of trial; $F(15,360)=19.07, \mathrm{p}<.001$. Escape latencies for all rats, regardless of dose, followed a downward linear trend over time; $F(1,24)=236.61, \mathrm{p}<.001$, indicating that performance on the Morris water maze task was positively related to the amount training received but not dependent on the dose of kainte (see Figure 4).

Upon visual inspection of the training trials (Figure 4), it appeared that rats injected with $100 \mathrm{nM}$ kainate recalled the location of the hidden platform more readily than all other doses on trial 1 of day 4 (as indicated by the lower escape latencies). A one-way ANOVA was run to determine whether $100 \mathrm{nM}$ kaiante-injected rats demonstrated superior performance on the first trial of the fourth training day. No differences in escape latencies were found between groups; $F(3,24)=.59, \mathrm{p}=.63$, suggesting that either 1$)$ the highest dose of kainate $(100 \mathrm{nM})$ did not significantly improve recall of the location of the hidden platform or 2) the variability in these data from the 25 and $50 \mathrm{nM}$ groups may have masked group differences between the saline and the $100 \mathrm{nM}$ group. 


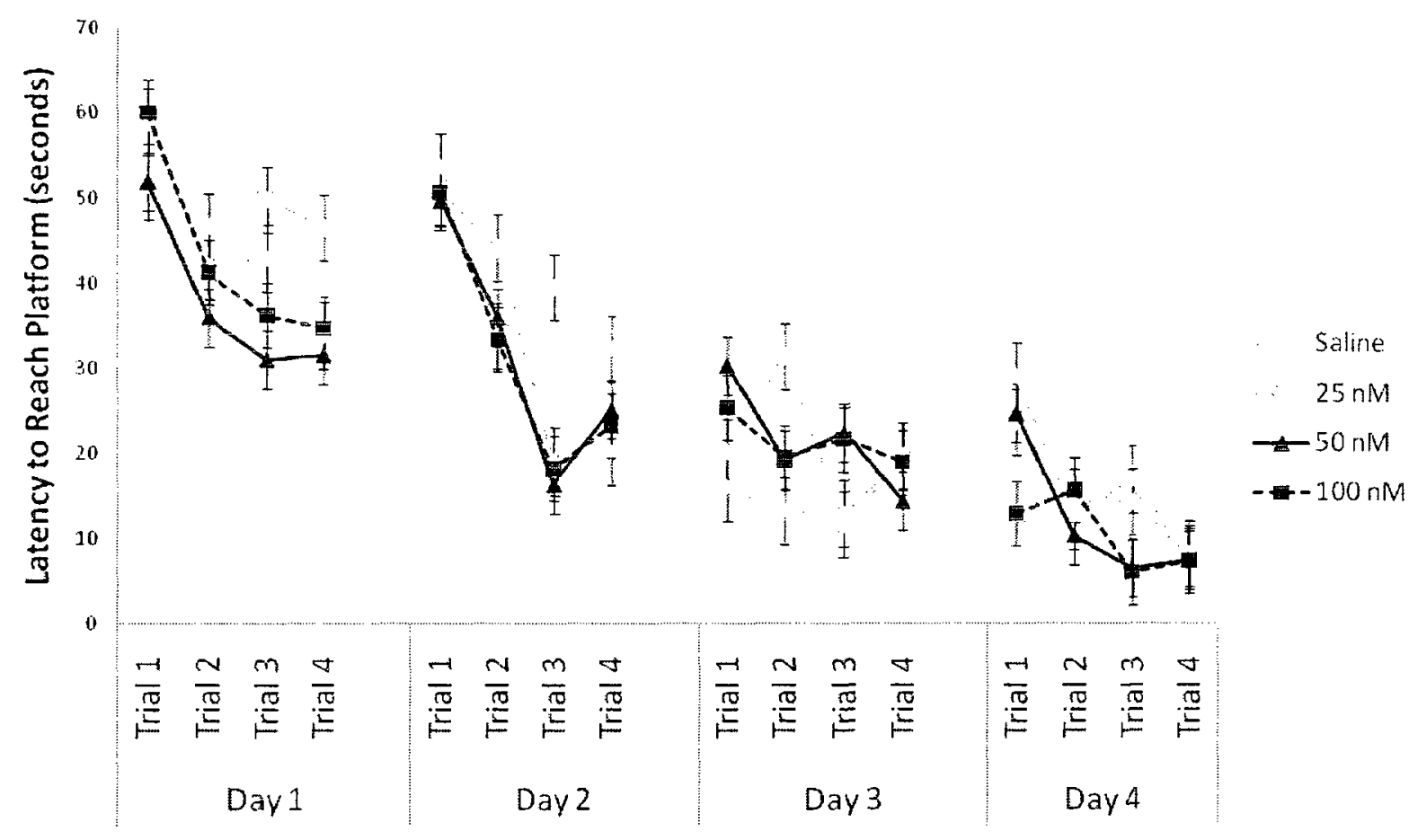


Figure 4. Latencies (seconds) to locate hidden platform over 4 days following intra-CA3 kainate injections of $0,25,50$ or $100 \mathrm{nM}(n=7)$. No differences were observed between groups, $\mathrm{p}>$ .05 . 
To reduce the variability in these data, a two-way dose by trial ANOVA was run with only the saline and $100 \mathrm{nM}$ animals. No interaction between dose and trial was found; $F(15,180)$ $=.68, \mathrm{p}=.80$, and there was no main effect of dose $F(1,12)=.07, \mathrm{p}=.80$. There was a main effect of trial; $F(15,180)=12.49, \mathrm{p}<.001$, which followed a downward linear trend. A one-way ANOVA of the escape latencies on the first trial of day 4 revealed no differences between saline and $100 \mathrm{nM}$ kainate-injected rats; $F(1,12)=1.64, \mathrm{p}=.22$. The results imply that perhaps the statistical analyses conducted were not sensitive enough to pick up the noticeable visual differences between these two groups. 


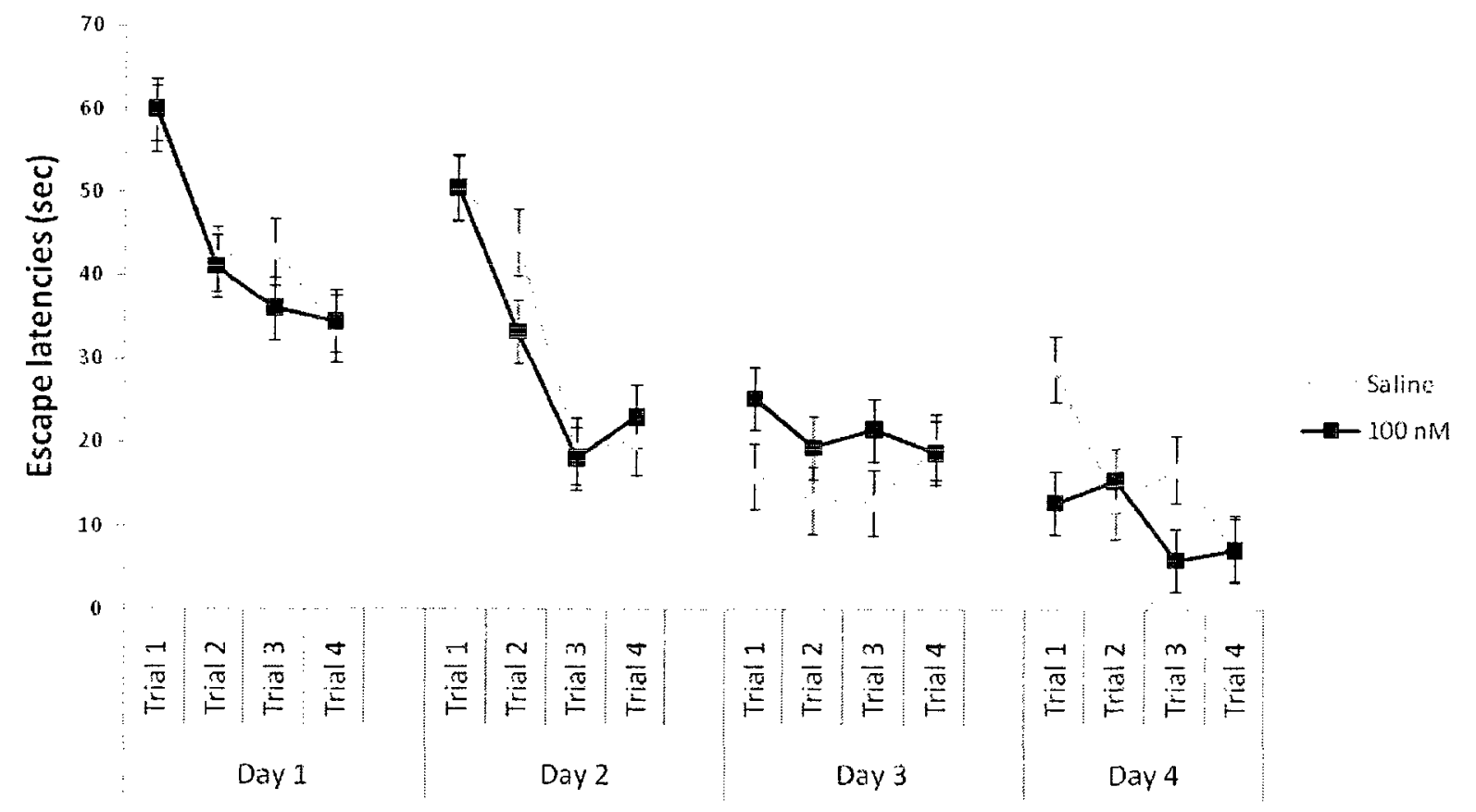


Figure 5. Escape latencies on the Morris water maze task following daily pre-training injections of saline and $100 \mathrm{nM}$ kainate. Although it appears $100 \mathrm{nM}$ injected rats recall the location of the hidden platform more readily on trial 1 of day 4, no differences were found between the two doses, $\mathrm{p}>.05$. 
An alternative way of looking at these data was to compare the last trial of one day to the first trial of the following day to evaluate whether the injections were enhancing performance on the first trial. This would allow an examination of how different doses of kainate influenced the recall of the platform's location 24 hour after the last trial across the four training days. To calculate the 24 hour recall effect, the last trial of the first day was subtracted from the first trial of the second day. This was repeated for days 2 and 3 and for days 3 and 4 . Negative difference scores indicated enhanced performance on trial 1 as compared to trial 4 from the previous day. Positive scores indicated poorer recall of the platform's location 24 hours after the last trial.

Upon visual inspection of Figure 6, escape latencies on the first trial compared to the last trial of the previous day followed a downward linear trend in only the $100 \mathrm{nM}$ condition suggesting these rats may have consolidated the platform location more efficiently. A two-way (group by 24 memory recall) ANOVA was conducted to evaluate whether the differences in escape latencies over a 24 hour period at three separate time points was differentially effected by pre-training kainate injections. No interaction between the 24 hour recall of platform location and group was found; $F(6,48)=.25, \mathrm{p}=.96$, and there was no main effect of group or time across the four training sessions; $F(3,24)=1.00, \mathrm{p}=.41 ; F(2,48)=2.12 ; \mathrm{p}=.13$, respectively. Although it is possible that injections of $100 \mathrm{nM}$ kainate into the CA3 had no effect on the recall of a spatial location 24 hours later, it is more likely that the subtle differences between saline and $100 \mathrm{nM}$ kainate-injected rats were lost amongst the variability in these data from the 25 and 50 nM groups. 


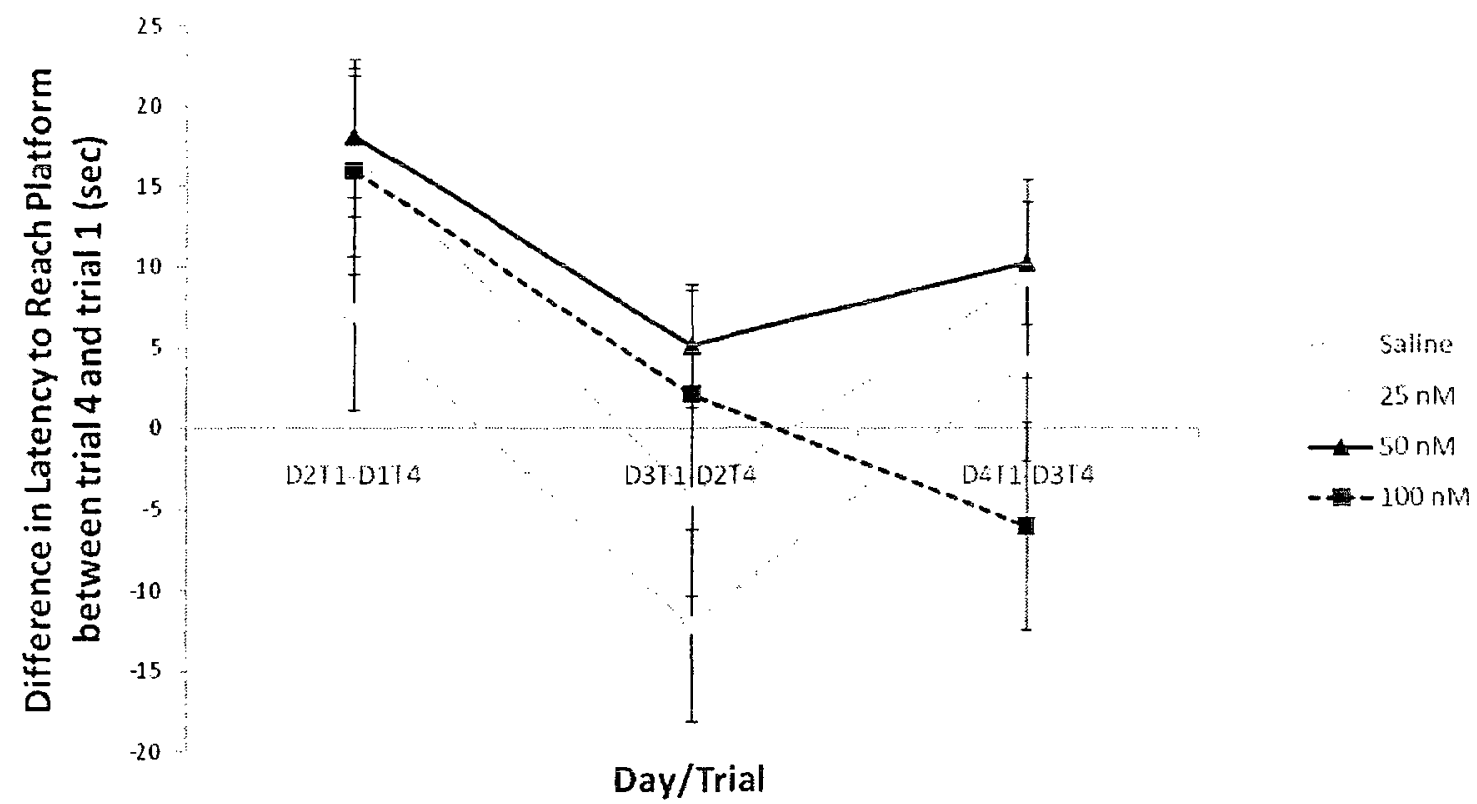


Figure 6. The difference in escape latency between last trial of one day and the first trial of the next training session 24 hours later following pre-training injections of saline or kainate $(25,50$ or $100 \mathrm{nM}$ ). No differences were found between groups or in 24 hour memory recall across the 4 training sessions, $\mathrm{p}>.05$. 
To evaluate whether the non-significant results from the above analysis could be attributed to 'noise' from 25 and $50 \mathrm{nM}$ kainate-injected rats, these groups were eliminated and a a two-way (group $\mathrm{x}$ time) ANOVA was run with only the saline and $100 \mathrm{nM}$ injected animals (see Figure 7). There was no interaction between group and time; $F(2,24)=.51, \mathrm{p}=.60$, and there were no main effects of group or of time; $F(1,12)=1.23, \mathrm{p}=.23 ; F(2,24)=1.50, \mathrm{p}=.24$, respectively. These results illustrate that although rats injected with $100 \mathrm{nM}$ kainate appeared to recall the location of the hidden platform more readily over the 4 training sessions (as evident from Figure 7), their overall performance did not differ significantly from saline-injected rats. It is possible that there is too much individual variability within these two groups to detect any differences between the doses. 


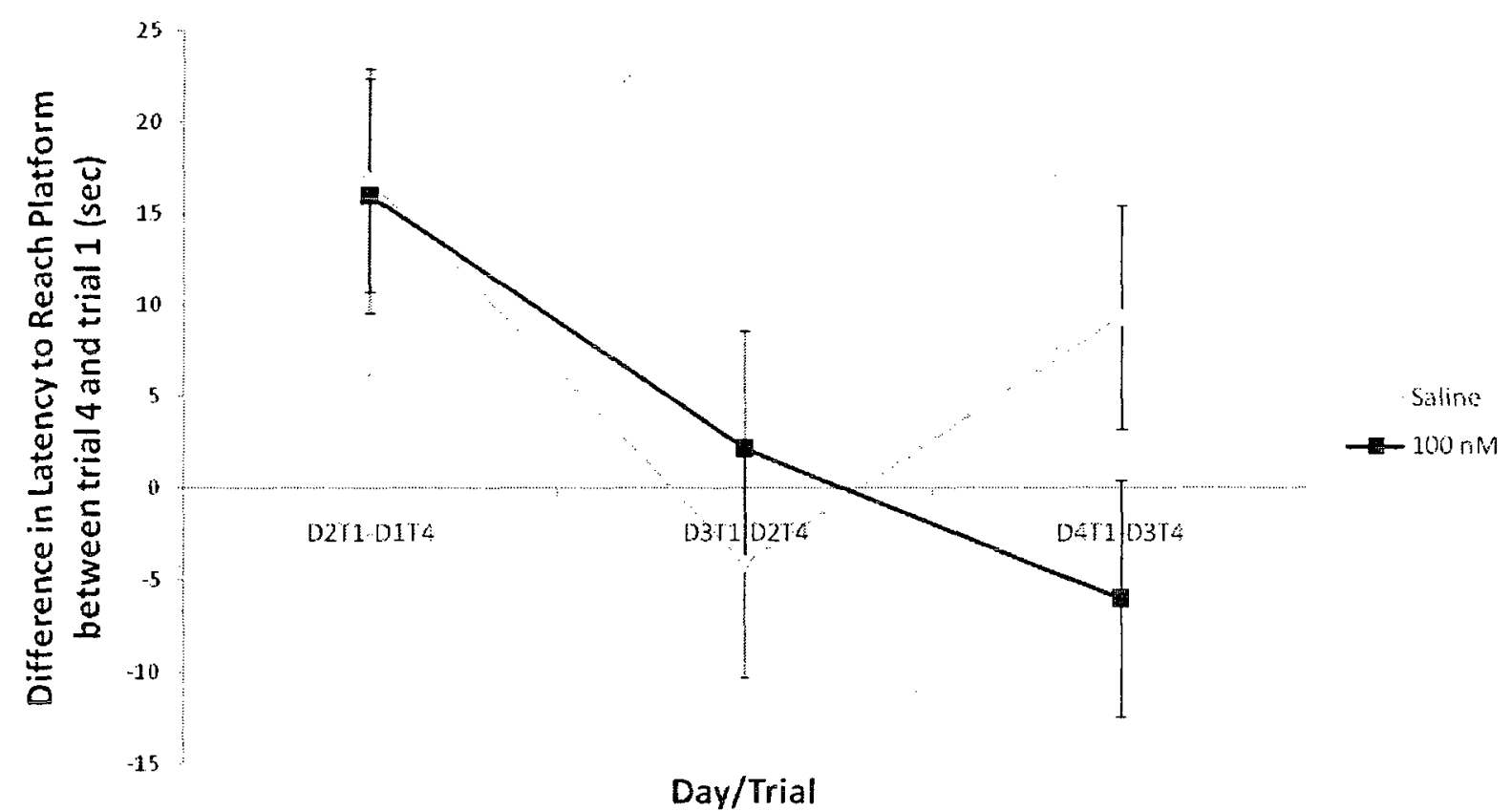


Figure 7. The difference in escape latency between last trial of one day and the first trial of the next training session 24 hours later following pre-training injections of saline or $100 \mathrm{nM}$ kainate. No differences were found between groups or in 24 hour memory recall across the 4 training sessions, $\mathrm{p}>.05$. 
Twenty-four hours after the last training session, a 60 second probe test (where the platform was removed from the pool) was conducted. All rats completed this test drug-free. Memory retention of the platform's location was inferred from the amount of time each rat spent searching within an area three times the diameter of the platform centered on the location of the platform during training (i.e., the target annulus). Given the diameter of the pool and of the target annulus, it is expected that each rat would spend $8 \%$ of the probe test searching within this region due to chance alone. The amount of time spent searching within the target annulus represents a good measure of memory retention. More searching in this region is thought to reflect better recall of the platform's location - in a positive, linear way.

All rats spent more time searching in the target annulus than what was expected from random chance $(8 \%)$. Each group spent $15-20 \%$ of the probe test searching in this region, suggesting that the memory for the former location of the platform, regardless of group, was quite strong in all groups (see Figure 8). No significant differences were found between the different doses of kainate, $F(3,24)=1.43, \mathrm{p}=.30$. 


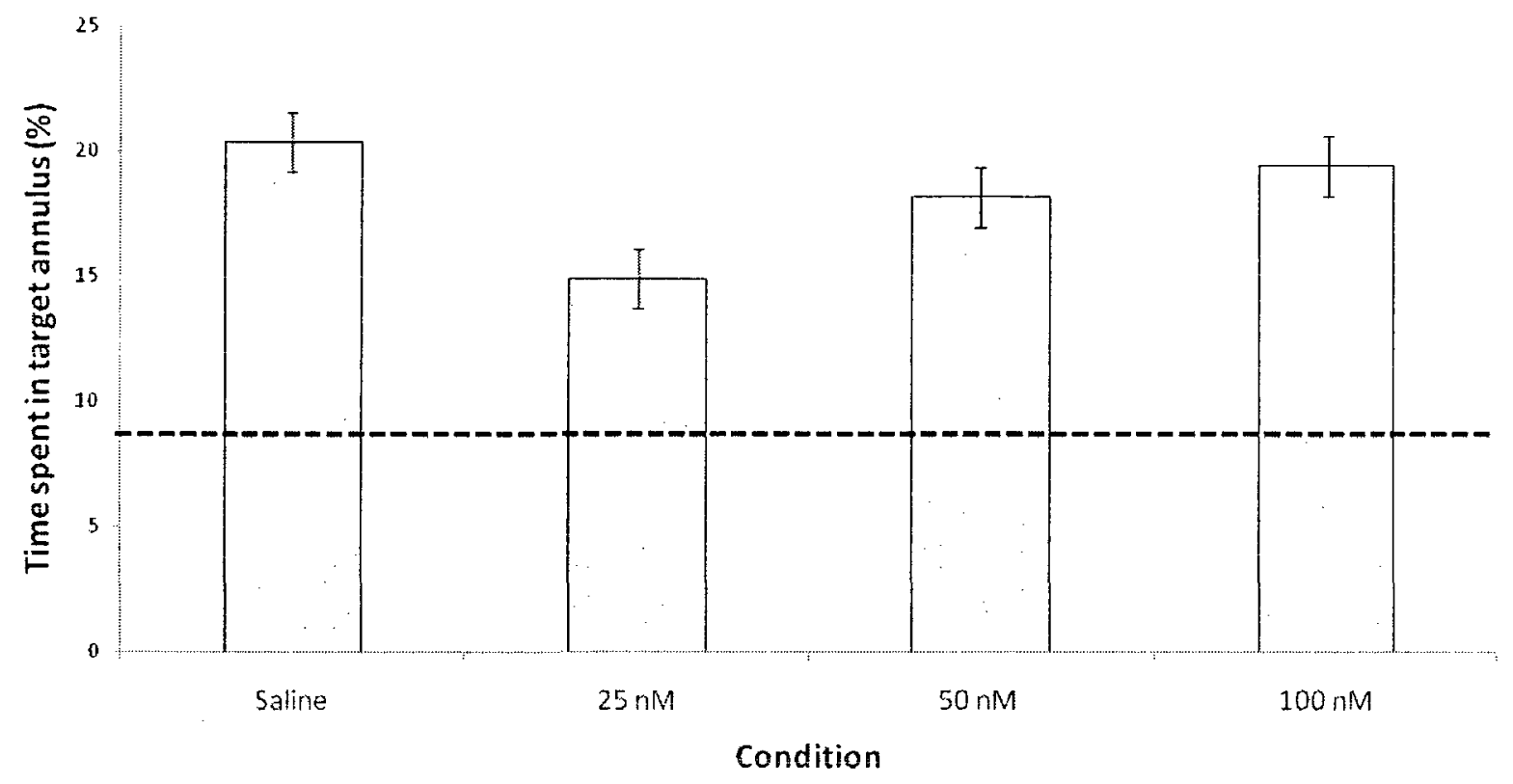


Figure 8. Time spent searching within the target annulus during drug-free probe test. The black line indicates the amount of time spent near the platform location expected due to chance alone. All rats show increased searching behaviour relative to random chance. No differences were found between doses of kainic acid, $\mathrm{p}>.05$. 


\section{Summary of Experiment 1}

No significant group differences were observed after pre-training intra-CA3 injections of kainate during acquisition or during the probe retention test, suggesting that the agonism of KARs in the CA3 may not play an integral role in the acquisition of spatial memories in rats. It was evident that the highest dose kainate $(100 \mathrm{nM})$, when administered prior to each training session, enhanced performance on the first trial of day 4 in the Morris water maze task when compared to all other doses; although these differences were not significant (Figure $4 \& 5$ ). It is possible that the large variability within each group contributed to these non-significant results. An alternate explanation may be that the activation of KARs in the CA3 by injections of kainate may have a more important role at other stages of memory formation, like memory retrieval or during the posttraining period.

\section{Experiment 2}

Experiment 2 examined whether a single injection of kainate administered just before the probe test would alter a rat's ability to retrieve the former location of the platform when all prior training on the task occurred in a drug-free environment. It was hypothesized that injections of kainate would show a dose-dependent enhancement of spatial memory retrieval during the probe test. First, a two-way (group $\mathrm{x}$ trial) ANOVA was conducted to confirm that there were no differences in escape latencies during the sixteen drug-free training trials between the groups of rats assigned to receive the different doses of kainate prior to the probe test. As expected, there was no interaction between group and trial; $F(45,480)=1.03, \mathrm{p}=.42$, and no significant differences in escape latencies were found between groups on any of the training trials across the four days; $F(3,32)=.24, \mathrm{p}=.87$ (see Figure 9). Therefore, any differences observed between 
groups during the probe test could be attributed to the kainate injections rather than pre-existing differences in the learning the location of the hidden platform during training. 


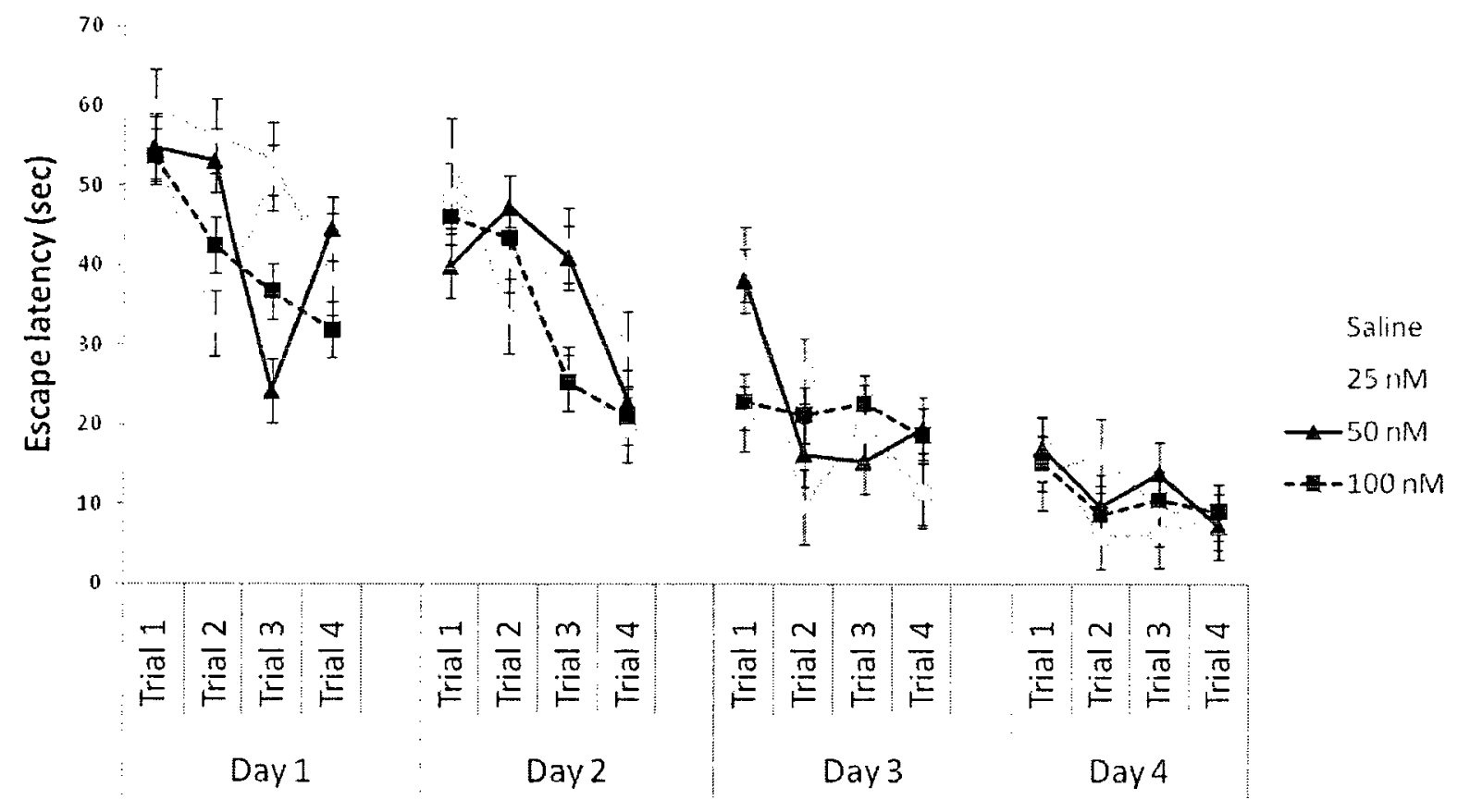


Figure 9. Latencies (seconds) to locate hidden platform over 4 days of drug-free training $(N=$ 33). Rats were split-up into groups according to what dose of kainate they would be injected with prior to the probe test on the fifth day. No significant differences were found between groups, $\mathrm{p}>.05$. 
A 60 second probe test was administered 24 hours after the last training session. Rats received a bilateral intra-CA3 injection of $0,25,50$ or $100 \mathrm{nM}$ kainate ten minutes before the start of the test $(n=9 /$ dose). The amount of time spent searching in the target annulus (an area three times the diameter of the platform) served as one measure of memory retention for the platform's location. Given that a rat has a strong desire to escape from the pool (i.e., find the hidden platform), it follows that during the probe test, when the platform was removed, the rat will have a tendency to swim in the area where it remembers the platform was located. By measuring the number of times a rat passed through the target annulus and the amount of time it searched for the platform in this region, retention of the platform's location can be quantified. It was expected that rats would spend $8 \%$ of the probe test searching in the target annulus due to random chance. Rats searching in this region at levels greater than chance were thought to have better recall of the platform's location.

Upon visual inspection of the raw scores for amount of time spent searching in the target annulus for each rat, three outliers were found. Analysis of standardized z-scores for each raw score identified three outliers two or more standard deviations from the mean - one each in the 0 , 25 and $50 \mathrm{nM}$ groups, $\mathrm{z}=+2.38,+3.35,+1.92$, respectively. These three outliers were removed from all subsequent analyses.

A one-way ANOVA was conducted to evaluate the relationship between dose of kainate and the amount of time spent searching in the target annulus during the probe test. Rats injected with 25 and $100 \mathrm{nM}$ kainate responded at around chance levels when searching in the target annulus suggesting pre-testing injections at these doses did not enhance the retrieval of spatial memories. Rats injected with 0 and $50 \mathrm{nM}$ kainate appeared to perform slightly below chance levels suggesting these doses may have impaired the retrieval of spatial information. However, 
no significant differences were observed between conditions; $F(3,29)=2.31, \mathrm{p}=.10$ (see Figure $10)$.

An alternate way to examine retention/recall of the platform's location was to calculate the number of times each rat crossed the exact location of the platform (i.e., phantom crossings). A second one-way ANOVA that investigate d the effect of kainate do se on the number of phantom crossings of the target annulus was conducted. No significant differences were found between the different groups, $F(3,29)=.99, \mathrm{p}=.41$ (see Figure 11), indicating that a single injection (even at the highest dose) did not sufficiently enhance a rat's ability to recall the location of the hidden platform. 


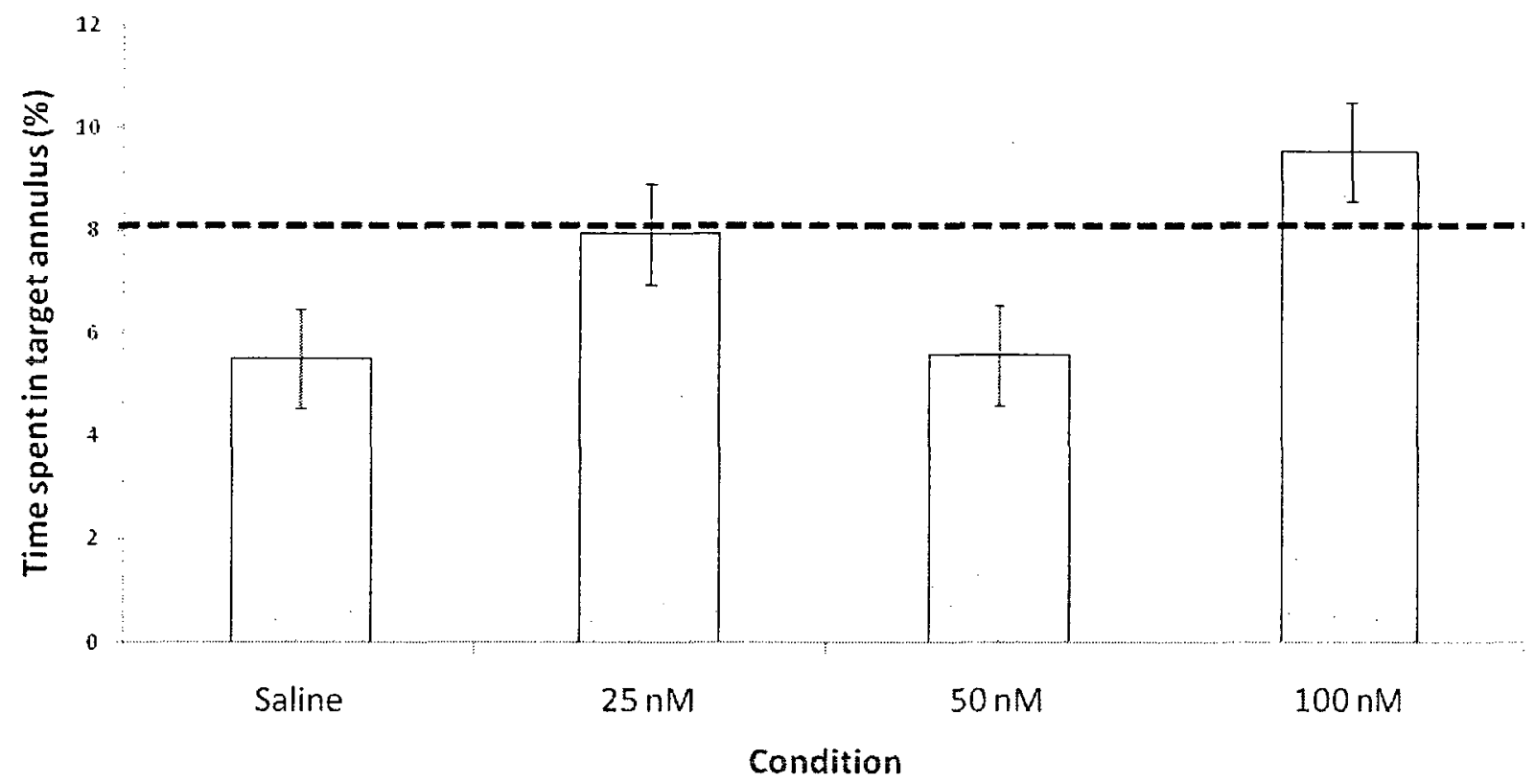


Figure 10. Time spent searching within the target annulus during probe test following intra-CA3 kainate injections of $0(n=8), 25(n=8), 50(n=8)$, or $100 \mathrm{nM}$ kainate $(n=9)$. The black line indicates the amount of time spent near the platform location expected due to chance alone. No significant differences between groups, $\mathrm{p}>.05$. 


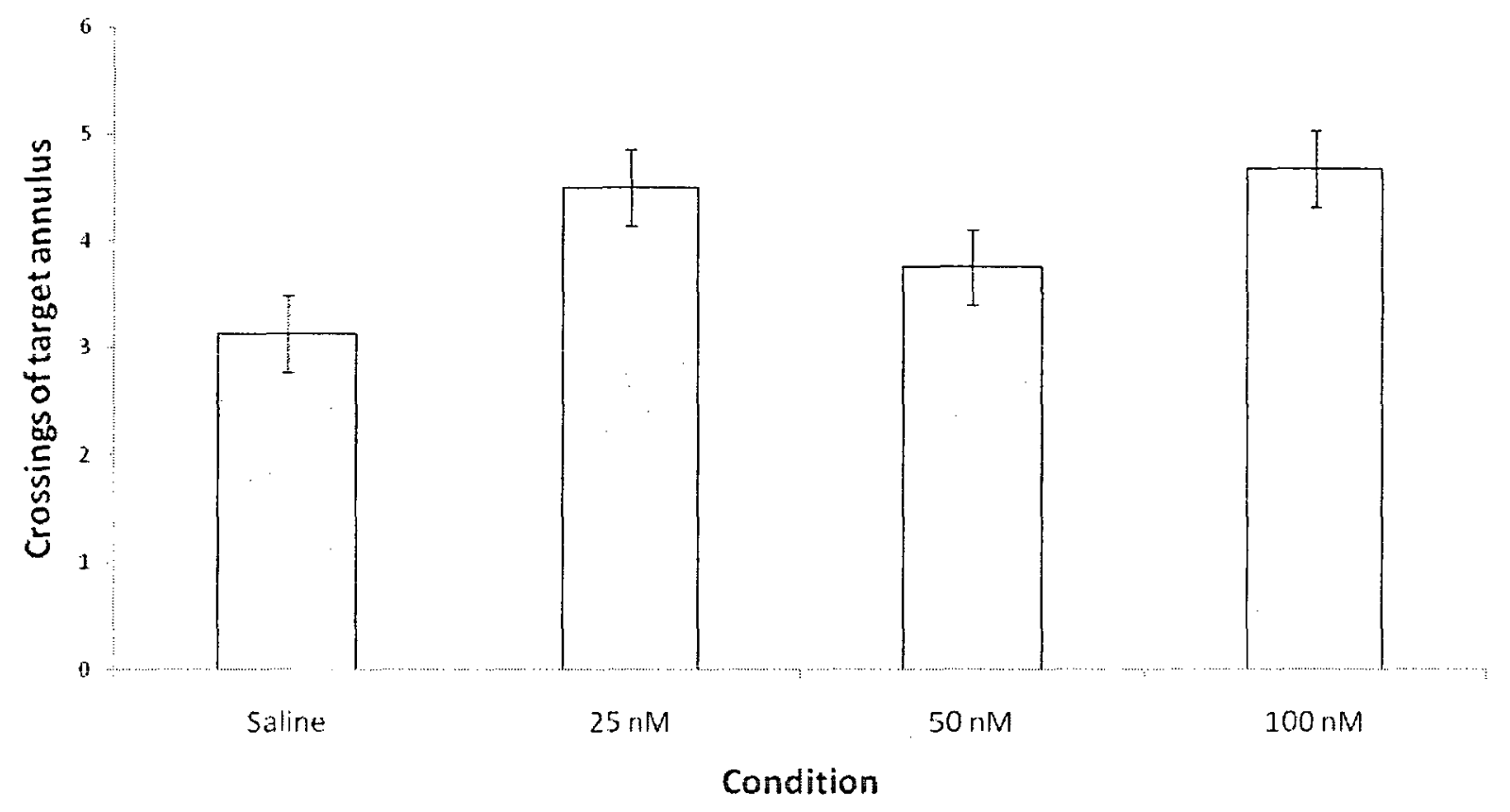


Figure 11. Average number of times rats passed through the target annulus during probe test following intra-CA3 kainate injections of $0(n=8), 25(n=8), 50(n=8)$, or $100 \mathrm{nM}$ kainate. $(n=$ 9). No significant differences between groups, $p>.05$. 
Rats injected with different doses might have different patterns of searching for the platform throughout the probe test. Perhaps rats injected with $100 \mathrm{nM}$ kainate spent more time searching for the platform in the first 30 seconds of test searching whereas saline-injected rats may have only started to search in the target annulus after 20 or 30 seconds of the test had passed. To determine whether groups differed in their search patterns during the probe test, it was divided into four intervals of 15 seconds and the effect of kainate injections on the amount of time spent searching in the target annulus for each interval was evaluated using a two-way mixed-design ANOVA. There was no significant interaction between group and time interval, $F(9,87)=.67, \mathrm{p}=.73 ;$ although there was a tendency for rats injected with 25 and $100 \mathrm{nM}$ kainate to spend less time searching in the target annulus as time passed (see Figure 12). No main effect of group, $F(3,29)=2.31, \mathrm{p}=.10$, or time interval, $F(3,87)=.73, \mathrm{p}=.54$, was found highlighting that the searching strategy was similar across all doses of kainite throughout the probe test. 


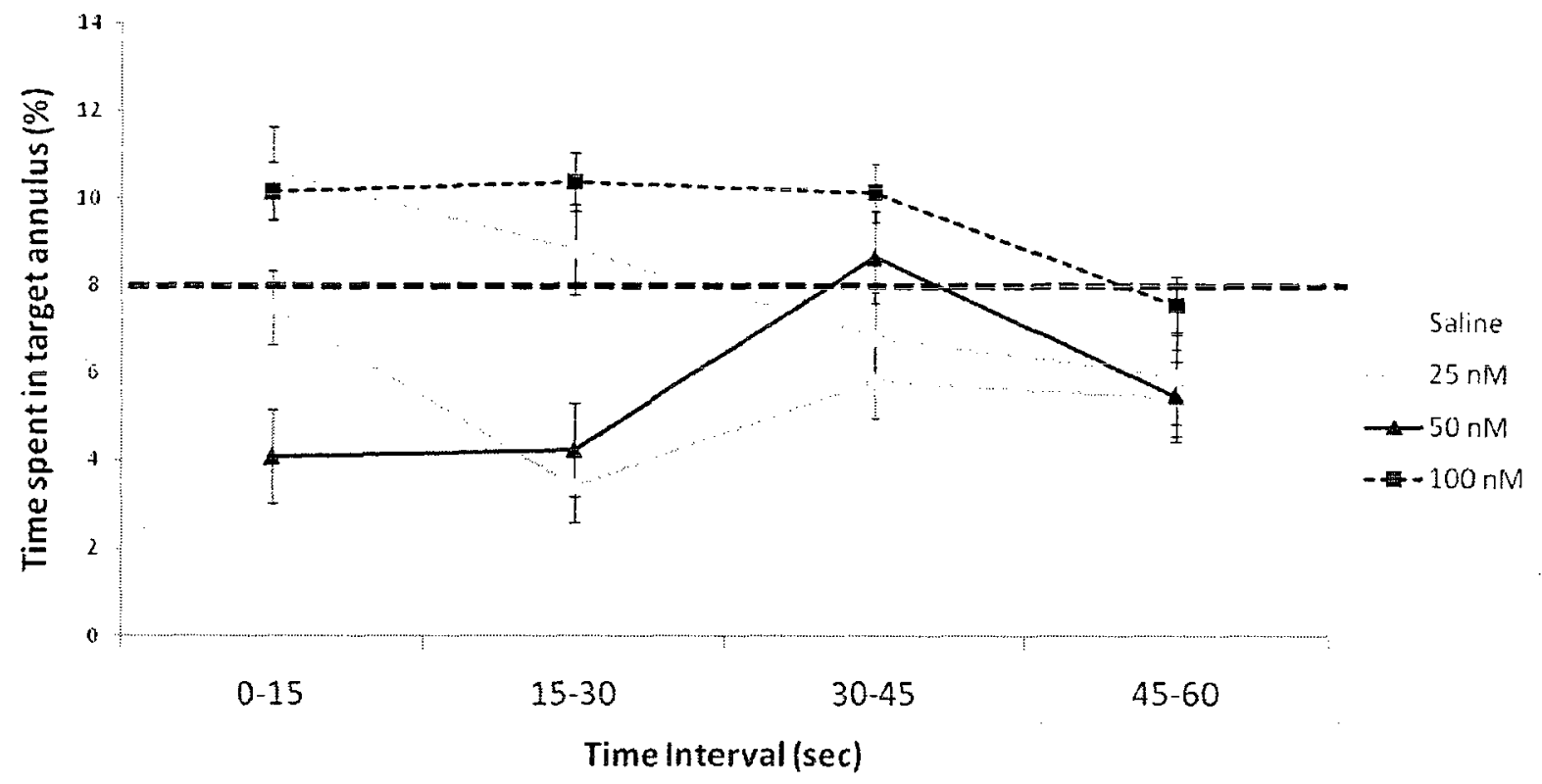


Figure 12. Retention of platform location at 15 second time intervals during probe test following intra-CA3 kainate injections of $0(n=8), 25(n=8), 50(n=8)$ or 100 nM kainate. $(n=9)$. The black line indicates the amount of time spent in target annulus expected by chance alone ( $8 \%$ ). No significant differences between groups or time intervals, $p>.05$. 
A final analysis compared the amount of time rats spent searching in the target annulus to three other annuli of equivalent size located in the pool. One annulus was specifically placed in each quadrant in the pool - target (centered on former platform location), adjacent right, opposite and adjacent left. Given the size of each annulus, rats were expected to spend $8 \%$ of the probe test searching in those locations due to random chance. A greater time spent searching in the target annulus compared to the other three annuli might suggest that the rat recalled the specific location of the platform dedicating a greater proportion of the probe test searching in that particular area.

A two-way ANOVA was conducted to determine the effect of kainate injections on the amount of time searching in the four distinct annuli during the probe test. The interaction between group and annuli location was not significant; $F(9,87)=1.50, \mathrm{p}=.16$, but there was a main effect of annuli location, $F(3,87)=2.69, \mathrm{p}=.05$. Tukey HSD follow-up analyses indicated that rats, irrespective of group, spent more time searching in the target and adjacent left annuli compared to the adjacent right annulus; mean difference $(\mathrm{MD})=1.53, \mathrm{p}<.03 ; \mathrm{MD}=2.16, \mathrm{p}<$ .02 , respectively, and spent a greater percentage of time searching in the adjacent left annulus relative to the opposite annulus, $\mathrm{MD}=1.67, \mathrm{p}<.02$ (see Figure 13 ). Even though rats showed a preference for searching within the target annulus compared to the right adjacent annulus, this does not mean that these animals had better recall for the former location of the platform. The percentage of time that was spent searching within the target annulus was very close to what was expected due to chance, indicating that recall for the platform's previous location was no better than random chance. The idea is further supported given that rats designated statistically equivalent amounts of time searching in the target annulus and the adjacent left annulus (a random location in the pool). 
A main effect of group was also found, $F(3,29)=3.03, \mathrm{p}<.05$. Tukey HSD follow-up analyses indicated that rats injected with 25 and $100 \mathrm{nM}$ kainate had a tendency to search more in all four annuli combined when compared to the saline-injected rats; $\mathrm{MD}=2.45, \mathrm{p}<.04 ; \mathrm{MD}=$ $3.21, \mathrm{p}<.01$, respectively. The 25 and $100 \mathrm{nM}$ kainate-injected rats spent a greater percentage of the probe test swimming within the inner portion of the pool where the four annuli were located, suggesting that kainate-injected and saline-injected rats may have employed different strategies when searching for the platform. These differences may also be explained by variations in swimming speed during the probe test between the groups. Perhaps rats injected with 25 and 100 $\mathrm{nM}$ kainate swam faster during the test as a result of the drug contributing to this increase in searching in the four annuli relative to saline-injected rats. A one-way ANOVA was conducted to determine if there was an effect of kainate dose on swimming speed during the probe test. A non-operated control group $(n=7)$ that was given the same training on the Morris water task as the four experimental groups was included in this analysis to highlight any potential differences in swimming ability as a result of surgery and/or injection procedures. No groups differences were found, $F(4,35)=1.11, \mathrm{p}=.37$ (see Figure 14), 


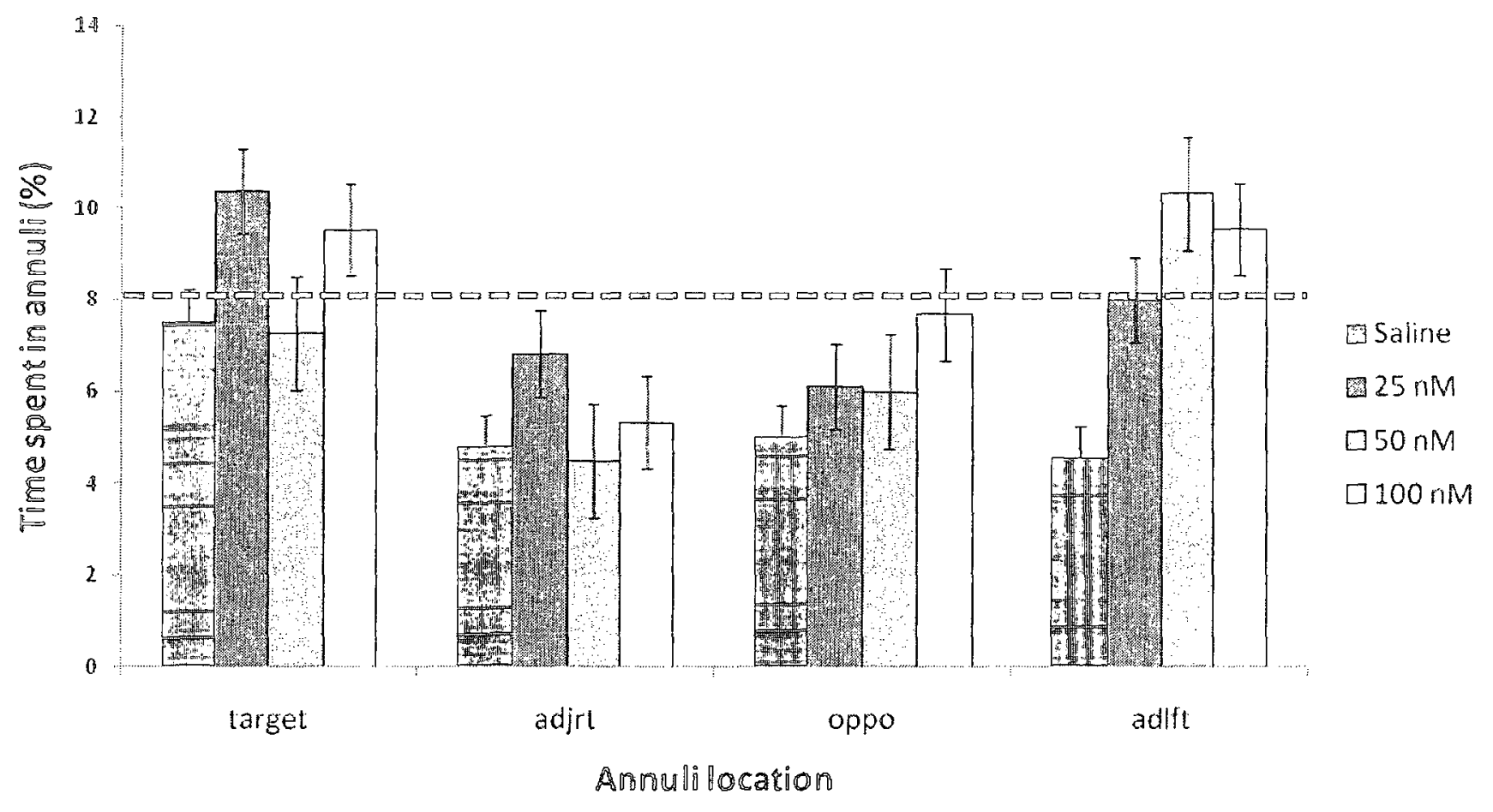


Figure 13. Percent time in annuli located in the four quadrants of the pool during probe test following intra-CA3 kainate injections of $0(n=8), 25(n=8), 50(n=8)$ or 100 nM kainate. $(n=$ 9). The black line indicates the amount of time spent in target annulus expected by chance alone (8\%). A main effect of annulus location was observed. Note: $*=p<.02, * * p<.03$. 


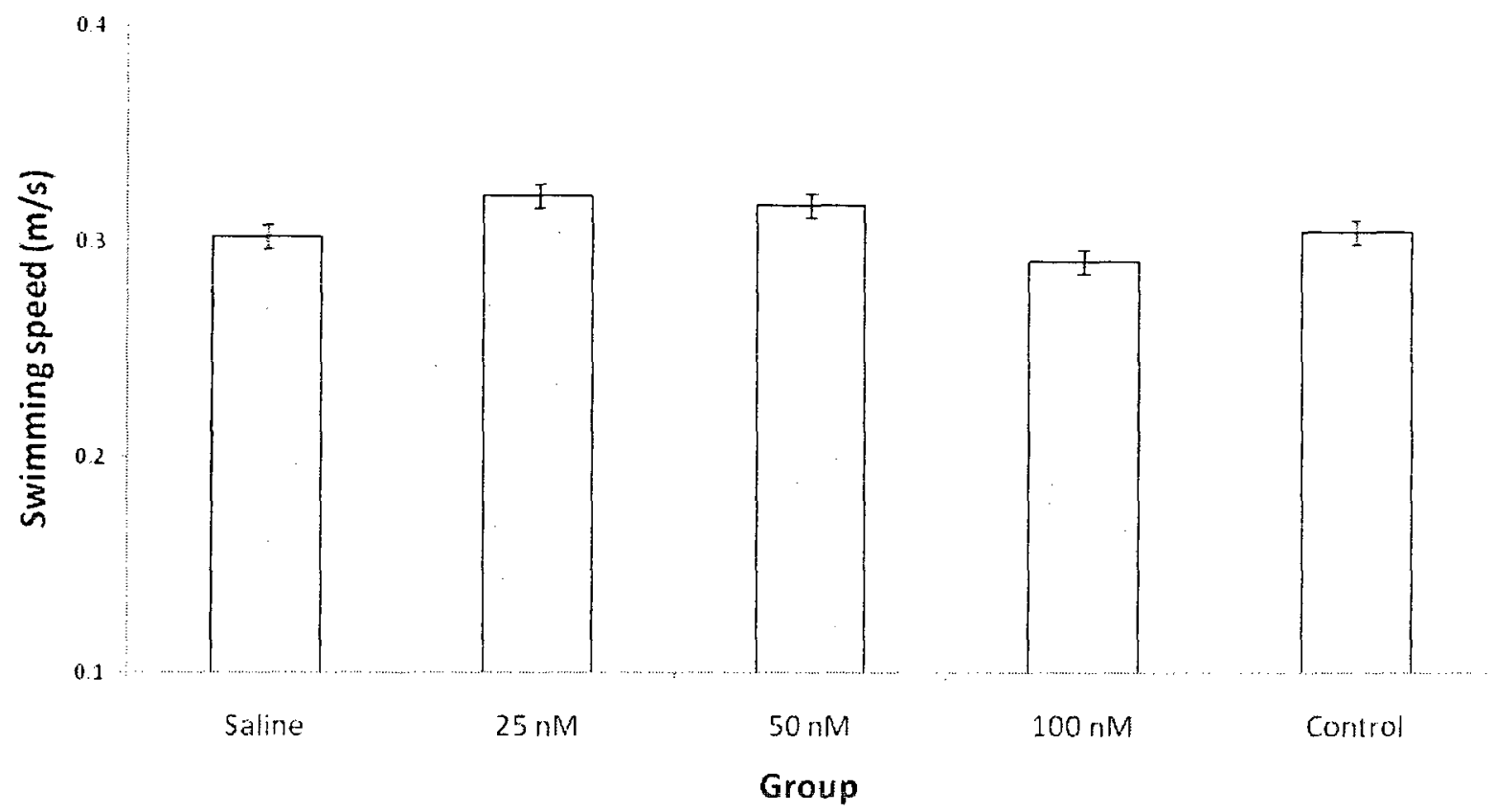


Figure 14. Average swimming speed for each group during the probe test. No differences were found between groups $\mathrm{p}>.05$. 


\section{Summary of Experiment 2}

Overall, pre-testing intra-CA3 injections of kainate, regardless of dose, had very little effect on the ability to recall the location of the hidden platform in the Morris water maze task. No dose-dependent enhancement of memory for the platform's location was observed during the probe test; although there was a tendency for rats injected with 25 and $100 \mathrm{nM}$ kainate to search more in the four annuli (three random, one centered on the platform's location) located in the pool when compared to rats injected with saline. One possible explanation for the observed results may be that a single pre-testing injection of kainate, even at high doses $(100 \mathrm{nM})$, was not effective in enhancing a rat's ability to recall the location of platform during the probe test. Perhaps multiple injections are required before differences become apparent between the groups.

Given that both pre-training (experiment 1) and pre-testing injections (experiment 2) had only minor effects on the acquisition and retrieval of spatial information, it seemed worthwhile to determine whether post-training injections would have an effect on spatial memory processes.

\section{Experiment 3}

The primary objective of experiment 3 was to explore whether post-training injections of $100 \mathrm{nM}$ kainate would enhance a rat's ability to process the location of the hidden platform. Rats received one injection of either saline or $100 \mathrm{nM}$ kainate immediately after each training session for four consecutive days ( $n=8$ / group). Given that the $100 \mathrm{nM}$ dose of kainate appeared to have the most profound effect on the acquisition of spatial information (experiment 1) and the retrieval of spatial memories (experiment 2), it was the only dose of kainate used for experiment 3. It was hypothesized that $100 \mathrm{nM}$ kainate would enhance a post-training consolidation process thereby improving the spatial abilities of these rats compared to saline-injected controls. 
A two-way ANOVA was conducted to determine the effect of post-training injections of saline or $100 \mathrm{nM}$ kainate on escape latencies during water maze training. There was no interaction between group and trial, $F(15,210)=1.62, \mathrm{p}=.07$, and no main effect of group, $F(1,14)=.10, \mathrm{p}=.76$. There was a main effect of trial, $F(15,210)=12.07, \mathrm{p}<.001$. Escape latencies for saline and kainate-injected rats followed a downward linear trend over time; $F(1,14)$ $=150.14, \mathrm{p}<.001$, indicating that performance on the Morris water maze task was positively related to the amount training received (see Figure 15).

Upon visual inspection of the training trials of Day 4 (Figure 15), it appeared that rats injected with $100 \mathrm{nM}$ kainate recalled the location of the hidden platform more readily than saline-injected rats on the first trial (as indicated by the lower escape latencies). A two-way (group by trial) ANOVA was run to determine whether saline and kainate-injected rats differed in their ability to locate the hidden platform across the four training trials on Day 4 . There was a significant interaction between group and training trial, $F(3,42)=5.86, \mathrm{p}<.01$, as well as significant main effects for group, $F(1,14)=6.35, \mathrm{p}<.03$, and for trial, $F(3,42)=7.63, \mathrm{p}<.001$. Four independent-samples $t$ tests were conducted to follow up the significant interaction. The inflation of the familywise error rate was controlled for using the Bonferroni approach - with the new alpha level set at, $\alpha=.01$. Kainate-injected rats showed lower latencies on the first trial of Day 4 as indicated by the significantly reduced escape latencies on Trial $1, t(14)=2.97, \mathrm{p}<.01$, suggesting that these rats had consolidated the platform's location more effectively. By trial 2, the saline-injected rats were able to locate the hidden platform as quickly as the kainate-injected rats, $t(14)=-.43, p=.68$. Interestingly, on trial 3 , differences in mean escape latency were found between the two groups, $t(14)=3.64, \mathrm{p}<.01$, with kainate-injected rats showing slightly lower escape latencies, but by trial 4 these differences were no longer significant, $t(14)=-.53, \mathrm{p}=.60$. 
These results show that although kainate-injected rats were initially better able to locate the hidden platform, saline-injected rats quickly "caught-up" and were able to locate the platform after similar latencies. Overall, injections of kainate led to enhanced consolidation of spatial information contributing to improved performance on the first trial of Day 4- an effect that lessened with more training trials. 


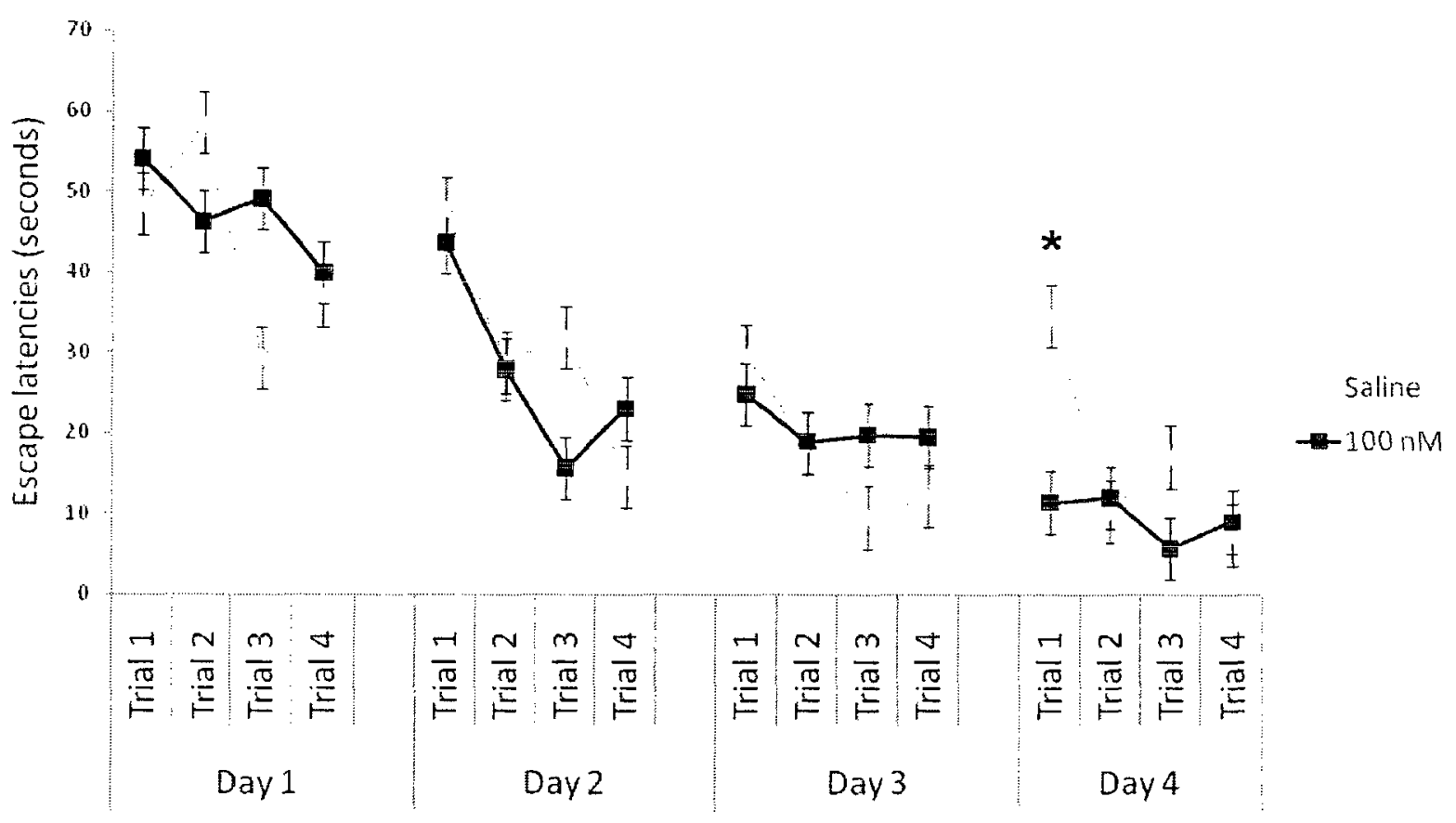


Figure 15. Latencies (seconds) to locate hidden platform over 4 days. Rats were injected with 0 or $100 \mathrm{nM}$ kainate $(n=8)$ following each training session. Kainate-injected animals displayed enhanced memory for the platform location on Trial 1 of Day 4 . Note: ${ }^{*}=p<.01$. 
Twenty-four hours after the fourth training session and post-training injection, the platform was removed from the pool and a 60 second probe test was administered. The amount of time a rat spent searching in the target annulus and the number of phantom crossings served as measures of memory consolidation for the platform's location. Given the size of the pool and target annulus, it was expected that rats would spend $8 \%$ of the probe test searching in the target annulus due to random chance. Rats searching in this region at levels greater than chance were thought to have consolidated the location of the platform more successfully.

A one-way ANOVA was conducted to determine the effect of kainate injections on time spent searching in the target annulus. Saline and kainate-injected groups spent more time searching in the target annulus than what was expected by chance alone; although, no significant differences were observed between groups, $F(1,14)=1.55, \mathrm{p}=.23$ (see Figure 16). A second one-way ANOVA was conducted to analyze the effect of post-training injections on the number of phantom crossings of the target annulus. No significant groups differences in the number of crossings were found, $F(1,14)=.85, \mathrm{p}=.37$ (see Figure 17). Overall, the administration of posttraining kainate injections did not improve probe test performance, illustrating that the enhancement of spatial memory seen on Day 4 in the kainate group was absent by Day 5 . 


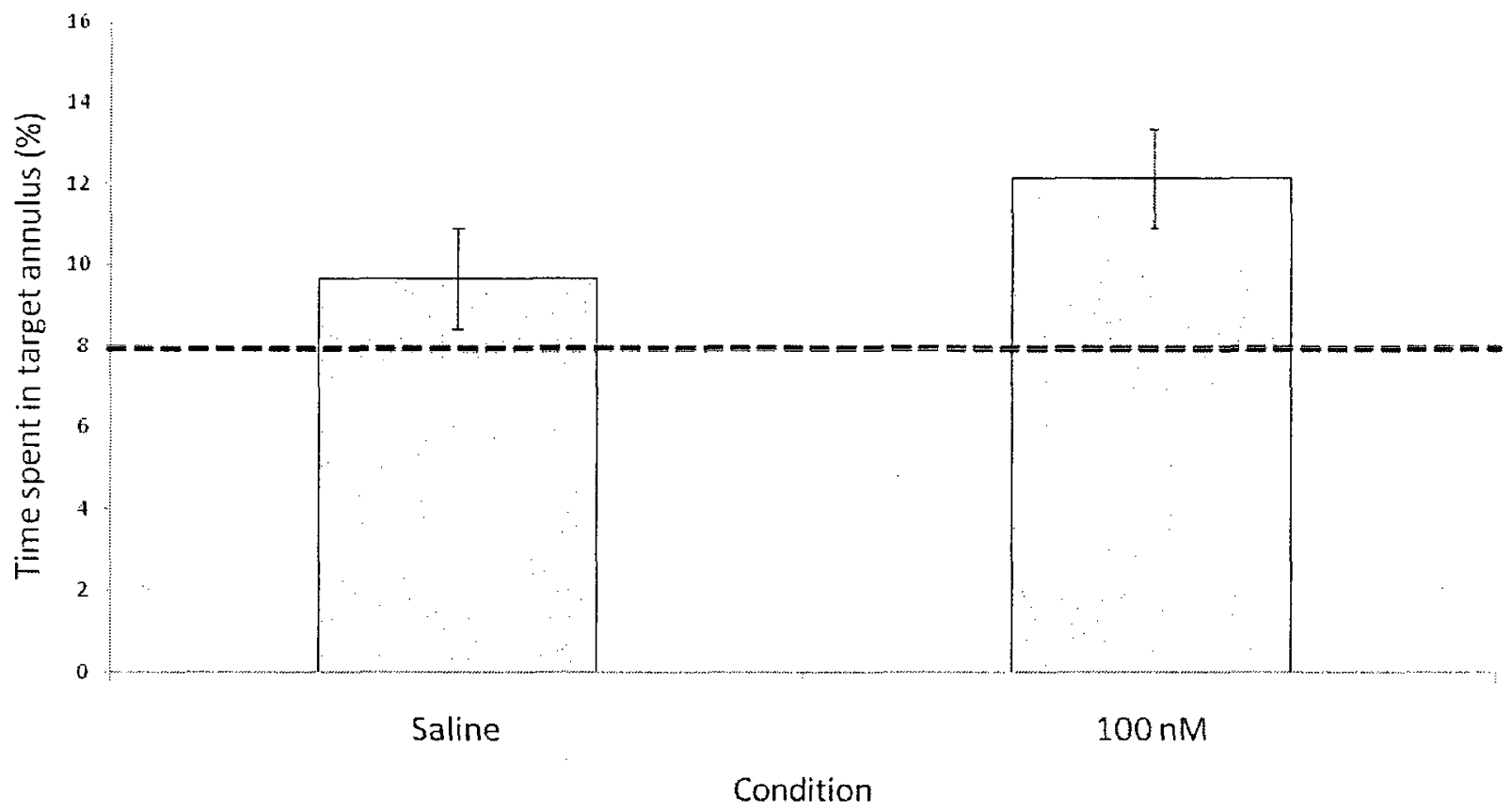


Figure 16. Time spent searching within the target annulus during probe test 24 hours after an intra-CA3 injection of 0 or $100 \mathrm{nM}$ kainate $(n=8)$. The black line indicates the amount of time spent near the platform location expected due to chance alone. No significant differences between groups, $\mathrm{p}>.05$. 

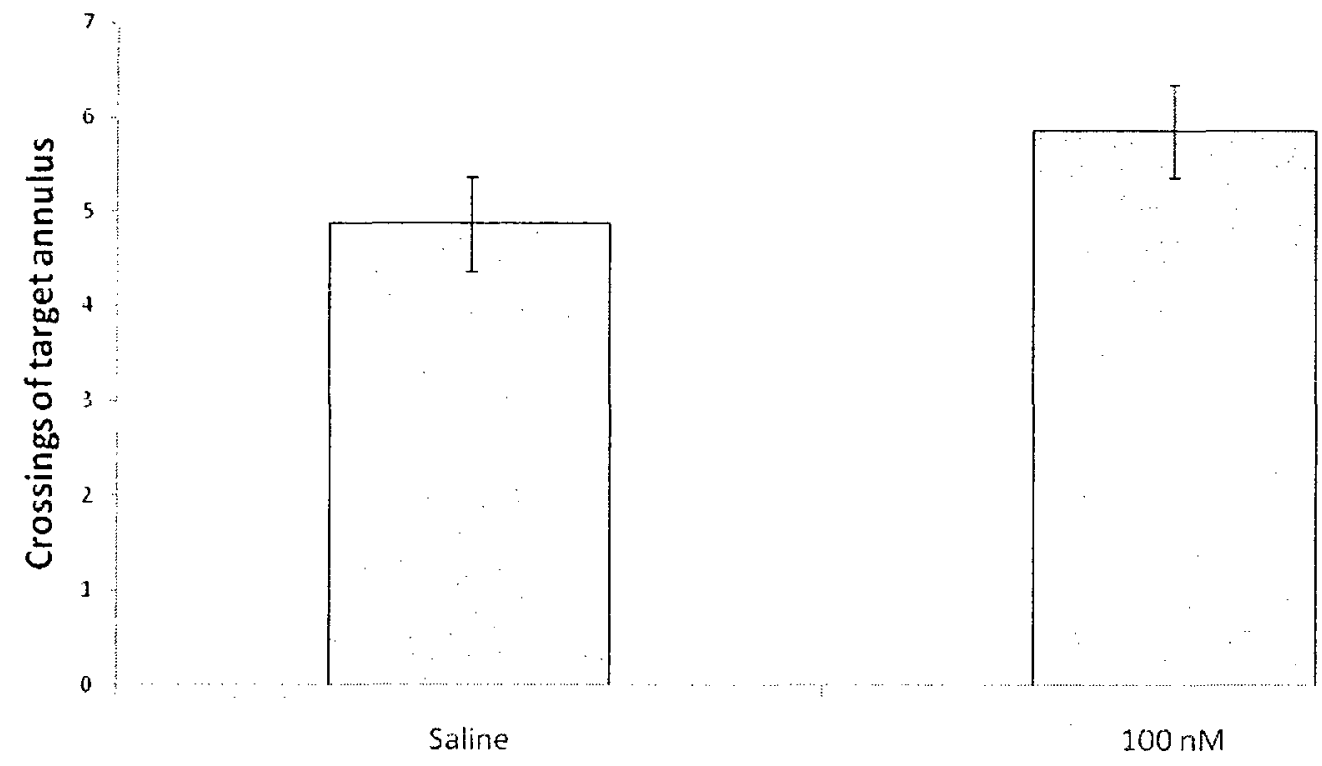

Condition 
Figure 17. Average number of times rats passed through the target annulus during probe test 24 hours after an intra-CA3 injection of 0 or $100 \mathrm{nM}$ kainate $(n=8)$. No significant differences between groups, $\mathrm{p}>.05$. 
A two-way mixed design ANOVA was conducted to evaluate the effect of saline and 100 $\mathrm{nM}$ kainate injections on the amount of time spent searching in the target annulus in 15 second intervals during the probe test. There was no interaction between dose and time interval, $F(3,42)$ $=.75, p=.53$, but a significant main effect of time was found, $F(3,42)=3.37, p<.03$ (see Figure 18). A greater percentage of time was spent searching in the target annulus during the first half of the probe test in both groups, suggesting that once the platform was not found in its original position both groups of rats modified their search strategy in an attempt to locate the platform elsewhere in the pool. In contrast, there was no main effect of group, $F(1,14)=1.53, \mathrm{p}=.24$, demonstrating that post-training injections of kainate did not lead to improved performance on the probe test. 


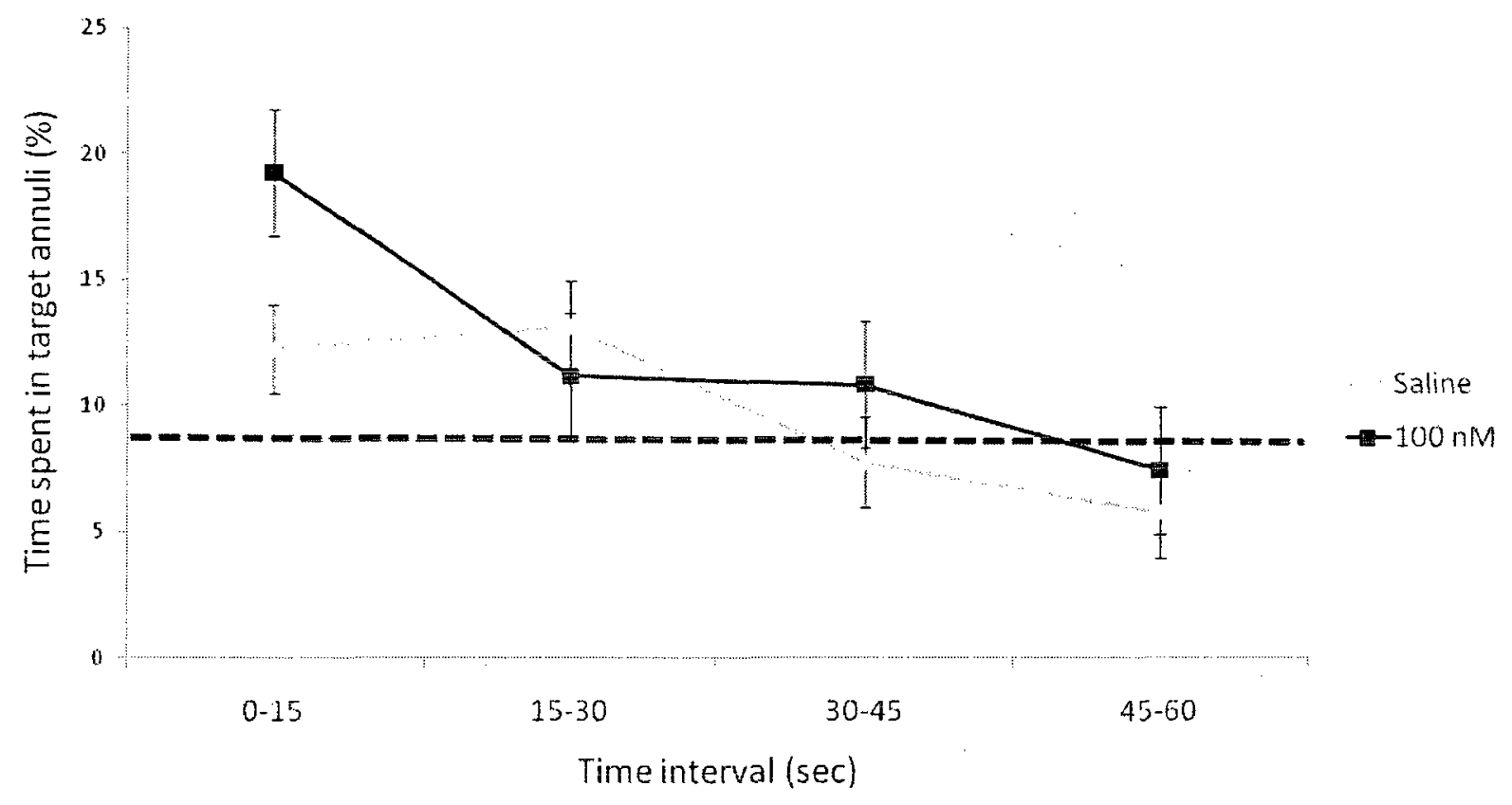


Figure 18. Retention of platform location at 15 second time intervals during probe test 24 hours after an intra-CA3 injection of 0 or $100 \mathrm{nM}$ kainate $(n=8)$. The black line indicates the amount of time spent in target annulus expected by chance alone $(8 \%)$. No significant differences between groups, $p>.05$. A main effect of time interval on searching behaviour was observed. Rats spent more time searching in the target annulus during the first 15 seconds compared to the final 30 seconds of the probe test. 
A final analysis compared the amount of searching in the target annulus to three other annuli of equivalent size (three times the diameter of the platform) specifically placed in each quadrant of the pool - target, adjacent right, adjacent left and opposite. Given the size of the pool and of each annulus, rats were expected to spend $8 \%$ of the probe test searching in each of these annuli due to random chance. A two-way ANOVA was conducted to evaluate the effect of posttraining injections on searching in each of the four annuli. There was no interaction between group and annuli location, $F(3,42)=.32, \mathrm{p}=.81$, but a significant effect of dose was found, $F(1,14)=6.56, \mathrm{p}<.03$ (see Figure 19). Kainate-injected rats spent more time searching not only in the target annulus but in all experimenter-chosen annuli, indicating that these rats devoted a larger percentage of the probe test to swimming within the inner portion of the pool (where the annuli were located) than the saline-injected rats. These results suggest that the saline and kainate-injected groups had different strategies when searching the pool. A significant main effect of annuli location was also found, $F(3,42)=11.33, \mathrm{p}<.001$. Irrespective of dose, rats spent more time searching in the target annulus than the three random annuli located in the pool (see Figure 19), suggesting that to both groups of rats recalled where the platform was located. 


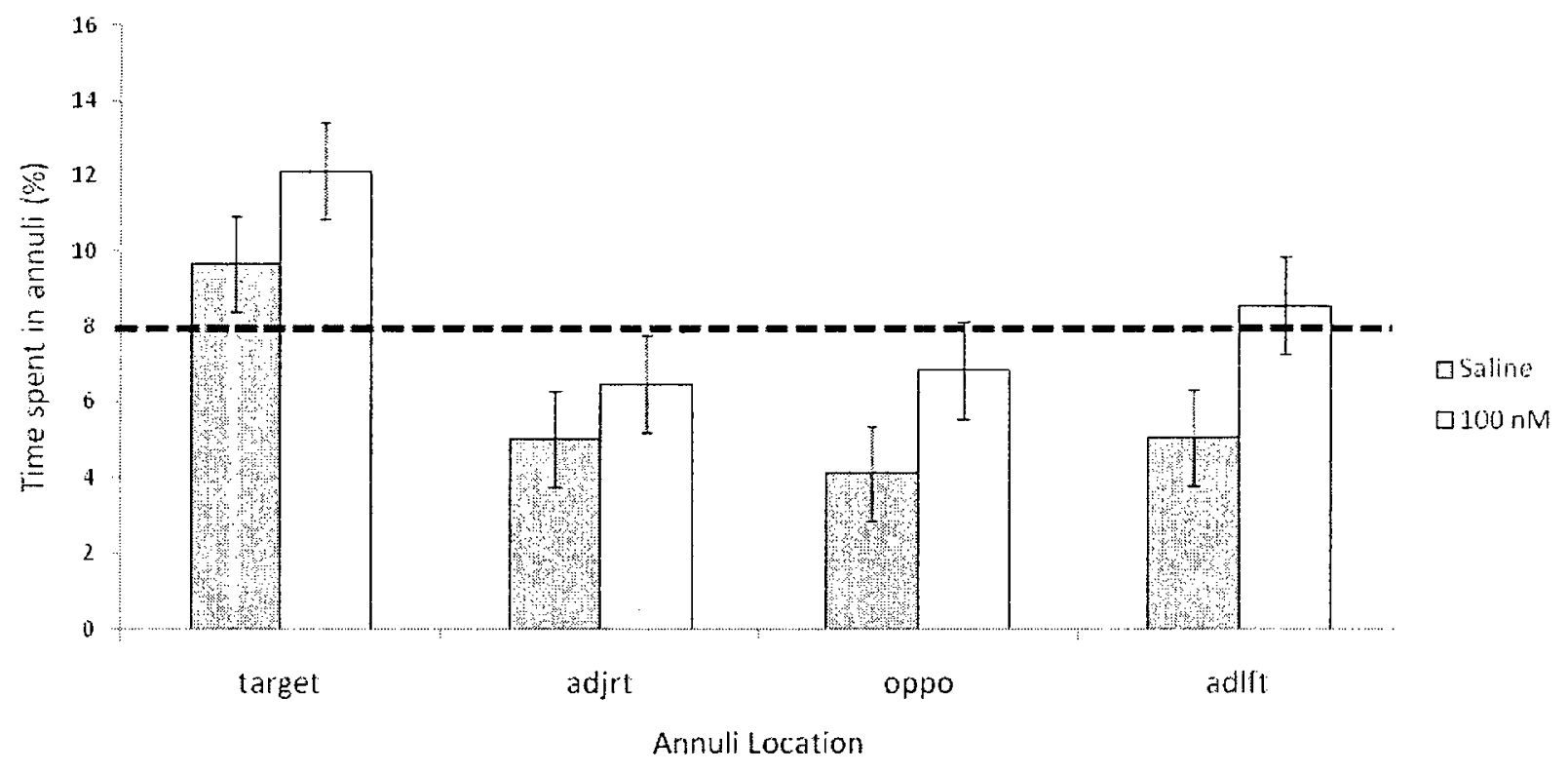


Figure 19. Percent time in annuli located in the four quadrants of the pool during probe test 24 hours after an intra-CA3 injections of 0 or $100 \mathrm{nM}$ kainate. $(n=8)$. The black line indicates the amount of time spent in target annulus expected by chance alone (8\%). A main effect of condition and platform location was observed. 


\section{Summary of Experiment 3}

Overall, the activation of KARs at mossy fibre synapses with post-training injections of $100 \mathrm{nM}$ kainate seemed to play a minor role in the consolidation of spatial information. During Morris water maze training, group differences were not observed until the fourth training session. One possible explanation for this delayed effect may be that multiple injections of kainate were required before the activation of KARs in the CA3 had an effect of memory consolidation. Post-training injections of kainate did not enhance performance during the probe test. Saline and kainate-injected groups showed no preference for the former location of the platform. A group effect on searching was found only when all four annuli (target and three random) were considered together - with kainate-injected rats searching more in all annuli combined.

\section{Cell death in the CA3}

Given that intra-cranial injections of kainate at high doses can produce cortical lesions (Gröticke et al., 2008; Stubley-Weatherly et al., 1996), it was necessary to confirm that the doses of kainate used in the present thesis did not cause cell death into the CA3. To determine whether intra-CA3 injections of kainate resulted in cell death, the number of cell bodies found in the CA3 after four injections of saline or $100 \mathrm{nM}$ kainate $(n=4 /$ group) were counted using a light microscope. Only the highest dose of kainate was only used since it would likely cause the most damage to the CA3 when injected. Please refer to Figure 20 for representative photomicrographs of the CA3 of saline and $100 \mathrm{nM}$ kainate-injected groups. A one-way ANOVA that examined the relationship between group and number of cell bodies in the CA3 was conducted. No group differences were found, $F(1,6)=.055, \mathrm{p}=.82$, confirming that injections of even the highest dose of kainate do not lead to cell death when injected into the CA3 of rats. 

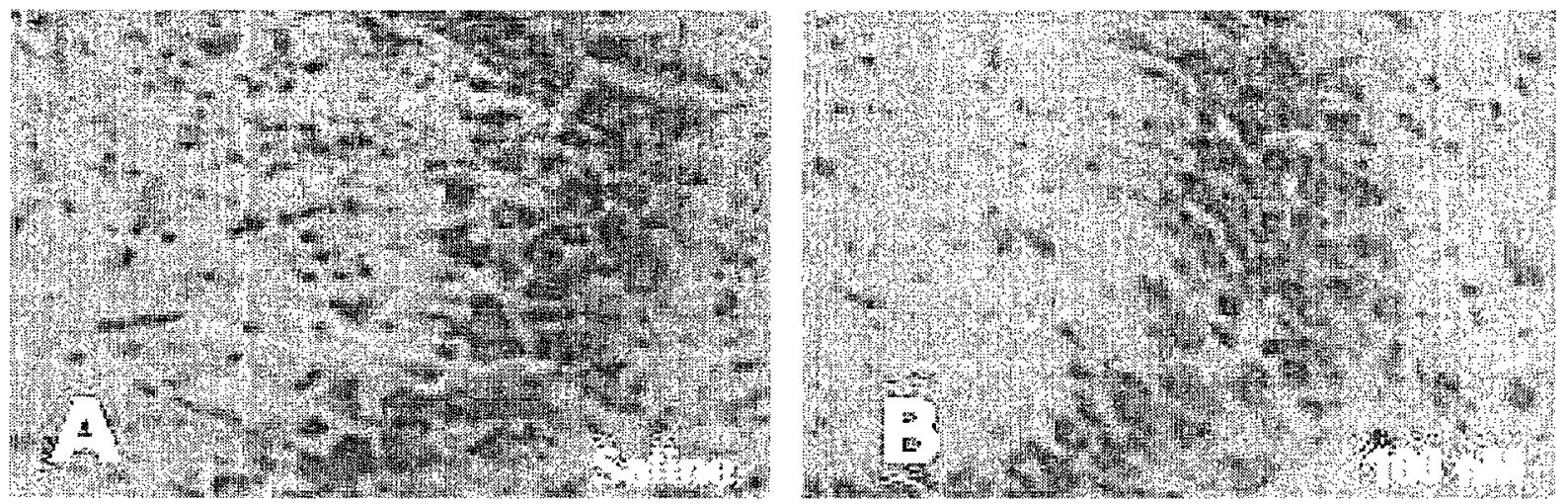
Figure 20. Representative photomicrographs of the $\mathrm{CA} 3$ region of the hippocampus following four injections of (A) saline or (B) $100 \mathrm{nM}$ kainate ( $n=4 \square /$ group). 


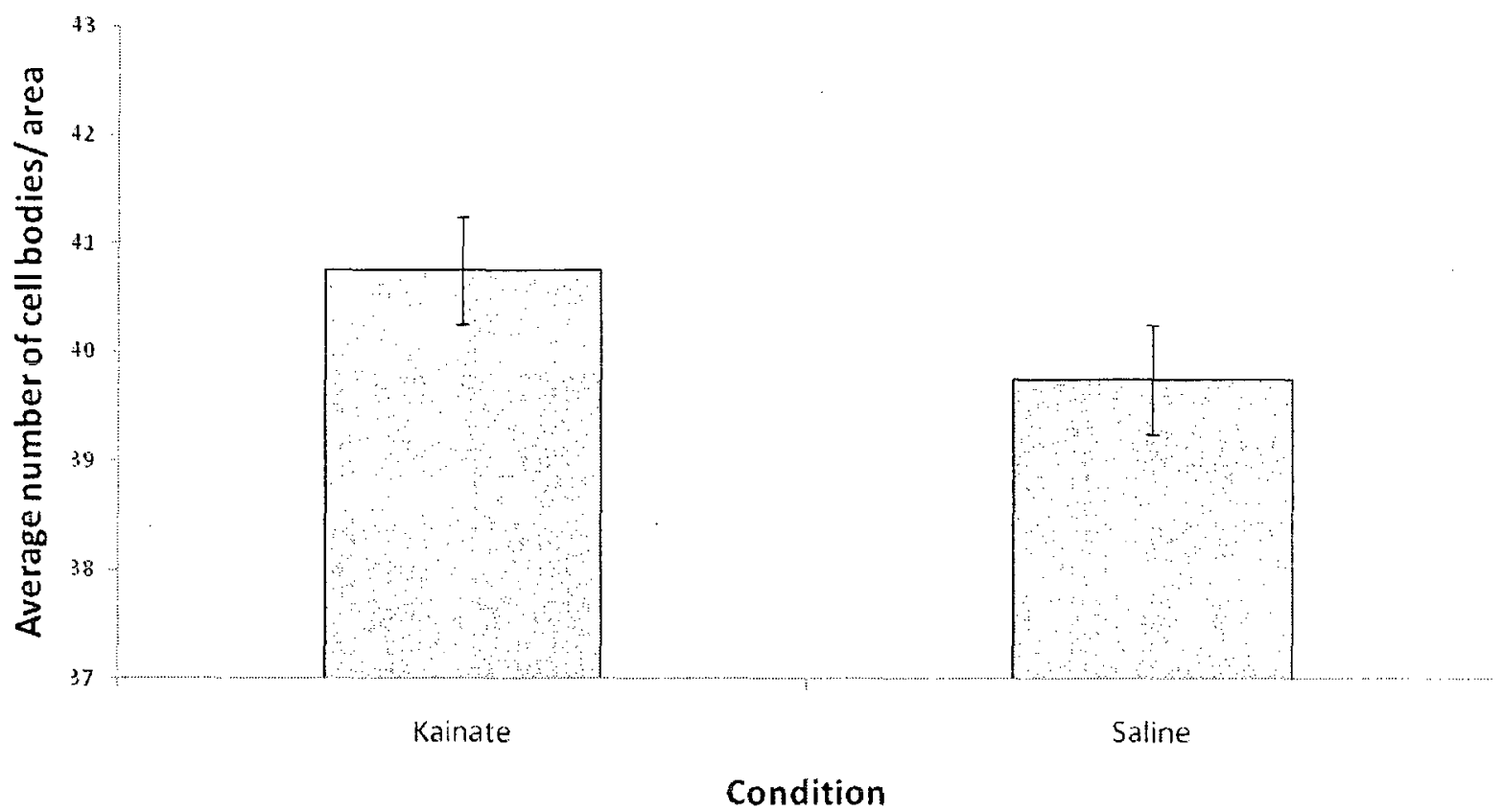


Figure 21. Average number of cell bodies found in the $\mathrm{CA} 3$ following four injections of saline or $100 \mathrm{nM}$ kainate. No differences were found between groups, $\mathrm{p}>.05$. 


\section{Phosphorylated ERK labeling in the CA3}

To determine the effect of saline and kainate injections on neuronal activation in the CA3, the nuclear expression of p-ERK (phosphorylated extracellular signal-regulated kinases) in the CA3 of saline and kainate-injected rats was quantified using immunofluorescence. Given that injections of $100 \mathrm{nM}$ kainate seemed to have to the largest effect on spatial memory performance in the Morris water maze task, only this dose was used. Rats received a bilateral intra-CA3 injection of saline or $100 \mathrm{nM}$ kainate ( $n=3$ / group) or a unilateral intra-CA3 injection of saline in the left hemisphere and $100 \mathrm{nM}$ kaiante in the right hemisphere $(n=2)$. All rats were sacrificed 15 minutes after the injection - a time that corresponded with Morris water maze training and testing in experiments $1 \& 2$. Therefore, the activation in the $\mathrm{CA} 3$ as a result of these injections would reflect the activation in the CA3 during behavioural testing in these experiments. Photomicrographs of the CA3 were taken for each rat and were analyzed for their degree of fluorescence (see Figure 21 for representative photomicrographs).

Upon visual inspection of the photomicrographs, bilateral injections of kainate appeared to increase the amount of p-ERK labeling in the CA3 when compared with bilateral injections of saline (Figure $21 \mathrm{~A} \& \mathrm{~B}$ ). Interestingly, of the two rats that received a unilateral injection of saline and kainate, only one seemed to follow the same activation pattern observed in the bilateral injections (i.e., higher intensity staining in the CA3 of the right (ipsilateral) hemisphere of kainate-treated animals). The second rat showed comparable amounts of labeling in both hemispheres, regardless of injection type (Figure $21 \mathrm{C} \& \mathrm{D}$ ). This suggests that the activation of one hemisphere by an injection of $100 \mathrm{nM}$ kainate may simultaneously activate the other hemisphere. Given the observable discrepancy in p-ERK labeling from the unilateral injections of saline and kainate, the rat which showed similar levels of labeling in both hemispheres was 
removed from the p-ERK quantification analyses. The average intensity of p-ERK staining per area in kainate-injected rats was $8.74 \pm 2.23 \%$ as compared to $4.65 \pm 1.06 \%$ in saline-injected rats $(n=4 /$ group; see Figure 22$)$. To determine whether these differences in intensity were statistically significant, a one-way ANOVA that evaluated the relationship between dose and pERK labeling was conducted. The intensity p-ERK staining in the CA3 of kainate-injected rats was not statistically different from saline-injected rats, $F(1,6)=2.74, \mathrm{p}=.15$. These nonsignificant findings may be explained by the large variability in p-ERK labeling for each group, with labeling ranging from as low as 4.26 to as high as 14.22 in the kainate group and ranging from 2.65 and 7.61 in the saline group. Further, p-ERK labeling for two of the four kainateinjected rats fell within the range of the saline-injected rats and when taken together with the large variability in these data, may account for the non-significant results. 

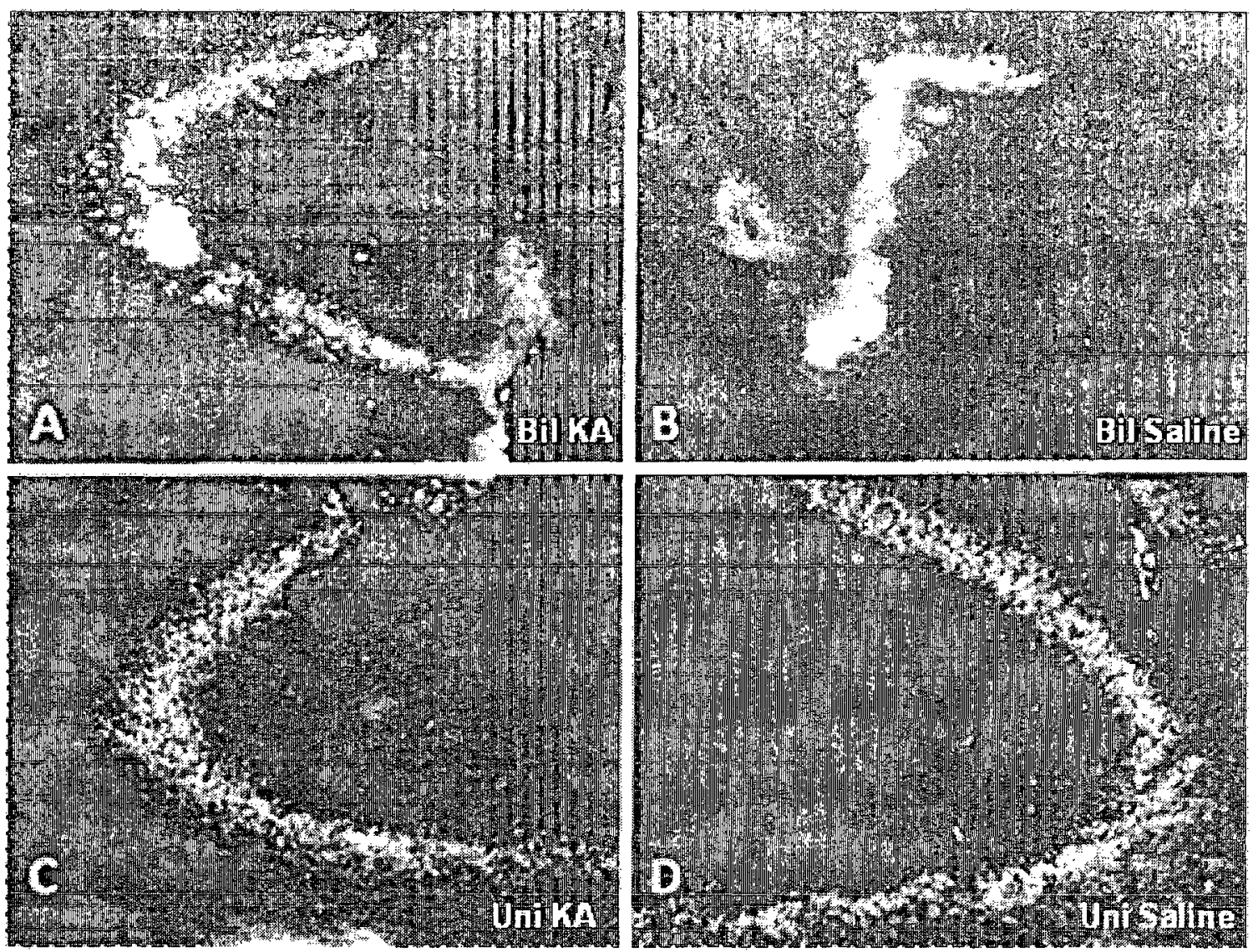
Figure 22. Representative photomicrographs of pERK labelling in the CA3 following a bilateral injection of $100 \mathrm{nM}$ kainate (A), a bilateral injection of saline (B), or a unilateral injection of 100 $\mathrm{nM}$ kainate into the left hemisphere (C) and a unilateral injection of saline into the right hemisphere (D). Note: $\mathrm{Bil}=$ bilateral injections, $\mathrm{Uni}=$ unilateral injection, $\mathrm{KA}=$ kainate 


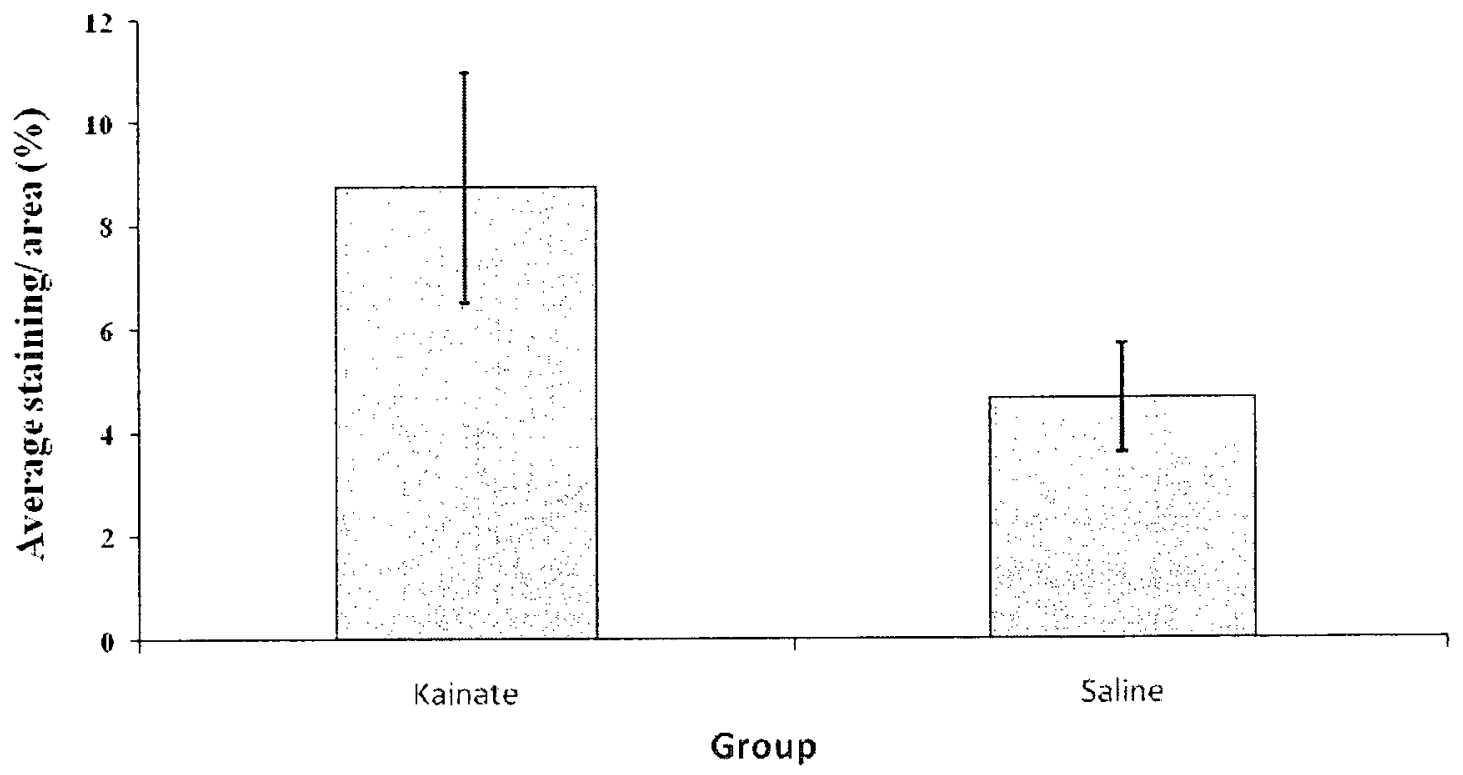


Figure 23. Average intensity of pERK staining in the CA3 for $100 \mathrm{nM}$ kainate and salineinjected rats $(n=4 /$ group). No groups differences in labelling were found, $\mathrm{p}>.05$. 


\section{Discussion}

Daily bilateral pre-training injections of kainate into the CA3 had little effect on the acquisition of spatial information in rats (experiment 1). During Morris water maze training, injections of $100 \mathrm{nM}$ kainate seemed to reduce escape latencies on Trial 1 of Day 4 when compared with all other doses; however, this decrease did not turn out to be statistically significant. Similarly, no group differences were found in the 24 hour recall of the platform's location (i.e., difference between first and last trial escape latencies between training days). This finding was surprising since the first trial escape latencies followed a downward linear trend in only the $100 \mathrm{nM}$ group - a finding that which suggested learning had occurred. During the probe test, a preference for the former location of the platform was demonstrated by all groups, regardless of the dose, indicating retention/ recall of the platform's location was not enhanced with injections of kainate.

A single bilateral intra-CA3 injection of kainate administered prior to the probe test had no effect on the retrieval of spatial information (experiment 2). Prior to the probe test, all groups were trained for four consecutive days on the Morris water maze task in a drug-free environment. No group differences in escape latencies were found on Days 1 through 4. Therefore, any group differences on the probe test could be attributed to the pre-testing injections and not to differences in the acquisition and/ or the consolidation of the platform's location during training. During the probe test, pre-testing injections of kainate (even at the highest dose) did not enhance recall of the previous location of the platform and no preference for its location was shown by any group.

Daily post-training kainate injections into the $\mathrm{CA} 3$ had the most proneunced effect on spatial memory performance (experiment 3). During the training, group differences in escape 
latencies were not apparent until the fourth day. The $100 \mathrm{nM}$ kainate group showed reduced latencies on the first trial of Day 4 compared to the saline group. When the probe test was given 24 hours later, this enhancement in the consolidation of spatial information in the kainate group was absent. Both groups spent similar percentages of time searching in the target annulus.

Overall, injections into the CA3 with the highest dose of kainate led to most overt behavioural differences in spatial memory performance on the Morris water maze task. Posttraining injections of $100 \mathrm{nM}$ kainate led to a 24 hour enhancement in performance from Trial 4 of Day 3 to Trial 1 of Day 4. A similar trend was observed with pre-training injections of 100 nM kainate from Day 3 to Day 4; however, the enhancement in the acquisition of spatial information was not statistically significantly. These improvements in spatial information processing were likely the result of the repeated activation of KARs in the CA3 with kainate (a Glu analog). These findings were consistent with in vitro studies, which illustrate that the activation of presynaptic KARs with low doses of kainate $(<100 \mathrm{nM})$ play an important role in short-term plasticity through the enhancement of synaptic neurotransmission and the increase in mossy fibre excitability (Contractor et al., 2000; Nicoll \& Schmitz, 2005; Schmitz et al., 2001). Given that substantial amounts evidence supports the idea that synaptic plasticity reflects a molecular mechanism of learning and memory (Bliss \& Collingridge, 1993; Blockland \& Boess, 2008), these improvements in the consolidation of spatial information in the $100 \mathrm{nM}$ injected group were likely the behavioural manifestation of these biochemical processes.

Pre-training, pre-testing and post-training injections did not affect the percentage of time spent searching within the target annulus during the probe retention test. It was expected that the saline group would have significantly poorer recall for the previous location of the platform and as a result would spend less time searching within the target annulus. However, in all three 
experiments, the saline- and kainate-injected groups spent equivalent proportions of time searching in the target annulus. A dose-dependent enhancement in the retrieval of spatial information was also expected across the three doses of kainate. Similarly, no group differences were detected in search times within the target annulus (experiments $1 \& 2$ ). A group effect during the probe test was only found when all four annuli (target and three random) were considered together (experiments $2 \& 3$ ) - with the $100 \mathrm{nM}$ kainate-injected group searching more in all annuli combined. These results can be explained given the distribution of the four annuli in the pool; all were situated within the inner portion of the water maze, suggesting 100 nM kainate group had employed a different strategy when looking for the previous location of the hidden platform. These animals were more likely to search for this location within the middle of the pool. This finding does not give any indication of retention/ recall of the platform's location since three of the four annuli included in the analysis are not connected to the previous location of the hidden platform.

One factor which may explain why group differences in search times in the target annulus were not found in the first experiment (pre-training injections of kainate) is state-dependent learning. All rats had learned the location of the platform under the influence of a drug, but were required to recall this location in a drug-free state. It has been well documented that animals will recall information more effectively when they are in the same state in which the information was learned (i.e., state-dependent learning; Colparet, 1990). The discrepancy between the learning state (i.e., training sessions - Day 1-4) and the recall state (i.e., probe test - Day 5) may have led to impaired performance on the probe test. It is possible that group differences in spatial memory would have been uncovered if groups had received both pre-training and pre-testing injections. 
The endogenous levels of Glu already present within the CA3 as a result of learning the Morris water maze task may have also contributed to the statistical similarities between groups in the time spent searching within the target annulus If endogenous levels of Glu were already high because of learning, then it is possible that many of the receptors were already occupied by Glu. Therefore, when kainate (a Glu analog) is added, there will be very few receptors available that it can bind and as a result, the ratio of occupied to unoccupied KARs (and other Glu receptors) at the mossy fibre synapse in the kainate-injected groups (all doses) may resemble the salineinjected group. If there were no differences in the number activated KARs between kainate and saline-injected groups, then it follows that no changes will be found when these groups are evaluated behaviourally. Additional data would be required to assess the likelihood of this hypothesis.

Alternatively, it is possible that after four training sessions the saline-injected group had learned the location of the hidden platform as successfully as the kainate group (experiment 3 ). Thus, when tested in a probe retention test 24 hours later, both groups performed equally as well. The kainate-injected group showed considerable reduction in average escape latency on trial 1 of Day 4 compared to the saline-injected group. However, after this initial impairment in performance on first trial, the saline group quickly "caught-up" to the kainate group on the second trial, demonstrating that with slightly more training the saline-injected group were able to locate the platform after similar latencies. On the third trial, the saline group once again showed slightly elevated latencies compared with the kainate group, but by trial 4 , this group difference had been abolished. Despite the inconsistencies in performance on Day 4 trials in the salineinjected group, the average latency to locate the hidden platform on the last trial was quite low in both groups, indicating they both were equally as efficient at locating the hidden platform at the 
end of the training trials. Furthermore, on the probe test, the saline and the kainate groups showed a preference for the target annulus over the three other annuli specifically placed in the pool, providing further support that both groups had consolidated the location of the platform equally as well.

It was important to confirm that injections of kainate did not trigger cell death as injections of this drug is a common technique used to cause hippocampal lesions (Gröticke, Hoffmann \& Löscher, 2008; Stubley-Weatherly, Harding \& Wright, 1996). Cell death in the CA3 was not expected as the doses of kainate used to produce a lesion in this brain region ranged from $9.4 \times 10^{5}$ to $4.9 \times 10^{7} \mathrm{nM}$, which were considerably higher than the doses used in the current experiments (25-100 nM). Multiple bilateral injections of the highest dose of kainate $(100 \mathrm{nM})$ did not cause cell death in the CA3 region of the hippocampus. No group differences were found in the number of cell bodies present in this region. Therefore, we can conclude that any differences in behaviour observed between the groups was not the result of cell death in the CA3, but was activation of KARs with low doses of kainate.

The surgical implantation of guide cannulae in the brain $1 \mathrm{~mm}$ above the CA3 hippocampal region leads to cell death in the immediate area surrounding the cannulae. Cortical damage, which increases as a function of time, is a normal consequence of cannulation as the insertion of cannulae in the brain will damage cells as well as destroy neuronal connections. To minimize variability in the degree of cortical damage, all animals were tested on the Morris water maze task within six to nine days of cannulation.

In a rat brain, the primary motor cortex $\mathrm{M} 1$ is located directly above the $\mathrm{CA} 3$ (Paxinos \& Watson, 1998). There is possibility that damage to this cortical region from the insertion of guide cannulae may impair locomotor abilities thereby altering performance on the Morris water maze 
task. Moreover, injections of the different doses of kainate in the CA3 may also affect swimming speed/ ability. A non-operated control group that underwent exactly the same behavioural testing as the four experimental groups was used to control for any changes in locomotor performance on the Morris water maze task as a result of cannulation or kainate injections. No group differences in swimming speed/ ability were found, indicating that injections of kainate, regardless of dose, and cortical damage as a result of cannulation did not impair locomotor abilities on the Morris water maze task.

Damage to neurons and neuronal connections from the bilateral insertion of guide cannulae and injector tips in the CA3 may also cause changes in spatial information processing. However, this was unlikely given that the non-operated control group and the four experimental groups showed similar patterns of learning during Morris water maze training and testing. Therefore, we can conclude that any behavioural changes observed between groups could be attributed to the different doses of kainate and not from cortical or hippocampal damage as a results of surgical and injection procedures.

Given that improvements in spatial memory performance were not apparent until the fourth day of training (after multiple post-training injections); we propose that the enhancement of spatial information processing was dependent on the repeated activation of the CA3. Consistent with this hypothesis, a single pre-testing injection with low doses of kainate (25-100 $\mathrm{nM}$ ) had no effect on the retrieval of spatial information during a probe retention test (experiment 2). Similarly, the repeated blockade of neural activity in the CA3 by daily posttraining injections of lidocaine (a drug which blocks voltage gated $\mathrm{Na}+$ channels thereby altering signal propagation) impaired spatial memory performance on the Morris water maze task (Holahan \& Routtenberg, submitted). Post-training lidocaine injections led to 24 hour 
impairment in retention of spatial information (as indicated by elevated first trial latencies) on Day 4 and Day 5 of water maze training. Like post-training injections of $100 \mathrm{nM}$ kainate, lidocaine injections did not affect spatial memory performance until a minimum of three posttraining injections were administered, providing support that the persistent change in neural activation in the CA3 may mediate spatial information processing. Furthermore, given that the global inactivation of the CA3 with injections of lidocaine led to such pronounced impairments in the storage of spatial information; it would be worthwhile to evaluate the effect of intra-CA3 injections of a KAR antagonist, such as LY382884, on spatial information processing. Would the same spatial memory impairments still be found or since only the KARs in the CA3 will be blocked, would these impairments be attenuated?

When neural activation in the CA3 was quantified, a single bilateral injection of $100 \mathrm{nM}$ kainate did not significantly increase the intensity of p-ERK labelling in the CA3, despite obvious visual differences in intensity. These results indicate that even at the highest dose of kainate, one injection was not enough to significantly alter neural activity in the CA3, providing further support that the CA3 requires repeated neural activation before it "turns on". Unilateral injections of $100 \mathrm{nM}$ kainate in the CA3 (right hemisphere) produce two contradictory patterns of activation in the CA3. In one animal, the intensity of p-ERK labelling in the hemisphere injected with kainate was consistent with the intensity of labelling found in the CA3 after bilateral injections of kainate. Likewise, a similar pattern in p-ERK labelling was observed in the CA3 after unilateral and bilateral saline injections. In the second animal, similar activation patterns were seen in both hemispheres. Cross-talk (i.e., a biochemical phenomenon in which synaptic transmission at one synapse can extend to neighbouring synapses; Rusakov, Kullmann \& Stewart, 1999) between the two hemispheres may underlie the activation of the hemisphere 
contralateral to the kainate injection. In the hippocampus, synaptically released Glu has been shown to activate receptors located intra- and extrasynpatically (Scimemi, Fine, Kullmann \& Rusakov, 2004). In the current experiment, there is a strong possibility that injections of kainate (a Glu analog) into mossy fibre-CA3 synapses may lead to extrasynapatic communication with neighbouring synapses. However, with a sample size of only two, it is impossible to conclude which finding represents the "true" activation pattern in the brain after a unilateral injection of kainate. More animals will need to be evaluated.

The intensity of p-ERK labelling in the CA3 only illustrates general neural activation after an injections of kainate from which it is impossible to establish which types of receptors kainate primarily activated - presynaptic or postsynaptic or a combination of them both. This is important as the activation of pre- and postsynaptic receptors influence different aspects of neurotransmission. Postsynaptic receptors generate EPSPs at CA3 pyramidal neurons when activated (Frerking \& Ohliger-Frerking, 2002), whereas presynaptic receptors modulate both neurotransmitter release and the depolarization of mossy fibres (Bortolotto et al., 2005; Lerma, 2003). Further, a recent study by Sachidhanandam and colleagues (2009) reported that in vitro pre and post-synaptic KARs work together to enhance synaptic transmission at mossy fibre synapses. Therefore, determining which types of KARs in the mossy fibre-CA3 synapse that kainate activates when the drug administered in vivo will provide some insight into the molecular mechanisms that underlie the cognitive and behavioural changes in response to the drug.

Pre- and postsynaptic receptors at the mossy fibre-CA3 synapse are composed primarily of the GluR6, KA-1 and KA-2 subunits (Bahn et al., 1994; Wisden \& Seeburg, 1993). While the KA-1 and KA-2 subunit are found on both pre- and postsynaptic membranes, the KA-1 subunit is primarily localized presynaptically and the KA-2 subunit postsynaptically. Likewise, the 
GluR6 subunits is found both pre- and postsynaptically where it forms functional heteromeric receptor complexes with the KA-1 and KA-2 subunits and functional homomeric receptor complexes with itself (Darstein, Petralia, Swanson, Wenthold \& Heinemann, 2003). There is a possibility that injections of kainate differentially affect pre- and postsynaptic KARs given their disparity in subunit composition. In fact, kainate is more effective in activating homomeric GluR6 receptors than heteromeric GluR6/KA-2 receptors (Howe, 1996). Given the unique organization of KAR subunits at the mossy fibre-CA3 synapse, the selective agonism or antagonism of specific subunits has important implications not only in the efficacy of synaptic transmission and synaptic plasticity, but in spatial information processing. Unfortunately, GluR6-, KA-1 and KA-2 selective agonists or antagonists are not yet available.

The activation of KARs play an important role in synaptic plasticity at the mossy fibreCA3 synapse in vitro. Given that the present experiments provide evidence that the repeated activation of KARs lead to the enhanced consolidation of spatial information, it is possible KARmediated synaptic plasticity represents the molecular mechanism through which these receptors influence consolidation processes. LTP is one form of synaptic plasticity mediated by presynaptic KARs at the mossy fibre synapse (Bortolotto et al., 2005; Breustedt \& Schmitz, 2004; Schmitz, et al., 2003). LTP shares many properties with what researchers have described as the "ideal memory process" (see Introduction; Martin, Grimwood \& Morris, 2000; Remy \& Spruston, 2007) making it a candidate mechanism for information processing and storage within the brain. The antagonism of KARs with CNQX (a non-NMDA antagonist) increases the induction threshold of mossy fibre LTP (Schmitz et al., 2003). In the presence of an AMPA antagonist (GYKI 53655) LTP is unaffected, suggesting that the blockade of KARs causes an increase in the threshold for inducing LTP. Since LTP can still be generated when KARs are 
blocked, it follows that KARs are not critical for its induction, but mediate mossy fibre LTP by lowering the threshold in which it can be induced. Taken together, these findings imply that while KARs are important for LTP, but their role is a secondary one. It is likely that KARs work in conjunction with other biochemical and synaptic elements to mediate the induction of LTP at mossy fibre synapses.

The KAR subunit GluR6 also plays an important role in LTP induction. GluR6 knockout mice show diminished mossy fibre LTP (Breustedt \& Schmitz, 2004; Contractor et al., 2001; Schmitz et al., 2003), which could not be reversed with an infusion of kainate (Breustedt $\&$ Schmitz, 2004). Interestingly, low levels of $\mathrm{K}^{+}$applied during tetanus were able to reverse the attenuation of LTP in these mutant mice (Schmitz et al., 2003), suggesting GluR6 subunits (1) are critically involved in LTP induction and (2) enhance LTP induction through the depolarization of the presynaptic terminal. Since LTP represents one of the main mechanisms of information processing and storage in the brain and GluR6 knockout mice show diminished LTP, it follows that these mice would show spatial learning and memory impairments. Interestingly, these mutant mice show deficits in contextual and auditory fear, but when tested in the spatial version of the Morris water spatial memory appeared normal (Mulle et al., 1998), proving further that while KARs play a role in spatial information processing, these receptors are not crucial for this type of learning. It is most likely that KARs alongside other synaptic elements mediate information processing and storage within the brain. An alternate possibility could be that compensatory mechanisms are in-place, which take over when KARs are blocked or knocked out. 


\section{Conclusion}

The present experiments demonstrate a potential role for KARs in the consolidation of spatial information, but not in the acquisition or the retrieval of spatial information. However, it is too early to conclude that KARs are not important for these types of information processing given that these experiments are the first to evaluate KARs in vivo through pharmacological means. The repeated activation of KARs with low doses of kainate appears to be additive over time. It is this persistent change in neural activation in the CA3 that is thought to mediate spatial information processing. However, the exact mechanism by which the activation of KARs lead to changes in information processing is unknown. Given the presence of pre and postsynaptic KARs as well as the unique organization of KAR subunits at the mossy fibre-CA3 synapse, the administration of KARs subunit specific agonists and antagonists in vivo will provide some insight into how different components of these receptors mediate learning and memory. 


\section{References}

Abraham WC, Mason SE. (1988). Effects of the NMDA receptor/channel antagonists CPP and MK801 on hippocampal field potentials and long-term potentiation in anesthetized rats. Brain Research. 462(1): 40-6.

Ambrosini, A., Bresciani, L., Fracchia, S., Brunello, N. \&Racagni, G. (1995). Metabotropic glutamate receptors negatively coupled to adenylate cyclase inhibit N-methyl-D-aspartate receptor activity and prevent neurotoxicity in mesencephalic neurons in vitro. Molecular Pharmacology. 47(5): 1057-64.

Anis NA, Berry SC, Burton NR, Lodge D. (1983). The dissociative anaesthetics, ketamine and phencyclidine, selectively reduce excitation of central mammalian neurones by $\mathrm{N}$ methyl-aspartate. British Journal of Pharmacology. 79(2): 565-75.

Areosa SA, Sherriff F, McShane R. (2005). Memantine for dementia. Cochrane Database Systematic Reviews. 3: 1-85.

Armstrong N, Jasti J, Beich-Frandsen M, Gouaux E. (2006). Measurement of conformational changes accompanying desensitization in an ionotropic glutamate receptor. Cell. 127(1): $85-97$.

Baddley, AD. (1986). Working Memory. Clarendon Press, Oxford, UK.

Bahn, S., Volk, B., and Wisden, W. (1994). Kainate receptor gene expression in the developing rat brain. J. Neurosci. 14: 5525-5547.

Banke TG, Bowie D, Lee H, Huganir RL, Schousboe A, Traynelis SF. (2000). Control of GluR1 AMPA receptor function by cAMP-dependent protein kinase. Journal of Neuroscience. 20(1): $89-102$ 
Bear MF, Abraham WC. (1996). Long-term depression in hippocampus. Annual Reviews in Neuroscience. 19: 437-62.

Bliss TV, Collingridge GL. (1993). A synaptic model of memory: long-term potentiation in the hippocampus. Nature. 361(6407): 31-9.

Bliss TV, Lomo T. (1973).Long-lasting potentiation of synaptic transmission in the dentate area of the anaesthetized rabbit following stimulation of the perforant path. Journal of Physiology. 232(2): 331-56.

Blokland, A. \& Boess, F. (2008). Use of behavioural and long-term potentiation models in the development of memory-improving drugs. Expert Opinion on Drug Discovery. 3(9): 1067-80.

Boehm, J., Kang, M.G.,Johnson, R.C., Esteban, J., Huganir, R.L. \& Malinow R. (2006). Synaptic Incorporation of AMPA Receptors during LTP Is Controlled by a PKC Phosphorylation Site on GluR1. Neuron. 51:213-25.

Bortolotto Z.A., Clarke V.R.J., Delany C.M., Parry M.C., Smolders I., Vignes M. et al., (1999). Kainate receptors are involved in synaptic plasticity. Nature. 402:297-301.

Bortolotto, Z.A., Nistico, R., More, J.C., Jane, D.E. \& Collingridge, G.L. (2005). Kainate Receptors and Mossy Fiber LTP. NeuroToxicology. 26: 769-77.

Bouilleret, V., Ridoux, V., Depaulis, A., Marescaux, C., Nehlig, A. \& Le Gal, L.S. (1999). Recurrent seizures and hippocampal sclerosis following intrahippocampal kainate injection in adult mice: electroencephalography, histopathology and synaptic reorganization similar to medial temporal lobe epilepsy. Neuroscience. 89, 717-729.

Breustedt, J. \& Schmitz, D. (2004). Assessing the Role of GLUK5 and GLUK6 at Hippocampal Mossy Fiber Synapses. The Journal of Neuroscience. 24(45): 10093-98. 
Bureau, I., Bischoff, S., Heinemann, S.F., and Mulle, C. (1999). Kainate receptor-mediated response in the CA1 field of wild-type and GluR6-deficient mice. J. Neurosci. 19, 653663.

Burgess, N. (2008) Spatial cognition and the brain. Ann N Y Acad Sci. 1124: 77-97.

Butelman ER. (1989). A novel NMDA antagonist, MK-801, impairs performance in a hippocampal-dependent spatial learning task. Pharmacol Biochem Behav. 34(1): 13-6.

Castillo, P.E., Malenka, R.C. \& Nicoll, R.A. (1997). Kainate receptors mediate a slow postsynaptic current in hippocampal CA3 neurons. Nature. 388:182-186.

Chen HS, Lipton SA. (2006). The chemical biology of clinically tolerated NMDA receptor antagonists. Journal of Neurochemistry. 97(6): 1611-26.

Chittajalla, R., Braithwaite, S.P., Clarke, V.R.J. \& Henley, J.M. (1999). Kainate receptors: subunits, synaptic localization and function. TiPS. 20: 26-35.

Citri, A. \& Malenka, R.C. (2008) Synaptic plasticity: multiple forms, functions, and mechanisms. Neuropsychopharmacology. 33(1): 18-41.

Clapcote SJ, Roder JC. (2004). Survey of embryonic stem cell line source strains in the water maze reveals superior reversal learning of 129S6/SvEvTac mice. Behva Brain Research. $152(1): 35-48$.

Clarke VR, Ballyk BA, Hoo KH, Mandelzys A, Pellizzari A, Bath CP, et al., (1997). A hippocampal GluR5 kainate receptor regulating inhibitory synaptic transmission. Nature. 389 (6651): 599-603.

Collingridge, G.L. \& Bliss, T.V.P. (1995). Memories of NMDA receptors and LTP. Trends in Neuroscience. 18: 54-56.

Collingridge GL, Singer W. (1990). Excitatory amino acid receptors and synaptic plasticity. 
Trends in Pharmacological Science. 7:290-6.

Collingridge GL, Kehl SJ, McLennan H. (1983). Excitatory amino acids in synaptic transmission in the Schaffer collateral-commissural pathway of the rat hippocampus. Journal of Physiology. 334:34-46.

Colparet, F.C. (1990). Amnesic trace locked into the benzodiazepine state of memory. Psychopharmacology. 102 28-36.

Contractor, A., Swanson, G.T., Sailer, A., O'Gorman, S. \& Heinemann. S.F. (2000). Identification of the Kainate Receptor Subunits Underlying Modulation of Excitatory Synaptic Transmission in the CA3 Region of the Hippocampus. The Journal of Neuroscience. 20(22): 8269-78.

Contractor, A., Sawnson, G. \& Heinemann, S.F. (2001). Kainate Receptors Are Involved in Short and Long-Term Plasticity at Mossy Fiber Synapses in the Hippocampus. Neuron. 29: 209-16.

Contractor A, Sailer AW, Darstein M, Maron C, Xu J, Swanson GT, Heinemann SF. (2003). Loss of kainate receptor-mediated heterosynaptic facilitation of mossy-fiber synapses in KA2-/- mice. Journal of Neuroscience. 23(2): 422-9.

Cowan, N. (2001). The magical number 4 in short-term memory: A reconsideration of mental storage capacity. Behavioral and Brain Sciences, 24, 87-185.

Darstein, M., Petralia, R.S., Swanson, T.S., Wenthold, R.J. \& Heinemann, S.F. (2003). Distribution of Kainate Receptor Subunits at Hippocampal Mossy Fiber Synapses. The Journal of Neuroscience. 23, 8013-8019. 
Delgado, J.Y., Coba, M., Anderson, C.N.G., Thompson, C.R., Gray, E.E., Heusner, C.L. et al., (2007). NMDA Receptor Activation Dephosphorylates AMPA Receptor Glutamate Receptor 1 Subunits at Threonine 840. The Journal of Neuroscience. 27(48): 13210-21.

Derkach, V., Barria, A. \& Soderling, T.R. (1999). Ca2_/calmodulin-kinase II enhances channel conductance of amino-3-hydroxyl-5-methyl-4-isoxazolepropionate type glutamate receptors. PNAS. 96:3269-3274.

Dingledine, R., Borges, K., Bowie, D. \& Traynelis, S.F. (1999). The glutamate receptor ion channels. Pharmacol Rev 51:7-61.

Evans RH, Francis AA, Watkins JC. (1977). Selective antagonism by Mg2+ of amino acidinduced depolarization of spinal neurones. Experientia. 33(4): 489-91.

Foster AC, Fagg GE. (1987). Neurobiology. Taking apart NMDA receptors. Nature. 329(6138): 395-6.

Frerking, M. \& Ohliger-Frerking, P. (2002). AMPA receptors and kainate receptors encode different features of afferent activity. Journal of Neuroscience. 22(17). 7434-43.

Frerking, M., Malenka, R.C. \& Nicoll, R.A. (1998). Synaptic activation of kainate receptors on hippocampal interneurons. Nat Neurosci. 1:479-486.

Gallagher M, Burwell R, Burchinal M. (1993). Severity of spatial learning impairment in aging: development of a learning index for performance in the Morris water maze. Behav Neurosci. 270(6): 742-4.

Globus, A., Rosenzwelg, M.R., Bennett, E.L. \& Diamond, M.C. (1973) Effects of differential experience on dendritic spine counts in rat cerebral cortex. J Comp Physiol Psychol. 82(2): $175-81$. 
Gluck MA, Myers CE. (1997). Psychobiological models of hippocampal function in learning and memory. Annual Review Psychology. 48: 481-514.

Greger, I.H., Ziff, E.B. \& Penn, A.C. (2007). Molecular determinants of AMPA receptor subunit assembly. Trends in Neuroscience. 30(8): 408-16.

Gröticke, I., Hoffmann, K. \& Löscher, W. (2008). Behavioral alterations in a mouse model of temporal lobe epilepsy induced by intrahippocampal injection of kainate. Experimental Neurology. 213, 71-83.

Hablitz, J.J. \& Langmoen, I.A. (1986). N-methyl-D-aspartate receptor antagonists reduce synaptic excitation in the hippocampus. Journal of Neuroscience. 6(1): 102-6.

Herron CE, Lester RA, Coan EJ, Collingridge GL. (1986). Frequency-dependent involvement of NMDA receptors in the hippocampus: a novel synaptic mechanism. Nature. 322(6076): 265-8.

Hlinák Z, Krejcí I. (2002a). N-methyl-D-aspartate improved social recognition potency in rats. Neurosci Lett. 330(3): 227-30.

Hlinák Z, Krejcí I. (2002b). MK-801 induced amnesia for the elevated plus-maze in mice. Behav Brain Research. 131(1-2): 221-5.

Holahan, M.R. \& Routtenberg, A. Lidocaine Injections Targeting CA3 Hippocampus Impair Both Learning-Induced Mossy Fiber Remodeling and Long-Term Spatial Memory. (Submitted).

Hollmann, M. \& Heinemann, S. (1994). Cloned glutamate receptors. Annual Review Neuroscience. 17:31-108.

Howe, J.R. (1996). Homomeric and heteromeric ion channels formed from the kainate-type subunits GluR6 and KA2 have very small, but different, unitary conductances. Journal of 
Neurophysiology. 76(1): 510-9.

Huettner JE, Bean BP. (1988). Block of N-methyl-D-aspartate-activated current by the anticonvulsant MK-801: selective binding to open channels. PNAS. 85(4): 1307-11.

Jiang, L., Xu, J., Nedergaard, M. \& Kang, J. (2001). A Kainate Receptor Increases the Efficacy of GABAergic Synapses. Neuron. 30: 503-13.

Jonas, P. (2000) The time course of signaling at central glutamatergic synapses. News Physiol. Sci. 15: 83-89.

Kamiya, H. \& Ozawa, S. (2000). Kainate receptor-mediated presynaptic inhibition at the mouse hippocampal mossy fibre synapse. J Physiol (Lond). 523:653-665.

Kant GJ, Wright WL, Robinson TN 3rd, D'Angelo CP. (1991). Effects of MK-801 on learning and memory as assessed using a novel water maze. Pharmacol Biochem Behav. 39(2): 479-85.

Kelso SR, Brown TH. (1986). Differential conditioning of associative synaptic enhancement in hippocampal brain slices. Science. 232(4746): 85-7.

Kim DY, Kim SH, Choi HB, Min C, Gwag BJ. (2001). High abundance of GluRI mRNA and reduced $\mathrm{Q} / \mathrm{R}$ editing of GluR2 mRNA in individual NADPH-diaphorase neurons. Molecular Cell Neuroscience. 17(6): 1025-33.

Koek W, Woods JH, Colpaert FC. (1990). N-methyl-D-aspartate antagonism and phencyclidinelike activity: a drug discrimination analysis. Journal of Pharmacol Exp Ther. 253(3): $1017-25$. 
Kolb B, Walkey J. (1987). Behavioural and anatomical studies of the posterior parietal cortex in the rat. Behav Brain Research. 23(2): 127-45.

Kopp, C., Longordo, F. \& Luthi, A. (2007). Experience-dependent changes in NMDA receptor composition at mature central synapses. Neuropharmacology. 53: 1-9.

Lauri, S. E. et al. (2001). A critical role of a facilitatory presynaptic kainate receptor in mossy fiber LTP. Neuron 32, 697-709.

Lauri, S.E., Bortolotto, Z.A., Nistico, R., Bleakman, D., Ornstein, P.L., Lodge, D. et al., (2003). A Role for Ca2_ Stores in Kainate Receptor-Dependent Synaptic Facilitation and LTP at Mossy Fiber Synapses in the Hippocampus. Neuron, 39, 327-341.

Lea PM, Custer SJ, Vicini S, Faden AI. (2002). Neuronal and glial mGluR5 modulation prevents stretch-induced enhancement of NMDA receptor current. Pharmacol Biochem Behav. 73(2): 287-98.

Lerma, J. (2003). Roles and rules of kainate receptors in synaptic transmission. Nature Reviews. 4: 481-95.

Lerma, J. (2006). Kainate receptor physiology. Current Opinion in Pharmacology. 6(1): 89-97.

Lerma, J., Paternain, A. V., Rodriguez-Moreno, A. \& López-García, J. C. (2001). Molecular physiology of kainate receptors. Physiol. Rev. 81, 971-998.

Li, F. \& Tsien, J.Z. (2009). Memory and the NMDA receptors. New England Journal of Medicine. 361(3): 302-3.

Lodge D, Dingledine R. (2000). Ionotropic glutamate receptors. The IUPHAR compendium of receptor characterization and classification. 2nd ed. London: IUPHAR Media Ltd.

Lodge, D. \& Johnson, K.M. (1990). Noncompetitive excitatory amino acid receptor antagonists. TiPS. 11:81-6. 
Logue, S.F., Paylor, R. \& Wehner, J.M. (1997). Hippocampal lesions cause learning deficits in inbred mice in the Morris water maze and conditioned-fear task. Behavioral Neuroscience. 111(1): 104-113.

Maei, H.R., Zaslavsky, K. Teixeira, C.M. \& Frankland, P.W. (2009). What is the most sensitive measure of water maze probe test Performance. Frontiers in Integrative Neuroscience. 3(4): 1-9. Maletic-Savatic, M., Malinow, R., Svoboda, K. (1999) Rapid dendritic mophogenesis in CAl hippocampal dendrites induced by synaptic activity. Science. 283(5409): $1923-7$.

Manev, H., Favaron, M., Guidotti, A. \& Costa, E. (1989). Delayed increase of Ca2+ influx elicited by glutamate: role in neuronal death. Molecular Pharmacology. 36(1): 106-112.

Martin, S.J., Grimwood, P.D., Morris, R.G., 2000. Synaptic plasticity and memory: an evaluation of the hypothesis. Annual Review of Neuroscience 23: 649-711.

Matlin, M. (2006). Cognition, Sixth Edition. Hoboken, New Jersey: John Willey \& Sons.

Mayer M.L., Westbrook G.L. \& Guthrie P.B. (1984). Voltage-dependent block by Mg2+ of NMDA responses in spinal cord neurones. Nature. 309(5965): 261-3.

McBain, C.J. \& Mayer, M.L. (1994). N-methyl-D-aspartic acid receptor structure and function. Physiology Review. 74(3): 723-60.

Monaghan, D. T. \& Cotman, C. W. The distribution of $[3 \mathrm{H}]$ kainic acid binding sites in rat CNS as determined by autoradiography. Brain Res. 252, 91-100.

More JC, Nistico R, Dolman NP, Clarke VR, Alt AJ, Ogden AM. et al. (2004). Characterisation of UBP296: a novel, potent and selective kainate receptor antagonist. Neuropharmacology. 47(1): 46-64.

Mori, H. \& Mishina, M. (1995). Structure and function of the NMDA receptor channel. 
Neuropharmacology. 34(10): 1219-37.

Morris, R. G. M. (1981). Spatial localisation does not depend on the presence of local cues. Learn. Motiv. 12:239-260.

Morris, R. (1984). Development of a water-maze procedure for studying spatial learning in the rat. J. Neurosci. Methods 11:47-60.

Morris, R.G. (1989). Synaptic plasticity and learning: selective impairment of learning rats and blockade of long-term potentiation in vivo by the N-methyl-D-aspartate receptor antagonist AP5. Journal of Neuroscience. 9(9): 494-501.

Morris, R. G., Garrud, P., Rawlins, J. N. \& O'Keefe, J. (1982). Place navigation impaired in rats with hippocampal lesions. Nature 297, 681-683.

Morris, R. G., Anderson, E., Lynch, G. S., \& Baudry, M. (1986). Selective impairment of learning and blockade of long-term potentiation by an $N$-methyl- d-aspartate receptor antagonist, AP5. Nature 319: 774-776.

Mulle, C., Sailer, A., Perez-Otano, I., Dickinson-Anson, H., Castillo, P.E., Bureau, I. et al., (1998). Altered synaptic physiology and reduced susceptibility to kainate induced seizures in GluR6-deficient mice. Nature. 392:601-605.

Nowak L, Bregestovski P, Ascher P, Herbet A, Prochiantz A. (1984). Magnesium gates glutamate-activated channels in mouse central neurones. Nature. 307(5950): 462-5.

Ohashi H, Maruyama T, Higashi-Matsumoto H, Nomoto T, Nishimura S, Takeuchi Y. (2002). A novel binding assay for metabotropic glutamate receptors using [3H] L-quisqualic acid and recombinant receptors. $Z$ Naturforsch C. 57(3-4): 348-55.

Olverman HJ, Jones AW, Watkins JC. (1984). L-glutamate has higher affinity than other amino acids for [3H]-D-AP5 binding sites in rat brain membranes. Nature. 307(5950): 460-2. 
Ozaki, H.S., Murakami, T.H., Toyoshima, T. \& Shimada, M. (1985). Differential Effects of Kainic-Acid-Induced Hippocampal Lesions on the Acquisition of the Jump-Box Avoidance Task in Mice. Journal of Neuroscience Research. 15, 241-252.

Palmada M, Centelles JJ. (1998). Excitatory amino acid neurotransmission. Pathways for metabolism, storage and reuptake of glutamate in brain. Frontiers in Bioscience. 3: 701 18.

Paternain, A.V., Morales, M., and Lerma, J. (1995). Selective antagonism of AMPA receptors unmasks kainate receptor-mediated responses in hippocampal neurons. Neuron 14, 185189.

Paternain, A.V., Herrera, M.T., Nieto, M.A. \& Lerma, J. (2000). GluR5 and GluR6 kainate receptor subunits coexist in hippocampal neurons and coassemble to form functional receptors. $J$ Neurosci. $20: 196-205$.

Paxinos G. \& Watson C. (2004). The Rat Brain in Stereotaxic Coordinates. Fourth Edition. New York, Elsevier.

Raedt, R., Van Dycke, A., Van Melkebeke, D., De Smedt, T., Claeys, P. \& Wyckhuys, T. (2009). Seizures in the intrahippocampal kainic acid epilepsy model: characterization using long-term video-EEG monitoring in the rat. Acta Neurol Scand. 119, 293-303.

Reisel, D., Bannerman, D.M., Schmitt, W.B., Deacon, R.M.J., Flint, J., Borchardt, T. et al. (2002). Spatial memory dissociation in mice lacking GluR1. Nature Neuroscience. 5(9): 868-73.

Remy, S. \& Spruston, N. (2007). Dendritic spikes induce single-burst long-term potentiation. PNAS. 104(43). 17192-97. 
Robinson DM, Keating GM. (2006). Memantine: a review of its use in Alzheimer's disease. Drugs. 66(11): 1515-34.

Rosenmund C, Stern-Bach Y, Stevens CF. (1998). The tetrameric structure of a glutamate receptor channel. Science. 280(5369): 1596-9.

Rusakov, D.A., Kullmann, D.M, \& Stewart, M.G. (1999). Hippocampal synapses: do they talk to their neighbours? Trends in Neuroscience. 22, 382-388.

Sachidhanandam, S., Blanchet, C., Jeantet, Y., Cho, Y.H. \& Mulle C. (2009). Kainate Receptors Act as Conditional Amplifiers of Spike Transmission at Hippocampal Mossy Fiber Synapses. The Journal of Neuroscience. 29, 5000-5008.

Sakimura K, Morita T, Kushiya E, Mishina M. (1992). Primary structure and expression of the gamma 2 subunit of the glutamate receptor channel selective for kainate. Neuron. 8(2): 267-74.

Schiffer, H. H., Swanson, G. T. \& Heinemann, S. F. (1997). Rat GluR7 and a carboxy-terminal splice variant, GluR7b, are functional kainate receptor subunits with a low sensitivity to glutamate. Neuron 19, 1141-1146.

Schmitz, D., Mellor, J., Breustedt, J. \& Nicoll, R.A. (2003). Presynaptic kainate receptors impart an associative property to hippocampal mossy fibre long-term potentiation. Nature Neuroscience. 6(10): 1058-63.

Schmitz, D., Frerking, M., and Nicoll, R.A. (2000). Synaptic activation of presynaptic kainate receptors on hippocampal mossy fiber synapses. Neuron 27, 327-338.

Schmitz, D., Mellor, J., Frerking, M. \& Nicoll, R. A. Presynaptic kainate receptors at hippocampal mossy fiber synapses. Proc. Natl Acad. Sci. USA 98, 11003-11008. 
Scimemi, A., Fine, A., Kullmann, D.M. \& Rusakov, D.A. (2004). NR2B-Containing Receptors Mediate Cross Talk among Hippocampal Synapses. The Journal of Neuroscience. 24, $4767-4777$.

Scott, R., Lalic, T., Kullmann, D.M., Capogna, M. \& Rusakov, D.A. (2008). Target-cell specificity of kainate autoreceptor and Ca2+-store dependent short-term plasticity at hippocampal mossy fiber synapses. Journal of Neuroscience. 28, 13139-49.

Scoville, W. B., \& Milner, B. (1957). Loss of recent memory after bilateral hippocampal lesions. Journal of Neurology, Neurosurgery and Psychiatry, 20, 11-21.

Seeburg PH, Burnashev N, Köhr G, Kuner T, Sprengel R, Monyer H. (1995). The NMDA receptor channel: molecular design of a coincidence detector. Recent Prog Horm Research. 50: 19-34.

Shi, S.H., Hayashi, Y., Esteban, J.A. \& Malinow, R. (2001). Subunit-specific rules governing AMPA receptor trafficking to synapses in hippocampal pyramidal neurons. Cell. 105: $331-43$.

Shigemoto R, Kinoshita A, Wada E, Nomura S, Ohishi H, Takada M. et al. (1997). Differential presynaptic localization of metabotropic glutamate receptor subtypes in the rat hippocampus. Journal of Neuroscience. 17(19): 7503-22.

Skeberdis VA, Lan J, Opitz T, Zheng X, Bennett MV, Zukin RS. (2001). mGluR1-mediated potentiation of NMDA receptors involves a rise in intracellular calcium and activation of protein kinase C. Neuropharmacology. 40(7): 856-65.

Smith, K.E., Gorski, J.A. \& Dell'Acqua, M.L. (2005). Modulation of AMP $\Lambda$ receptor activity by associated proteins. Cellscience Reviews. 2(1): ISSN 1742-8130 
Sommer, B. et al. A glutamate receptor channel with high affinity for domoate and kainate. EMBO J. 11, 1651-1656.

Song I, Huganir RL. (2002). Regulation of AMPA receptors during synaptic plasticity. Trends in Neuroscience. 25(11): 578-88.

Squire, L.R. \& Kandel. E.R. (1999). Memory: From Mind to Molecules. W.H. Freeman \& Co., New York.

Stubley-Weatherly, L., Harding, J.W. \& Wright, J.W. (1996). Effects of discrete kainic acidinduced hippocampal lesions on spatial and contextual learning and memory in rats. Brain Research. 716, 29-38.

Swanson, G. T., Gereau, R. W., Green, T. \& Heinemann, S. F. (1997). Identification of amino acid residues that control functional behavior in GluR5 and GluR6 kainate receptors. Neuron 19: 913-926.

Tsanov, M. \& Manahan-Vaughan, D. (2008). Synaptic plasticity from visual cortex to hippocampus: Systems intergration in spatial information processing. The Neuroscientist. 14(6): 584-597.

Tsien, J. Z., Huerta, P. T., and Tonegawa, S. (1996). The essential role of hippocampal CA1 NMDA receptor-dependent synaptic plasticity in spatial memory. Cell 87: 1327-38.

Vignes, M. \& Collingridge, G.L. (1997). The synaptic activation of kainate receptors. Nature. $388: 179-182$.

Watkins JC, Evans RH. (1981). Excitatory amino acid transmitters. Annu Rev Pharmacol Toxicol. 21:165-204.

Wenthold, R.J., Petralia, R.S., Blahos, J., II, and Niedzielski, A.S. (1996). Evidence for multiple AMPA receptor complexes in hippocampal CA1/CA2 neurons. J. Neurosci. 16: 1982-89. 
Whishaw, I.Q. (1989). Dissociating performance and learning deficits on spatial navigation tasks in rats subjected to cholinergic muscarinic blockade. Brain Res Bull. 23(4-5): 34758.

White, N.M. \& McDonald, R.J. (2002). Multiple parallel memory systems in the brain of the rat. Neurobiology of Learning and Memory. 77:125-84.

White, N. M.,\&Ouellet, M.-C. (1997). Roles of movement and temporal factors in spatial learning. Hippocampus, 7: 501-10.

Wilding TJ, Huettner JE. (1996). Antagonist pharmacology of kainate- and alpha-amino-3hydroxy-5-methyl-4-isoxazolepropionic acid-preferring receptors. Molecular Pharmacology. 49(3): 540-6.

Wisden W, Seeburg PH. (1993). A complex mosaic of high-affinity kainate receptors in rat brain. Journal of Neuroscience. 13(8): 3582-98.

Wong EH, Kemp JA, Priestley T, Knight AR, Woodruff GN, Iversen LL. (1986). The anticonvulsant MK-801 is a potent N-methyl-D-aspartate antagonist. PNAS. 83(18): 7104-8.

Zajaczkowski W, Quack G, Danysz W. (1996). Infusion of (+) -MK-801 and memantine -contrasting effects on radial maze learning in rats with entorhinal cortex lesion. European Journal of Pharmacology. 296(3): 239-46. 